\title{
Tourism Observatory of the Canary Islands
}
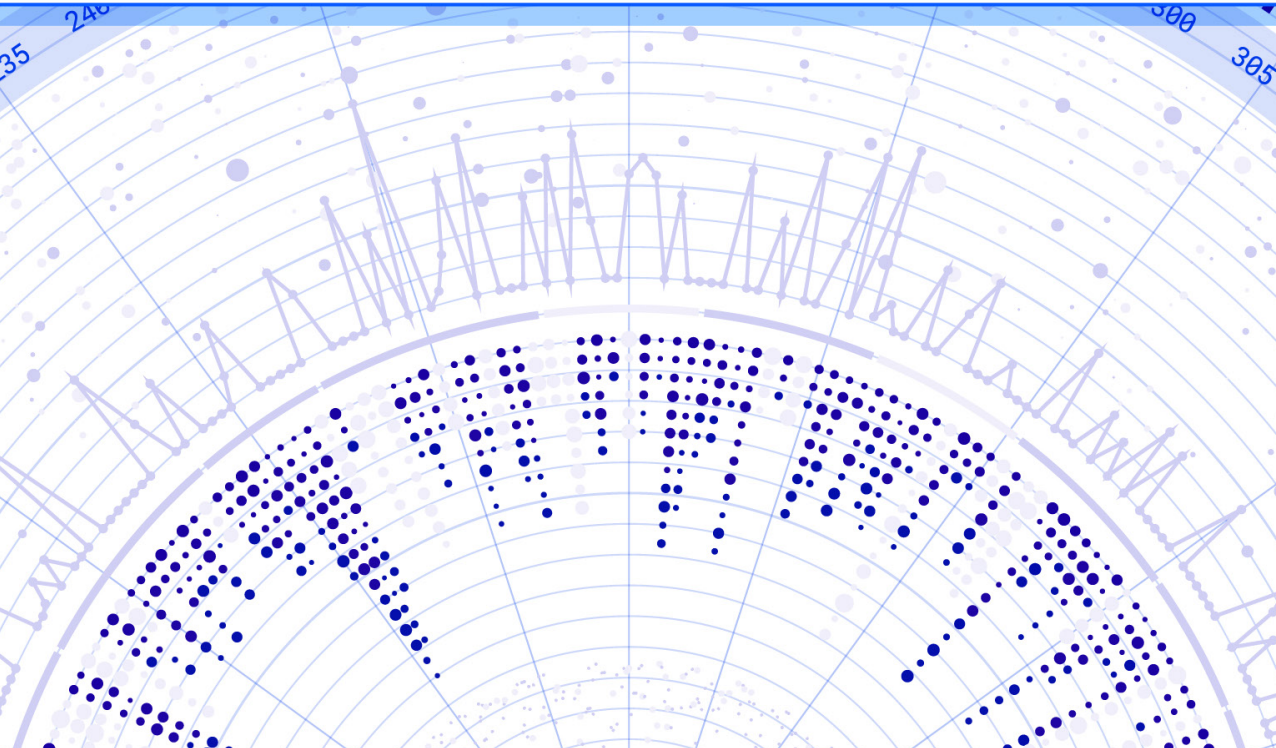

${ }_{3}{ }_{3}$

$\mathrm{N}^{\theta}$ 
This document has been prepared by a research team of the University of La Laguna and the University of Las Palmas de Gran Canaria at the request of the Ministry of Tourism, Industry and Commerce of the Canary Islands in the context of the application to the International Network of Sustainable Tourism Observatories of the United Nations World Tourism Organization. On 21 October 2020, the annual Global INSTO meeting confirmed the Canary Islands as a new member of the network.

Title: Tourism Observatory of the Canary Islands. Preliminary Report

Copyright $@$ the authors

Editor: Raúl Hernández-Martín

Published by Cátedra de Turismo CajaCanarias-Ashotel de la Universidad

de La Laguna

Published in La Laguna, Canary Islands, 2021

Design by Proyectran

ISBN: 978-84-09-29391-9

DOI: https://doi.org/10.25145/b.TourismCanary.2021

\section{Members of the research team:}

Raúl Hernández-Martín (dir.), University of La Laguna

Natalia Antonova, University of La Laguna

Daniel Celis Sosa, University of Las Palmas de Gran Canaria

Carlos Fernández Hernández, University of La Laguna

Matías González Hernández, University of Las Palmas de Gran Canaria

Félix Herrera Priano, University of La Laguna

Carmelo León González, University of Las Palmas de Gran Canaria

Javier Mendoza Jiménez, University of La Laguna

Noemi Padrón Fumero, University of La Laguna

Pablo Rodríguez González, University of La Laguna

Agustín Santana Talavera, University of La Laguna

Moisés Simancas Cruz, University of La Laguna

Published by Cátedra de Turismo CajaCanarias-

Ashotel de la Universidad de La Laguna
Funded by Viceconsejería de Turismo del Gobierno de Canarias 


\section{Table of contents}

1. Introduction

2. Destination profile

2.1. General characteristics of the region

2.2. Overview of the tourism sector. Basic economic data

3. Key sustainability issue areas in the Canary Islands

3.1. Stakeholders' consultation

3.2. Key sustainability issue areas in the Canary Islands

3.3. Key sustainability issue areas and UN Sustainable Development Goals

3.4. A proposal of key performance indicators for the issue areas

4. The Regional Tourism Information System

4.1. The Institute of Statistics of the Canary Islands

4.2. Data and information availability, gaps and needs

5. Current monitoring entities and relevant stakeholders in tourism

6. Design of the Tourism Observatory

6.1. Objectives of the observatory 60

6.2. Organization of the observatory and the role of stakeholders 61

6.3. Monitoring methodology and objectives for the first reporting year 61 


\section{Introduction}

$\mathbf{T}$ his report has been conducted by a research team with members of the two public universities of the Canary Islands. The team includes researchers from the Chair of Tourism of the University of La Laguna and the Institute of Tourism and Sustainable Development of the University of Las Palmas de Gran Canaria. The first version of this document was finished and sent to INSTO-UNWTO just before the outbreak of the pandemic and, therefore, it does not consider the new tourism context. This new situation requires rethinking some of the Observatory's priorities with a greater focus on health, safety and resilience issues, which were already present in the first version of this document.

The Canary Islands are an archipelago consisting of eight islands in the Atlantic Ocean. It is an autonomous region of Spain located 1,300 km away from the Spanish mainland and with the easternmost island being just
$100 \mathrm{~km}$ from the African coast. The islands have a land extension of around $7,500 \mathrm{~km}^{2}$ with a population of $2,127,685$ in 2018. The aggregated growth of the population from 2000 to 2018 was $24 \%$. Tourism is the main economic activity on the islands, with around 15 million inbound tourists, $89 \%$ of which come from the main European outbound tourism countries and $11 \%$ from the Spanish mainland. These inbound figures mean tourism contributed $35 \%$ to the GDP of the Canary Islands in 2018. There are four main tourism islands, Tenerife (5.8 million tourists in 2018); Gran Canaria (4.4 million); Lanzarote (2.9 million) and Fuerteventura (2.1 million). The other three islands, La Palma, La Gomera and El Hierro have less intensive tourism development, which is based on their natural attractions. Finally, La Graciosa is a small, scarcely-populated island where tourism is mainly dependent on boat day-trips from Lanzarote.

Figure 1. Tourist arrivals (foreign + mainland Spain) to the main tourism islands 2018 in millions

Source: ISTAC (Institute of Statitics of the Canary Islands)

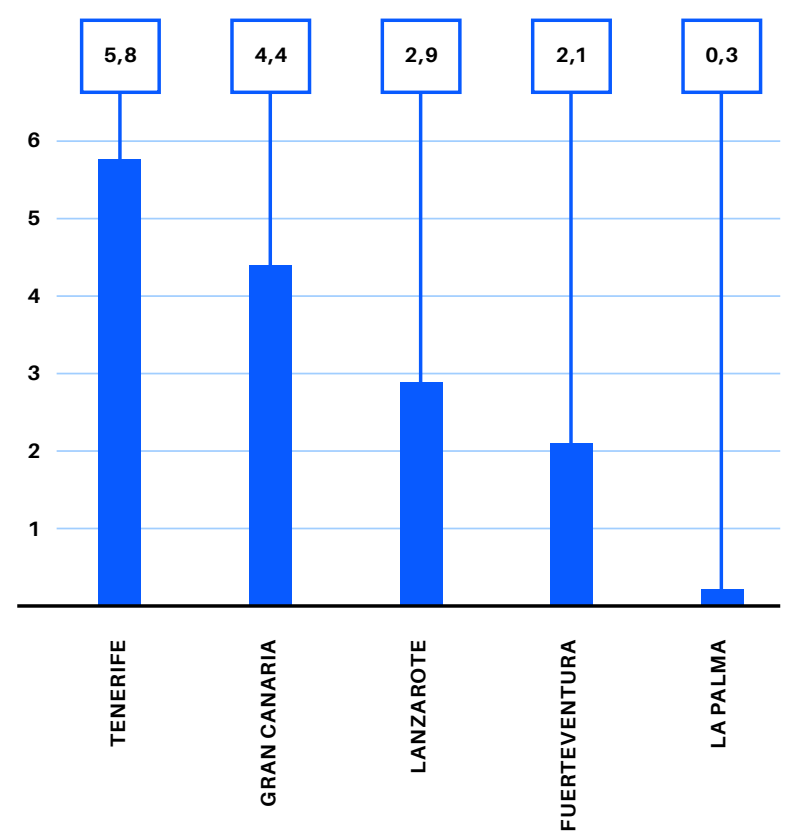


In addition to the $\mathbf{1 5 . 6}$ million tourist arrivals by plane in the Canary Islands in 2018, the ports of the islands received 2.4 million cruise passengers during that year. Regarding tourist arrivals, $89 \%$ were foreign tourists, while 1.7 million, the remaining $11 \%$, have their residence in other regions of Spain. Regarding foreign tourists, the United Kingdom shows the highest figures, slightly over 5 million tourists in 2018, representing approxi- mately a third of the tourists in the Canary Islands. Germans, with around 3 million, represent $20 \%$ of tourist arrivals, and in the third place in terms of arrivals are the tourists from the rest of Spain. Taken together, the Nordic countries represent $11 \%$ of tourist arrivals, while other relevant countries ranging between 2 and $4 \%$ of the arrivals are the Netherlands, France, Ireland, Italy and Belgium.

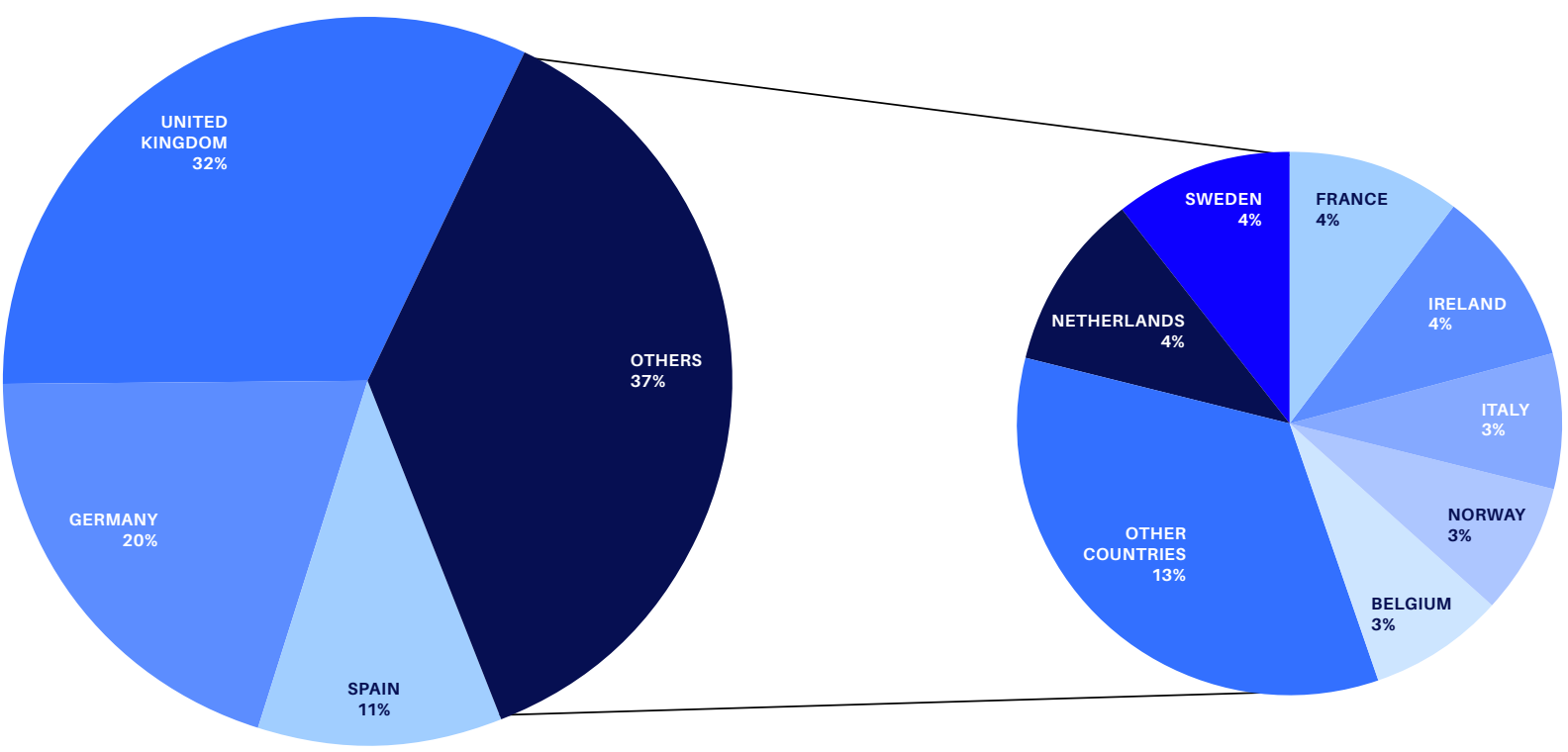

Figure 2. Distribution of tourists by origin. 2018 | Source: ISTAC (Institute of Statistics of the Canary Islands)

The main attractions of the Canary Islands are its climate, landscape and quality of tourism supply. The archipelago benefits from mild climatic conditions given that the average temperature during the day in winter is $22.1^{\circ} \mathrm{C}$ and $26.2^{\circ} \mathrm{C}$ in the summer season. The beauty of the landscape is related to its biodiversity and natural richness, making the islands a unique natural environment which has been recognized by international organizations. These conditions have promoted an outstanding tourism supply since the decade of the 1960s that has led to a mass tourism model supported by international tour operators. The proportion of tou- rists still using tourism packages is high, representing $59 \%$ of arrivals in 2018 . The average length of stay in all types of accommodation was 9.32 days in 2018, while the average length of stay in hotels was 7.18 days. Another relevant feature is that all-inclusive deals account for $30 \%$ of the tourist arrivals. The average expenditure by tourist and trip in 2018 was $€ 1,195.70$, while the average daily tourist expenditure was $€ 143.59$. This expenditure is mainly divided into accommodation (43\%), transport to the destination (29\%), eating (14\%), and others (14\%), according to figures provided by the Institute of Statistics of the Canary Islands. 


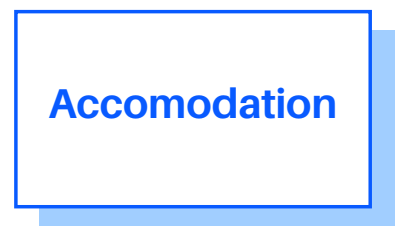

Bed places in hotels and apartments: 414,017

Annual overnights (hotel + appartments): 107 million

Occupancy rate: $70.75 \%$ (by bed places)

ADR/RevPar: €82.49 / €65,49

Average stay in hotels: 7.1 nights (Spain: 3.2 nights)

\section{Average \\ Expenditure}

Daily by tourist: $€ 143.59$

\section{Main \\ aggregates}

Tourism GDP 35\% (Spain:12.3\%)

Local employment from tourism: 40.4\% (Spain:12.7\%)

Foreign tourist expend. (mill. €) 170,112 (19\% of Spain)

\section{Tourist}

\section{Arrivals}

Foreign origin: 13.82 million

Mainland Spain: 1.74 million

Figure 3. Tourism dashboard of the Canary Islands 2018

The structure of monitoring and reporting tourism in the Canary Islands in the last decade has consisted of a network of institutions owing to the size of the tourism sector and the complexity of its management as an archipelago destination. There are four main stakeholders: the Tourism Observatory of the Canary Islands, which is aimed to coordinate the network of observation; the Institute of Statistics of the Canary Islands, which provides some of the best regional statistics in Europe; Promotur is the public-owned firm in charge of destination promotion that counts with a research department providing information for decision-making; and the two public universities of the Canary Islands, which provide their expertise in tourism analyses. Beyond these main institutions, there are several institutions developing tasks on monitoring, reporting and tourism management of tourism with particular relevance for the tourism boards at the island scale.
The Canary Islands is a leading region in European Tourism with a developed system of tourism information and monitoring. In this document, the main elements of the Tourism Observatory of the Canary Islands and its context are presented. After this introduction, a detailed description of the destination's profile is presented with some of the main features of the region and its tourism sector. Then, the third section contains the key sustainability issue areas from economic, social and environmental points of view. The regional tourism information system developed by the Institute of Statistics of the Canary Islands is described in the fourth section, along with the information on gaps and needs that have been detected. Section five describes the current tourism monitoring processes, with a focus on the network of stakeholders involved. Finally, the sixth section explains the organization and objectives of the observatory. 


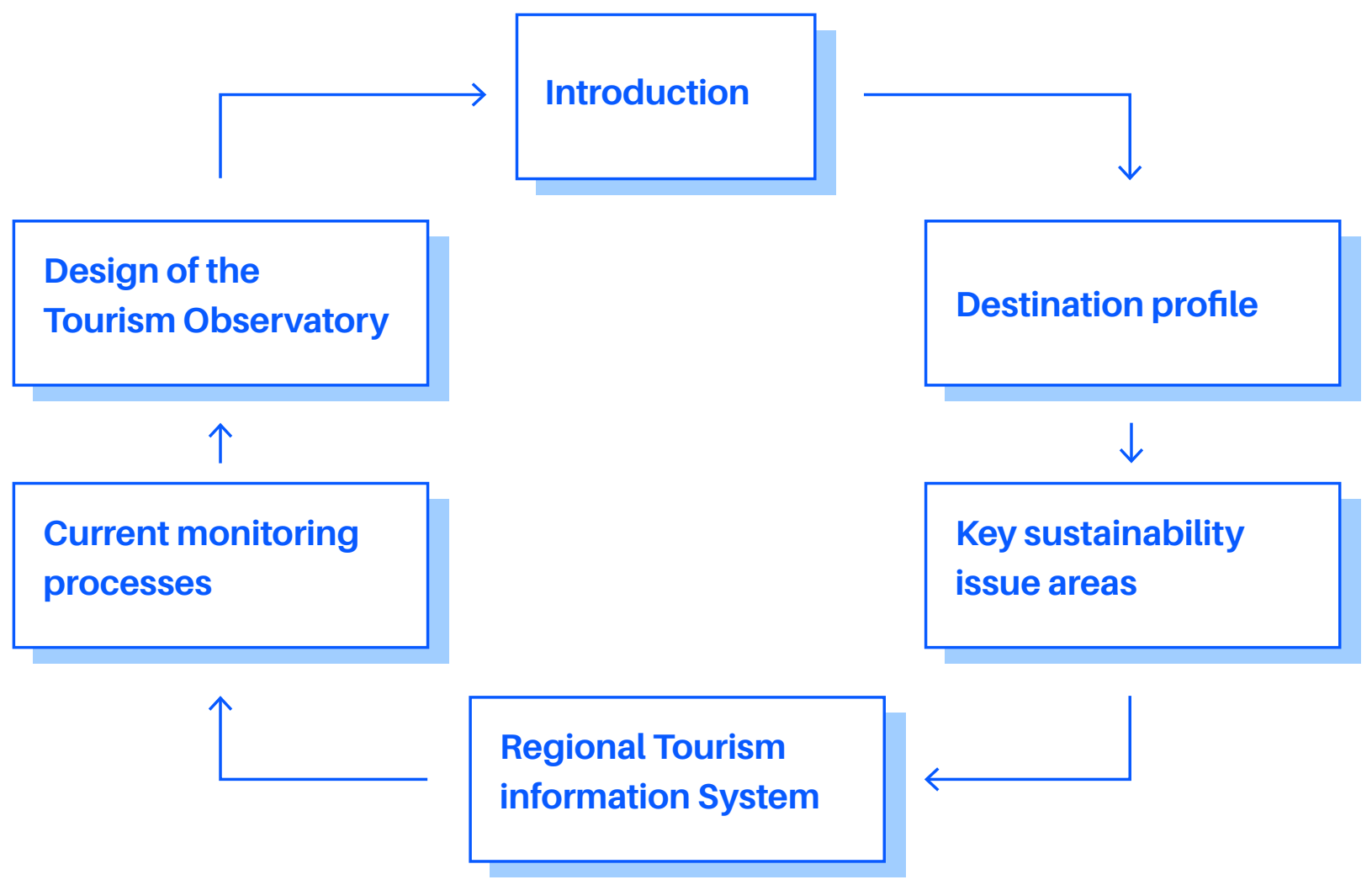

Figure 4. Outline of the report

\section{Destination profile}

T he Canary Islands are a well-known tourism destination in a region with certain specific features owing to its climatic conditions and location in the Atlantic Ocean, close to the African Coast.

\subsection{General characteristics of the region}

The Canary Islands are an autonomous region of Spain with a special economic and fiscal regime to compensate for its remoteness from the European continent and its insularity. The Treaty of the European Union recognizes the archipelago as an Outermost Region of the European Union that can take advantage of certain fiscal benefits, like transport aid, agriculture promotion initiatives, no obligation to apply certain European policies, etc.

The population of the Canary Islands was above 2.1 million inhabitants at the beginning of 2018, which represents $4.6 \%$ of the population of Spain and is distributed on eight islands. Each of the two most populated islands, Tenerife and Gran Canaria, comprise around 


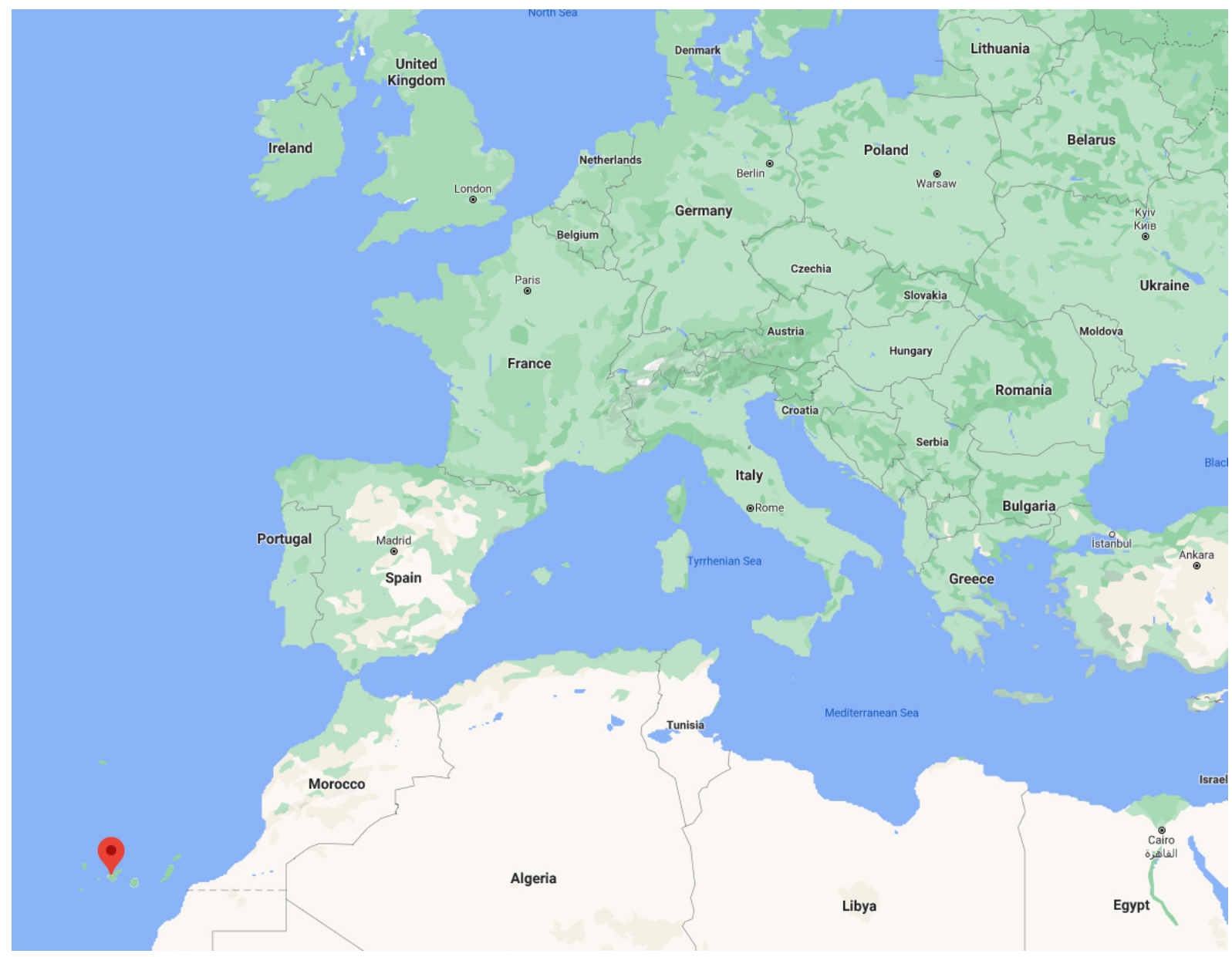

Figure 5. Location of the Canary Islands

$40 \%$ of the population. The capital of the region is shared between the main cities of Santa Cruz de Tenerife and Las Palmas de Gran Canaria. The administrative and policy organization of the region is strongly based on the Island Councils given that important competencies and public funding are managed on the island scale, which has implications for tourism monitoring and planning.

The archipelago was conquered in the 15th century, and since then, the economy of the islands has specialized in export-crops and port activities related to its strategic position in the middle of the Atlantic Ocean. Industry has never had a great development, given the lack of raw materials, the cost of transport and limited domestic demand. From the middle of the 20th century, the decline of agriculture was parallel to the expansion of the services sector that accounted in 2018 for almost $85 \%$ of the value-added of the Archipelago according to the figures from the National Institute of Statistics of Spain. In this year, the GDP was around $€ 46$ billion. However, the GDP per inhabitant has reached only $€ 21,031$, which places the archipelago among the three regions with the lowest GDP per capita in Spain. The rate of unemployment in 2018 and 2019 was around $20 \%$, after being over $30 \%$ during the years of the international crisis. The low GDP per capita is related to a series of reasons such as the high level of unemployment; lack of education skills; lack of entrepreneurship; the difficulties to integrate the internal market and the difficulties to promote economic activities beyond tourism.

The Canary Islands from an environmental point of view can be considered a unique territory in the world. 
The Canary Islands contributes with 184 spaces covering 351,327 hectares to the Natura 2000 Network, which makes it the most committed Spanish region with European environmental network. Almost half the territory of the Canary Islands (46.74\%) corresponds to natural protected areas. The biodiversity of the islands is very rich sharing with the Portuguese island of Madeira the greatest concentration of endemism in Europe. The Canary Islands have more than 4,000 endemic species, which means approximately one endemism per two $\mathrm{km}^{2}$ of surface area. In total, there are more than 17,000 terrestrial and marine species, which place the archipelago among the 15 richest biodiversity regions on the planet. For this reason, the Canary Islands are internationally recognized as a hotspot of world biodiversity (Biodiversity Data Bank of the Canary Islands).

\subsection{Overview of the tourism sector. Basic econo-} mic data

The Canary Islands have for centuries been connected with travelers and international openness. However, since the decade of the 1960s, tourism has experienced rapid growth in the archipelago with relatively low revenues and high dependence on agricultural export crops. The rapid growth of tourism in the islands was fostered by foreign investments and tour operators and resulted in rapid change in the economy and society. This quick change has its origins in the improvement of the economic conditions of the local population, but is also in an imbalance with the economic, social and environmental situations ${ }^{1}$.

\section{Leadership in tourism figures among European regions}

Even a quick glimpse at the Canary Islands' tourist reality verifies that the Canary Islands are a leading area in the international tourism arena. The European Union (before Brexit) had 28 member states and 272 regions (NUTS 2, which in Spain correspond to the Autonomous Regions). Among these regions, the Canary
Islands occupy the top position in several of the main tourist indicators. In the next figure, it can be seen that in the most recent year that statistics are available for all regions in the ranking of non-resident overnight stays in tourism establishments, the Canary Islands is in the first position, above the regions of Adriatic Croatia, Catalonia, Venice, Balearic Islands, London or Paris. The relevance of the Canary Islands is evident if we take into account that European countries make up the main receiving area of international tourism, representing in 2015 half of the world's tourist trips.

This relevant position of the Canary Islands is not only related to statistical indicators. The Canary Islands also play a very important role in the strategies of global tourism business groups, particularly those most linked to the vacation segment and the so-called sun and beach tourism.

\section{Dependence on environmental resources and high tourist volumes}

The Canary Island tourism model is strongly resource-based and not supported sufficiently by intelligence and knowledge. As has been repeatedly pointed out and affirmed by Acemoglu et al. (2012), countries whose development is based on resources have a very limited development capacity. In the case of the Canary Islands, the tourism model has been driven by the Islands' unique climatic conditions (Hernández Martín et al., 2012) and by their natural and landscape richness.

Progressive societies are those that efficiently use resources, including resources they lack. Even an abundance of resources often generates a dependence on them and their inefficient use. Therefore, it is important to provide an adequate institutional environment that generates the necessary incentives to incorporate knowledge to create value-added. This is often repeated systematically in developed societies.

Although the climate could be considered a non-exhaustible resource, the truth is that in years to come the 


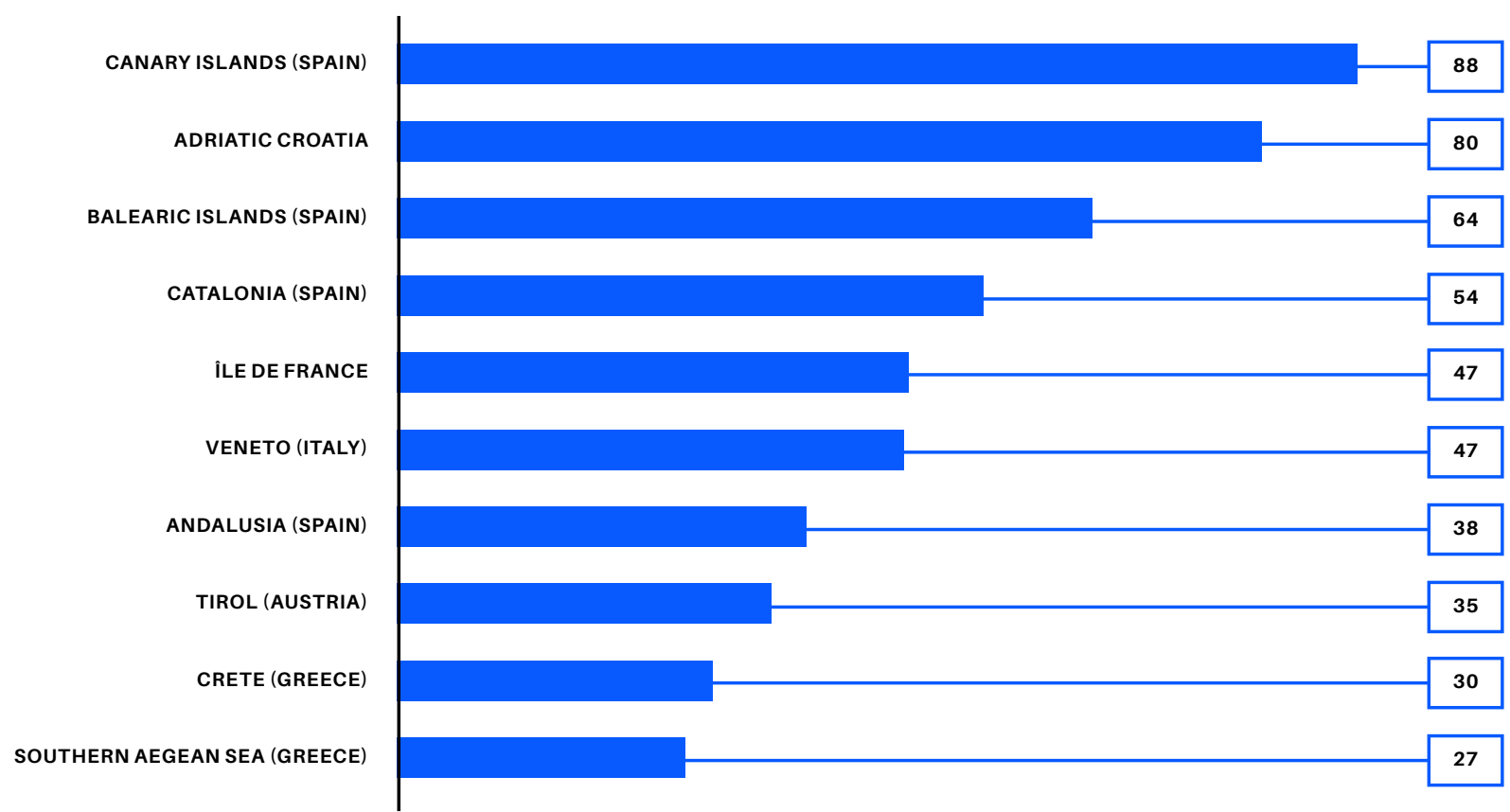

Figure 6. Overnight stays of non-residents in the main European tourism regions, 2018 (millions). Source: EUROSTAT

challenges posed by climate change will have to be addressed. These changes will affect tourism flows due to changes in the climate in the countries of origin and destination, as well as the impact that mitigation policies may have on the cost of transport.

At the environmental level, the tourism model has tended to increasingly exploit the scarce environmental resources of the archipelago, such as the territory itself or the natural landscapes. This creates a contradiction, since these resources are necessary and intended to serve as a visitor attraction.

Tourism growth in the Canary Islands has historically been based on increasing production scale and volumes. In fact, any paralysis in tourist arrival figures has historically led to situations of economic crisis. This is because the driver of economic growth in the archipelago in recent decades, particularly in the moments of greatest expansion, has been the real estate appreciation linked to tourism development: a phenomenon that is very limited by the growth of the accommoda- tion supply. However, this expansive dynamic cannot be maintained indefinitely, especially when the limits of tourism such as deteriorating social and environmental conditions become more visible.

This scale-based model is related to the close dependence of tourism development on the revaluation of real estate assets in the creation of new tourist areas. The Canary Islands have had to attract more and more tourists to achieve economic growth, since commercial margins in tourism are relatively narrow given the subordinate position of the archipelago in the global tourism value chain, as will be seen later. Tourism growth in the Canary Islands (Figure 7) can be summarized in four cycles. It starts with explosive growth and ends in a crisis, except the last cycle, in which the order of these elements has been reversed, as a consequence of the international economic crisis and the effects of the Arab Spring, which caused an intense fall followed by a very strong rebound in tourist arrivals between 2011 and 2018. 


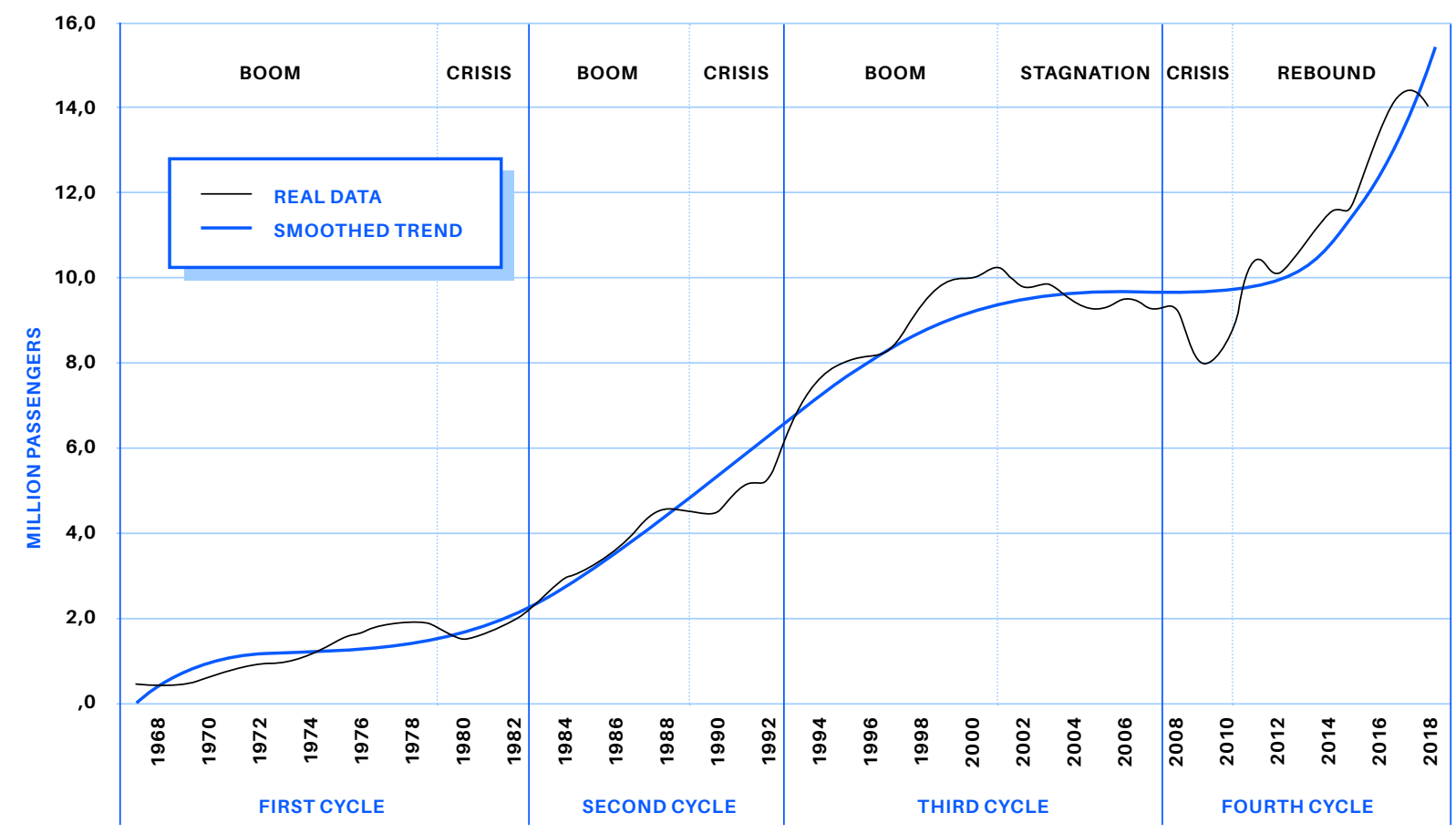

Figure 7. Evolution of arrivals of passengers from foreign countries to the Canary Islands Source: AENA (Spanish airport operator)

This model is based on high production scales and increasing costs, particularly in the environmental field. Factors such as the increase in all-inclusive packages, dependence on foreign trade or tourists' low expenditure in destination are evidence of this situation of weakness, which is only compensated by an expansion in production, in other words, with the objective of beating new arrival records. In addition, these high production levels are related to a standardized model with limited use of knowledge.

\section{Lack of marked seasonality}

The absence of pronounced seasonal behavior is probably the most characteristic feature of the Canary Islands tourism model. A review of the arrival of foreign tourists in relevant competitors in the Mediterranean region allows us to verify that the behavior of the Canary Islands is totally different from the rest. Figure 8 compares the overnights of foreigners in hotels of the
Canary Islands with respect to Greece, Croatia and Cyprus, where arrivals in the summer months are very high compared to winter.

The reason for the lack of seasonality in the Canary Islands is obviously the weather. The characteristics of the climate in the Canary Islands are practically unique in the international tourism sector. In the case of the European environment, climatic differences with the main outbound countries are very important, but also regarding the two main competitors of mass tourism in the coastal areas of the Mediterranean. According to a report on climate and tourism in the Canary Islands (Hernández Martín et al., 2012), the average temperature at noon during the winter season is $22^{\circ} \mathrm{C}$, while in Berlin and London for the same period it is $6.0^{\circ} \mathrm{C}$ and $8.5^{\circ} \mathrm{C}$, respectively. With respect to the competitors of the Canary Islands in the European environment, the only area with temperatures similar to those of the Canary Islands during the winter months are Agadir and, mainly, the destinations of the Red Sea in Egypt. However, the ave- 


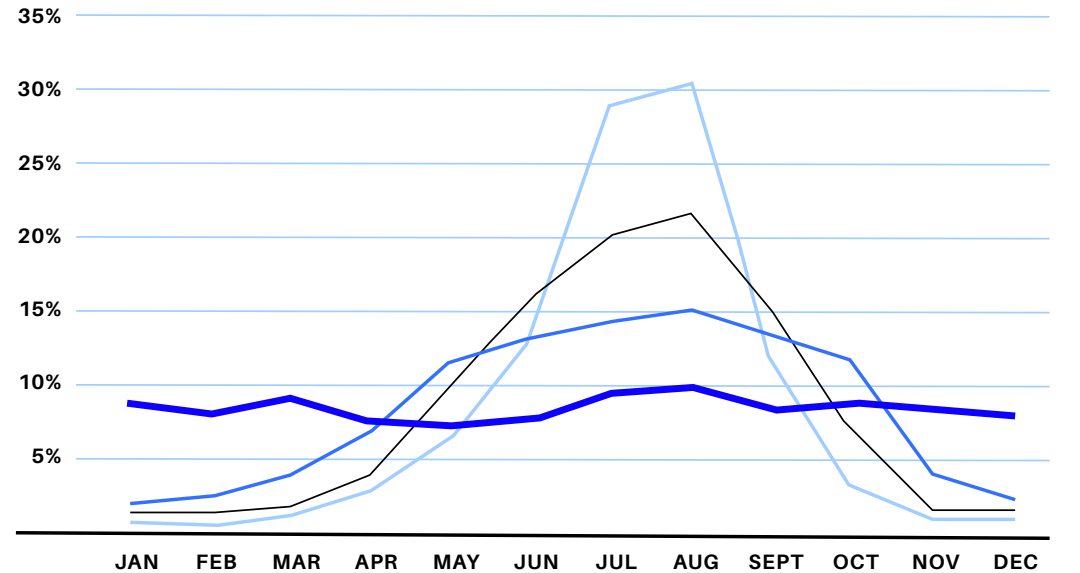

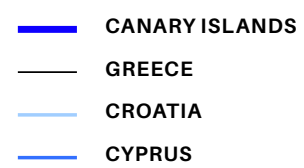

Figure 8. Monthly share of overnight stays of foreigners in hotels in 2018. Source: EUROSTAT rage temperature at noon, in the latter zone during the 6 months of the summer tourist season is $35.5^{\circ} \mathrm{C}$, compared to an average of $26.2^{\circ} \mathrm{C}$ for the Canary Islands. An international comparison of the seasonality of tourism in coastal destinations shows that only in some areas of the Caribbean, seasonal levels can compete with those of the Canary Islands. Meanwhile, the figures for tourist concentration in the Mediterranean are very high, both in the Spanish mainland and, even more, in the coastal destinations of Greece or Turkey.

Seasonality has traditionally had negative consequences for most tourist destinations and, to a much lesser extent, in the Canary Islands. One of the main ones is associated with the effects on business profitability of substantial investments that will only be used during a short period of the year. This effect also occurs for public transport, electricity or water infrastructure. In addition, a concentrated arrival of visitors around certain dates may also have negative environmental consequences due to an increase in waste generation or massive human presence in certain natural areas. Seasonality also has negative effects on the workforce. If employment generated by the tourism sector is highly seasonal, the workforce must look for other occupa- tions the rest of the year, which makes professionalization and training difficult.

The relative stability of arrivals of foreign tourists to the Canary Islands during the year hides, in part, the reality that the high season corresponds to winter, since it is in this period when higher prices are perceived. Thus, during the winter months of 2018-19, the hotel RevPAR in the Canary Islands were between $€ 79$ and $€ 86$ when in the main Spanish Autonomous Tourism Regions most of the establishments were closed and this indicator was from $€ 30$ to $€ 40$.

\section{Safety and security}

Security is one of the most important aspects for tourism development (Ritchie \& Jiang, 2019). The importance of safety and security are related to health, food, legal certainty against robberies, attacks, natural disasters, etc. The Canary Islands are a safe destination for European tourists. In fact, the tourist growth of the Canary Islands since the Arab Spring has been intense. Tunisia and Egypt are two competitors of the Canary Islands in the winter season, especially the Egyptian destinations of the Red Sea such as Sharm el Sheikh or Hurghada. The 
situation of some of the main competitors of the Canary Islands has been marked by insecurity, as in the case in Egypt, which has lost 5 million tourists and half of its international revenue from tourism between 2010 and 2015 . In fact, the recovery of such destinations from instability has affected the arrival figures in the Canary Islands.

\section{Maturity in a changing environment}

The Canary Islands are a mature or consolidated destination. From around 2000, the effects of maturity associated with changes in the behavior and interests of tourists begin to be felt more clearly in tourism products and how to market them and in the development of new competing destinations.

The possibilities of rejuvenating mature destinations have been subject to intense academic debate. The position of Knowles and Kurtis (1999) is pessimistic about the perspectives of mature Mediterranean destinations due to their overdevelopment and environmental degradation. However, Aguiló et al. (2005) and Claver-Cortés et al. (2007) suggest that sun and beach tourism is viable in the long term, if appropriate adaptation policies are implemented. This idea is also supported by the thesis of restructuring by Agarwal (2002), and it is the position that we maintain as well. Such restructuring should take as one of its references the strategies followed by the industry in the most advanced countries to compete with low-cost mass production in new industrialized countries (Ioannides and Debbage, 1997).

The maturity of the Canary Islands as a destination contrasts with the evolution of emerging Mediterranean destinations. In other words, we have reached maturity in the tourism field at a time when new destinations, new tourist products and new types of tourists are appearing.

\section{Weakness of economic impacts on well-being}

A defining feature of the Canary Islands as a destination is the weakness of economic impacts, that is, the insufficient capacity of tourism activity by itself (not the construction of new infrastructure) to become a more dynamic element of the economy providing higher living standards. This is related to the difficulties of the destination to generate employment even in an economic expansion phase. However, the problem is not in tourism or, at least, it is not only in tourism. This limitation is related to the way in which tourism spending is linked to the production and generation of income throughout the entire economic structure of the Canary Islands, which presents important weaknesses that become leaks and a weakness of the so-called tourism impacts multipliers.

A very significant part of tourist expenditure visiting the Canary Islands goes to companies at origin. Around $30 \%$ of tourist expenditure takes place in the archipelago, while expenditure at source is around $70 \%$. This is related to the relevance of tourism packages and, particularly all-inclusive deals. All-inclusive deals accounted for $30 \%$ of tourist arrivals in the Canary Islands in 2018, while packages were the form chosen by $59 \%$ of tourists visiting the islands. This kind of tourism model along with the weakness of the local entrepreneurship and innovation systems does not encourage economic impacts in the archipelago. The control by foreign companies, from hotels to restaurants and leisure activities, the lack of internationalization of local firms or the weight of foreign workers in the sector are symptoms of a feebleness in the economic structure of the Canary Islands. Though there are some exceptions, we can talk about weakness of entrepreneurs, weakness in the training and skills of workers, particularly in foreign languages, and institutional weakness, which have not properly addressed this situation. However, it is important to highlight that European tour operators and several external hotel chains are responsible for taking the Canary Islands to the top of European tourism regions, but it is time to make the Islands' tourism model stronger and more committed to the economic, social and environmental sustainability of the destination.

The expenditure that tourists make outside the accommodation and, to a large extent, the expenditure made by residents in the Canary Islands has a high component of imports, direct and indirect, that do not generate impacts on other activities in the Canary Islands. In this 
way, the productive structure of the Archipelago is not taking advantage of the opportunities derived from demand. In the Figure 9, there is an outline of the econo- mic impacts of tourism. The volume of tourist demand is very high, but there is room to enhance the economic impacts in terms of well-being of local population.

\section{Demand perspective}

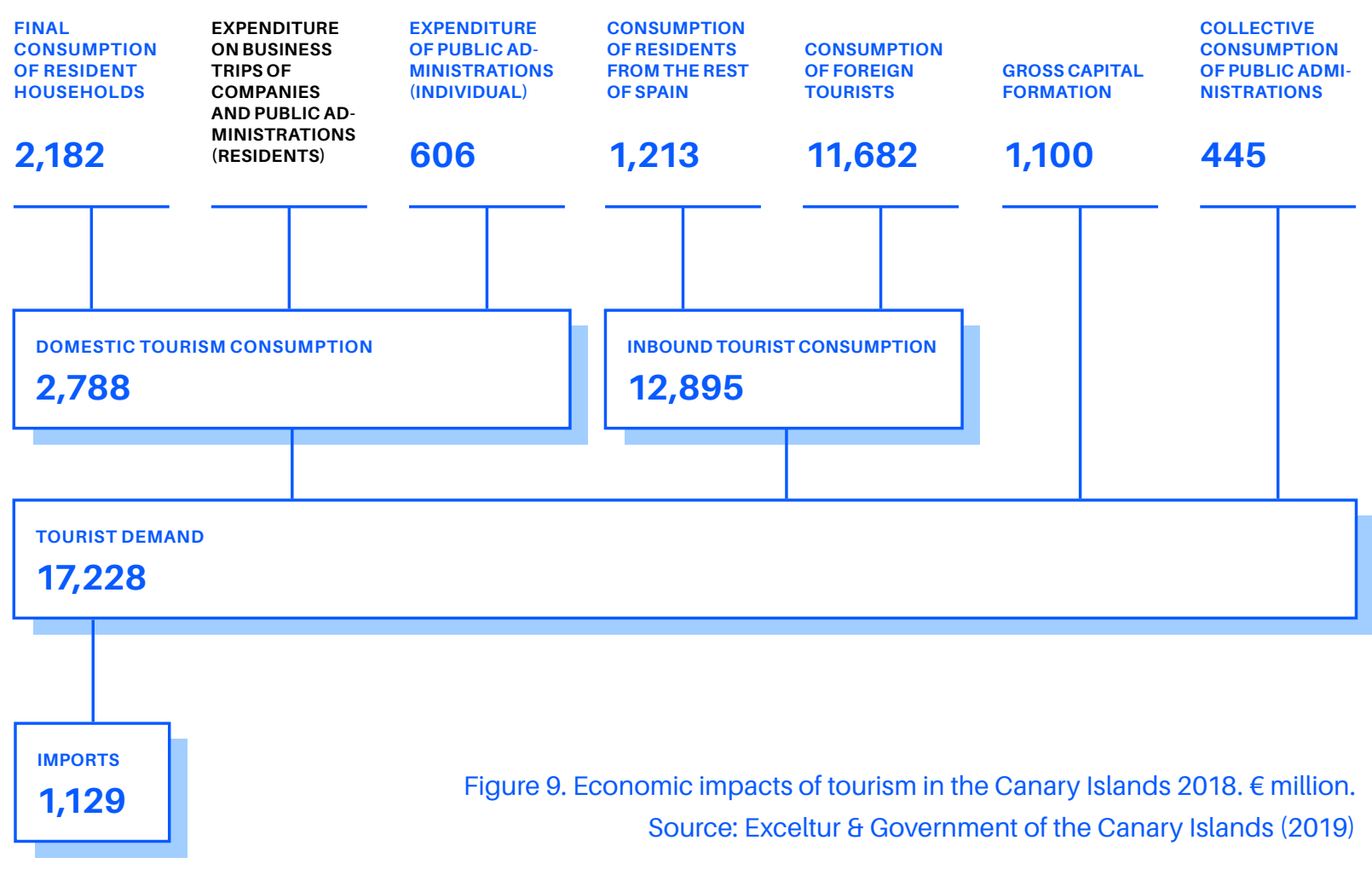

\section{Destination governance difficulties}

The role of the institutional factor has been considered an increasingly relevant factor in explaining the success or failure of countries and regions (Acemoglu et al. [2012]). In the field of tourism, this concern for the institutional factor goes even further, since in the value chain different actors coexist: large actors (airlines, tour operators) with micro-service companies in the destinations; policies of public administrations at different levels and departments with very varied interests; public and private interests of a very different nature. In addition, tourism is a field of action for numerous governmental organizations, social groups and lobbies; and, finally, the competitiveness of tourism companies is conditioned by the environment in which they are located, the destination (Candela and Figini, 2012). Following Scott and Marzano (2015), governance is the way in which social groups govern, organize and coordinate the actions of individuals to achieve collective results, it would be a broader concept than government, and in the field of tourism, it has crucial importance.

At the international level, there is great debate about the management of tourist destinations (Beritelli, Bieger and Laesser, 2014). In the case of the Canary Islands, destination management organizations are called to play a fundamental role in tourism coordination, as there are currently numerous overlaps, gaps and contradictions in the management of destinations not being clearly defined or the needs or the skills to solve them identified. 
The situation is not simple. The tourism departments at the level of the Autonomous Regions lack the competences and economic capacity, as they are very oriented towards promotion. They have little capacity to really influence the management of destinations in areas related to local transport, education, safety, traffic, cleanliness, culture, the environment, etc. In addition, there is no specific tourist sensitivity in decisions made by institutions that affect tourism in a very marked way (departments of transport, environment, culture, education, research, etc.). The Canary Islands need greater coordination between institutions and departments and between public and private interests. But it is also necessary to integrate the citizens as a whole in a better knowledge of the tou- rism sector and in the design of a future tourism model with broader social support.

The problem of tourism governance has been observed in the tourism accommodation moratorium that was in force from 2001 until approximately 2018 (Simancas, 2015). This regulation was designed with a territorial planning perspective but without a clear strategy of a long-term tourism model. Although the management of the growth of tourism destinations is a fundamental task, the implementation of these policies is a very complex element, which can unleash new dynamics and potentially counterproductive effects, not only in the Canary Islands, but in any destination (Hernández Martín et al ., 2015).

\section{Key sustainability issue areas in the Canary Islands}

$\mathrm{n}$ this section, the most relevant sustainability issue areas in the Canary Islands are presented. These areas have been chosen based on:

- The stakeholder consultation on the key areas of tourism in the region analyzed in the Strategic Plan of the Canary Islands towards Tourism (2019).

- International agenda on sustainable development goals and tourism.

- Reports and statistics on tourism in the Canary Islands.

- International standards and guidelines for tourism sustainability indicators.

This section is organized as follows, first we present the main results from the stakeholders' consultation on tourism strategy of the Canary Islands, then the key sustainability issues are presented. After the key sustainability issue areas are established, we show a set of indicators that can be used to monitor these areas and their potential contribution to the UN Sustainable Development Goals.

\subsection{Stakeholders' consultation}

The stakeholders' consultation was conducted in 2019 in the context of the Strategic Tourism Plan of The Canary Islands towards Tourism (Gobierno de Canarias, 2019) that provided very valuable insights into selecting the key sustainability issue areas of the Canary Islands and to obtain information about current data availability and existing data gaps and needs. It took six months to complete the consultation and included qualitative interviews, technical roundtables and online questionnaires with different agents from the Canary Islands.

Regarding the methodology of the consultation, 56 qualitative interviews were conducted with experts in tourism from the destination and included issues related to the strategic development of the tourism sector 
in the Canary Islands. These interviews comprised the public and private sectors and academic institutions.

Seven technical roundtables were also set up in the following areas:

- Tourism and environment

- Tourism and promotion governance

- Tourism and governance

- Tourism and legislation / management

- Tourism and mobility / connectivity

- Tourism and intelligence / knowledge

- Tourism and training / employment

These roundtables were composed of different agents from the tourism sector of the Canary Islands, which discussed different factors related to the area of each roundtable during a two-hour session. There were also sessions organized on the same topics on each island in the Archipelago with a total of 254 participants. As the final part of the consultation, a quantitative questionnaire was prepared and distributed among 240 agents of the tourism sector during the sessions. In addition, in these sessions approximately 80 questions were asked to the attendees.
The most mentioned areas for tourism development in the Canary Islands were arranged in several spheres, such as environmental, human, economic and territorial:

\section{Environmental sphere:}

A1 Environment and climate change

\section{Human sphere:}

A2 Integration of society with tourism

A3 Generation of experiences

A4 Trends in the international environment and strategic base for the future

\section{Economic sphere:}

A5 Innovation and intersectoral linkages

A6 Digitalization, knowledge and tourism intelligence A7 Tourism Internationalization

\section{Territorial sphere:}

A8 Tourism governance

A9 Planning of the territory and renovation of the tourist space

A10 Strategic infrastructures.

Figure 10. Four spheres of the main key issue areas according to stakeholders

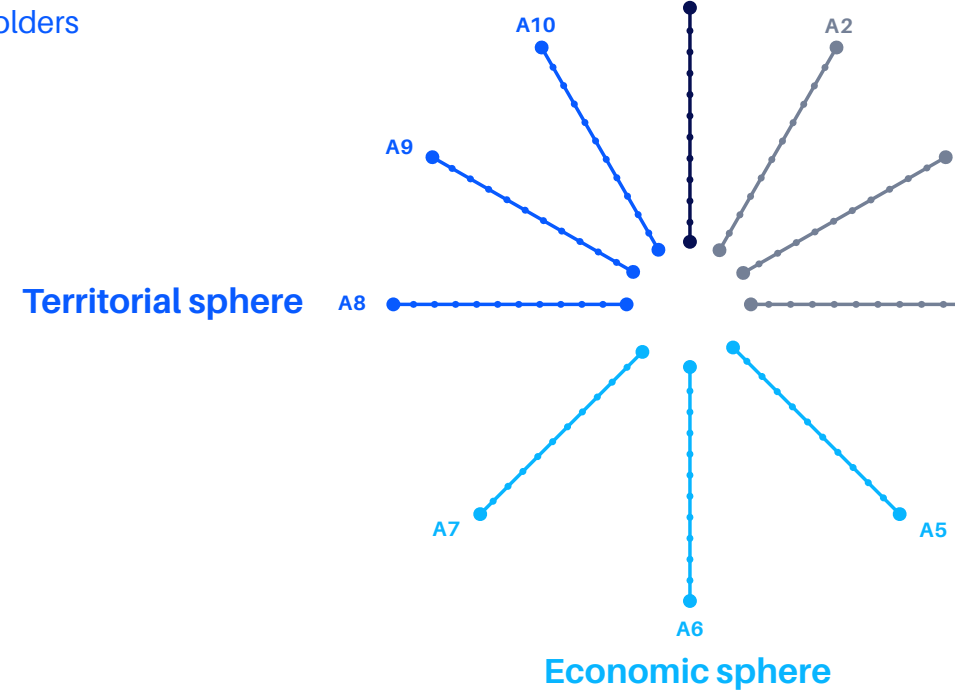


Figure 10 synthesizes the issue areas identified from the survey divided into corresponding spheres. The areas were analyzed at the level of the archipelago and of each island. All the key issue areas detected were attributed to the corresponding technical roundtable, where themes, challenges and actions for each area were discussed. Afterwards, a SWOT analysis of each area was conducted.

\section{A1 Environment and climate change}

The challenging issues highlighted in this area were as follows:

- The fragility of the natural environment in the Canary Islands

- Environmental sustainability as a factor of competitiveness of companies and destinations

- The generation of environmental innovations for the tourism sector

- Good environmental practices in companies and destinations

- The measurement of tourism environmental sustainability

- Fight against climate change and adaptation strategies to stimulate greater energy efficiency and the reduction of fossil fuel use, etc.

The destination can be characterized by a slow legislative adaptation to climate change, lack of leadership of the Administration and lack of sustainability in the tourism sector. The most important weaknesses in this issue area in the Canary Islands include the vulnerability of coastal urban areas, lack of adequate resource management, lack of environmental responsibility of public administration to demand actions from private entities and absence of environmental awareness. $\mathrm{Ne}$ vertheless, the archipelago has many strong points in this area, such as natural and landscape heritage, initiatives linked to tourism and sustainability through European programs, sustainable technologies for water management and successful experiences regarding sustainability in general.

\section{A2 Integration of society with tourism}

The social dimension of tourism implies considering the inclusive nature of tourism, that is to say, the use of tourism and leisure services by residents, corporate social responsibility of companies, the quality of employment or the quality of life in the surroundings of tourist areas.

It will also include aspects of interest such as the adequacy of the educational system in language learning and its effect on labor insertion in the sector or the analysis of the aging process and life expectancy of the population in tourist areas. In this field, the question of the functioning of the labor market, the adequacy of human resources in tourism and the value of entrepreneurship should be particularly analyzed. High unemployment rates in the archipelago and training deficits should receive special attention as well.

The Canary Islands present a lack of equal training opportunities for workers at all levels, scarce language skills of tourism sector staff, not enough collaboration between training entities, businesses to communicate needs to employment service. Yet, there is a consolidated public center for professional training in tourism (Hecansa) with the potential infrastructure and location to improve this situation. In addition, this area can be characterized by a high demand for middle managers with specific training (room managers, chefs,), programs for entrepreneurs and other initiatives.

Altogether, the most important challenges in this area are the following:

- Improve the orientation towards the most appropriate training profiles

- Spread the diversity of current and potential jobs in the tourism sector

- Provide equal training for all the islands of the archipelago

- Increase teaching at all levels in relation to language knowledge

- Become a leader in training to build an international network, etc. 


\section{A3 Generation of experiences}

The archipelago has a high volume of resources capable of generating new and varied tourist experiences supported by micro-segmentation of market. Aspects such as culture, identity or authenticity, the enhancement of the landscape, urban environments, opportunities for sports, etc., represent strategic areas in this field. It also includes the aspects that are derived from 'circular economy' strategies.

The area of experience generation in the Canary Islands has multiple negative aspects that hold back its development, such as the:

- Focus on the offer of sun and beach tourism

- Lack of promotion of a sustainable offer for demand interested in the less touristic places

- Deficit of high-level tourism products

- Lack of development of the rural world

- Legislative barriers that prevent generation of tourist experiences

At the same time the generation of experiences in the archipelago can be characterized by voluntary maintenance initiatives in rural areas, availability of sustainable local products, multiple hiking trails, rich landscapes and natural attractions. One of the ways to generate positive experiences is golf and the Canary Islands have an ideal climate and environment for playing golf along with a good management of the territory and natural resources. Moreover, one of the strong points of the destination to generate positive tourist experiences is related to its intangible assets and historical-cultural heritage that present high potential for tourism products.

\section{A4 Trends in the international environment and strategic base for the future}

This area considers the following aspects:

- Relevant international trends and their potential impact on the Canary Islands tourism model
- Analyses of international resource exploration works

- Demographic changes in outbound markets

- Climate change and its effect on tourist consumption patterns

- The effects of climate change mitigation policies on air transport

- Brexit

- Social behavior in the face of tourism

- Insecurity or the challenge that the millennial generation represents, etc.

Upon closer examination, this issue area reflects several weaknesses: a lack of vision in the existing model from the point of demand and supply; lack of adaptation of products and segments to different demand profiles (micro-segmentation); not enough training on the importance of tourism as an economically sustainable activity for the Canary Islands and others. One of the topics that needs special attention is vacation homes. Owners see the possibility of renting vacation homes as an equitable redistribution of the tourism economy (not only for large companies).

Despite the negative aspects mentioned above, there are numerous strengths the Canary Islands have regarding trends in the international environment. They include the strong positioning of the archipelago in the international market, public-private collaboration to promote destination at international level and the specific features of each island, which complement one another instead of competing. Also, the proximity to Africa and increasing air connectivity with this continent are becoming a competitive advantage of the destination.

\section{A5 Innovation and intersectoral linkages}

Competition in global markets requires an innovative tourism sector with the capacity for entrepreneurship at the local level. The strategies for the generation of new processes, new products and the ability to take advantage of the opportunities that exist in sectors such as tourism leisure, product marketing and specialized suppliers of a high quality tourism sector (design, architecture, audiovisual, culture, renewable energy, 
marketing, consulting, etc.) represent an area of strategic importance. Also, the positive relationship of the tourism sector with the rest of the economic framework of the islands is a key factor to develop such linkages.

However, the study and improvement in this field are being hindered by several weaknesses, such as a lack of appreciation of the primary sector and of support for the self-employed, small and micro businesses (for example, rural hotels) of the tourism sector as added value for the destination. There is also quite a weak link between leisure and accommodation sectors.

In spite of these weaknesses, this issue area is characterized by a number of strengths as follows:

- Canary Island information system developed by ISTAC as a support instrument for business innovation

- Small business network that can promote the local product / service

- Non-lodging leisure sector as a differential sector between the Canary Islands and some competitors in the Mediterranean

- Mentoring and counselling initiatives to give visibility to SMEs and start-ups in tourism innovation projects - Strengths of the cultural sector and its contribution capabilities to any future development project, and other strong points

\section{A6 Digitalization, knowledge and tourism intelligence}

Tourism is one of the activities that have been rapidly incorporated into the digital society and, therefore, digitalization is at the forefront of strategic priorities in the region. Aspects to consider in this area are:

- Greater generation and use of tourism intelligence

- Decision-making based on information and knowledge

- Development of the R\&D sector linked to tourism to take advantage of opportunities that digitalization and technology bring to cooperation, tourism development and collective well-being, the development of intelligent destinations, etc.
It is essential to make use of tourism intelligence from past and real-time data with successive interpretation of data and subsequent conversion into tourism knowledge. Also, an important aspect in this area consists of the creation of innovative open knowledge exchanges between public and private sectors, companies and universities.

Despite ISTAC being a reference as a leading tourist intelligence system in the destination, there are several negative aspects that prevent the development of digitalization and tourism intelligence. Some of them involve bureaucratic complexity, insufficient data on tourism expenditures, lack of digital tools provided by the administration and personal resources necessary to meet the services required by society, insufficient big data analysis to know in advance the expectations of customers and meet their needs and other issues.

\section{A7 Tourism internationalization}

Competing in global markets involves having the ability to participate in new ones. It is essential to elaborate strategies aimed at promoting companies and professionals in the Canary Islands to generate and export tourism knowledge and know-how to other markets. Additionally, it is essential to pay attention to the global interests of the world's real estate investors, which define the markets.

Although the Canary Islands suffer from a lack of anti-competition strategies, their experience and maturity mean the destination can export knowledge, maintain a powerful brand positioning and gain leading positions in international tourism research.

\section{A8 Tourism governance}

Aspects related to regulation and decision-making capacity at different levels of administration and departments of public and tourism administration represent an important area . Legislative simplification and compliance with current regulations are also basic elements in the dynamization of tourism destinations, such as regulation of the tourist use of vacation homes. Moreover, destination management organizations are undergoing 
transformations at the international level that must be taken into consideration. The design of coordination mechanisms between departments of public administrations, public-private cooperation and the development of instruments for citizen participation in tourism decision-making should be included in this area.

The main weaknesses of the current area identified through a SWOT analysis are as follows:

- Lack of agility in the administrative processes of public and private works

- Lack of constructive dialogue and legislative simplification between the public and private sectors

- Lack of regulation of the individual exploitation of vacation homes, etc.

Contrariwise, the strengths that can help improve the tourism governance in the Canary Islands are:

- Management and marketing units as a means of guaranteeing quality control

- Consortiums as tools or organizations of interest to carry out tourism activities

- Vacation housing as an element that allows certain establishments to be in the market, with fiscal transparency

- The concept of tourist municipality (to be validated with legislation), etc.

\section{A9 Planning of the territory and renovation of the tourist space}

After more than fifty years of tourism growth, one of the greatest challenges for the Canary Island Archipelago is to renew the public and private tourist space, which includes the whole territory, urban space, rural landscape, the coast, etc. The work here involves the renovation of urbanized tourist spaces linked to an integral planning of the territory and analysis of the legal impediments that renovation has had.

There are several weak points that slow down the development in this area. They include a lack of analysis of the economic activity in protected spaces to ge- nerate resources for their maintenance, lack of recovery of high value territories without occupying more land, lack of mechanisms to conserve or restore the landscape and others.

Simultaneously, these negative points are further affected by the destination strengths in this area: urban planning legislation for new sectors, applying renewal and not expansion; tax incentives for renovation provided by law; different landscape actors and renovation promotion measures.

\section{A10 Strategic infrastructures}

The most important aspects to consider in this area are as follows:

- Transport infrastructures (within each island, between the islands and abroad)

- Energy and water needs

- Infrastructures and services of information and communications

- Solid waste management and wastewater

- Mobility, connectivity and sustainability

- Accessibility to the tourist spaces

- Detection of sources of financing that will enhance infrastructures

The strong points of the destination in the issue area of strategic infrastructures include extensive European connectivity, in number of destinations and frequency, also between the main islands by ferry and plane, decrease on the dependence on tour operators, improvement of the network of roads, including landscape elements and others. To the contrary, there are some weaknesses such as the scarce implementation of extra-European air routes, low internal accessibility between local destinations and a lack of formal public-private collaboration frameworks in the islands' transport sector.

\subsection{Key sustainability issue areas in the Canary Islands}

In this section, the main sustainability issues areas in the Canary Islands' tourism are evaluated. These areas 
have been selected following the guidelines provided by UNWTO Network of Observatories, which identifies international recognized main areas and was further completed with an analysis of previous monitoring tourism reports in the Canary Islands and the stakeholders' consultation that took place in the archipelago during the development of the Strategic Plan of the Canary Islands towards Tourism in 2019. In total, sixteen areas have been identified in the Canary Islands:

1. Local satisfaction with tourism and local well-being

2. Labor skills, entrepreneurship and employment

3. Destination innovation, economic impacts and benefits

4. Tourism seasonality

5. Tourism products, culture, leisure and tourist satisfaction

6. Digitalization, knowledge and smart tourism

7. Energy management

8. Water and wastewater management

9. Solid waste management

10. Climate change impacts and mitigation

11. Governance and the territorial scale of analysis and policies

12. Air transport connectivity and intermediation

13. Overtourism, vacation homes and mass tourism

14. Maturity of the destination and renovation

15. Natural capital supporting tourism. Protected areas and fragile ecosystems

16. Universal accessibility and inclusivity

\section{Local satisfaction with tourism and local well-being}

A tourism destination will never be sustainable if it does not take into account the needs and expectations of its population. The satisfaction of the local population with tourism, conventionally measured in aggregate form as the percentage of population that is not opposed to the growth of tourist arrivals, reflects a process of social perception involving, inter alia, the identification of positive or negative impacts of tourism activity, the valuation of alternative economic development strategies and the legitimacy of (or lack of support for) specific tourism policies. The relevance of this issue is justified by the following statements:

- The key idea of social sustainability is that the economic model should be oriented towards the present and future needs of the population. The social contract to which the local population agrees to not only covers the economic income generated by tourism, but also the recognition by the population that such income is a counterpart to its socio-cultural and environmental impacts, as well as identifying and aligning with the practices of the sector aimed at reducing the environmental and climatic impact of tourism. Residents' attitudes towards cultural and natural heritage conservation are also important for long range economic sustainability of the sector.

- The need for tourism governance processes to be transparent and consider the priorities and demands of citizens and not only of the central actors in the industry. In the short term, tourism policies improve their chances of success if they obtain democratic legitimacy through public opinion monitoring. - The growing spatial dispersion of tourists and their search for authenticity increases interactions with the local non-professionalized population, so that their attitudes in these interactions gains importance in the quality of the tourist experience.

The Canary Islands have failed to consolidate a regular, transparent and neutral system for monitoring regional public opinion. This lack significantly affects the perceptions and valuations of the population regarding tourism activity, economic policy in a region highly dependent on tourism or the environmental problems of the archipelago and the connection with the economic model. A study of regional scope allowing comparisons between islands was carried out in 2011 and 2012 (Economic and Social Council). It showed a very high recognition of the economic impact of tourism in the region, although a greater division of opinions was detected regarding the sustainability of the sector. The most unsatisfactory aspect is the level of overcrowding in some 
tourist areas. More recently, narrow scope research has shown that tourism remains slightly problematic in the public opinion of the Canary Island population, with negative perceptions being detected at the sub-regional level regarding its impact on the landscape and the environment. A critical or even tourism phobic discourse has been identified that, although minority, accompanies the emergence of several social protest movements articulated around the opposition to the development of tourism projects or specific infrastructures by environmental activists. Latest available data come from the Vacation Homes module of the ISTAC's Socioeconomic habits and confidence survey, a 58 item and 3,800 respondents research covering perceptions on economic, social, cultural and environmental impacts of vacation homes. Results show that $76 \%$ of citizens of the region agreed or strongly agreed with the idea that tourism development has been very beneficial for the islands and their population, although values ranged between $67 \%$ in La Palma and 78\% in Lanzarote. Greater differences between islands in the valuation of the vacation homes impact can be found in this survey, showing the challenge of a homogeneous regulation for the archipelago and the need to monitor this issue.

This is one of the issues in which there is a significant gap between the requirements for monitoring sustainable tourism and the capabilities of the current regional tourism information system. Ideally, this gap should be covered by including a block of perception and valuation of tourism and the environment using a Canary Island Public Opinion Barometer, which could collect information at least annually for a sample that allows a maximum error of $\pm 5 \%$ for the different islands. This Barometer must be carried out with the highest standards of quality, objectivity and transparency, and if possible, under an institutional umbrella that reaffirms its neutrality.

\section{Labor skills, entrepreneurship and employment}

The quality and stability of employment are considered critical success factors for any destination. Howe- ver, the Canary Islands currently have unemployment rates that are totally unacceptable by the society, which are among the highest in Spain and Europe. All this combined with high rates of productivity and profitability of tourism companies in the Canary Islands, as tourism contributes $35 \%$ to total GDP in the Canary Islands with over 16,000 million euros (IMPACTUR, 2019).

Therefore, it is vital to verify the effects of tourism business activity on employment and to propose corective measures that would help generate quality and lasting jobs. In 2018, the number of direct tourism jobs in the Canary Islands was 343,899 jobs, and it is the second Autonomous Region in Spain after the Balearic Islands in number of tourism workers (IMPACTUR, 2019). In addition, the Canary Islands is by far the first region in Spain in which tourism professionals represent more than $40.4 \%$ of the total employment in the Canary Islands, followed by the Balearic Islands with $32 \%$ of the total. Likewise, for every $€ 100$ direct income, $€ 50.7$ of indirect income was generated in other sectors.

Likewise, equal opportunities in access to employment and entrepreneurship are considered structural objectives (Government of the Canary Islands, 2019). Indeed, reducing the gender gap is another objective to be achieved. In the case of entrepreneurship there is a need to increase the orientation in entrepreneurship within the education system and promote employment through new labor activation and insertion policies. The Canary Islands must be able to identify employment opportunities in the tourism sector and promote first employment in tourism with guarantees of success and continuity. In addition, identifying and promoting entrepreneurship in the tourism sector should be of capital importance.

Another challenge faced by the Canary Islands as a sustainable and smart tourist destination is the adequacy of its educational system in language learning.

Moreover, it is essential to know the current offer of tourism training programs in the Canary Islands, so that these programs can be adapted to market trends and needs. Aspects such as basic digital competen- 
cies that every professional in tourism must possess in order to successfully cope with the digital transformation must be approached from an integral perspective that allows a smooth labor transition for human resources and tourism businesses.

The identification and proposals of the new digital profiles most demanded by the sector are fundamental for the generation of employment in the tourism sector. Today, we anticipate that tourism companies in the Canary Islands will demand profiles such as: Digital Marketing Manager; Community Manager; Digital Communication Manager; Content Manager; Digital Analyst; Customer Experience Manager; Inbound Marketing Specialist; Growth hacker; Transmedia \& Branded Content Specialist, among others.

In conclusion, it is imperative that information and data be integrated in a scorecard to allow the alignment of training actions and education trends in Hospitality \& Tourism Education with the achievement and maintenance of quality jobs.

\section{Destination innovation, economic impacts and benefits}

Tourism development in the Canary Islands over the last 60 years has brought to the archipelago an improvement in income and living conditions, reflected in the rise of the GDP per capita of a region suffering from backwardness. Nevertheless, there is a concern regarding the fact that despite the leadership of the Canary Island tourism sector in the European tourism market, the figures on income, poverty and employment of the Canary Islands have traditionally placed the islands among the poorest regions of Spain and Europe. The explanation for this situation is not simple and depends on several factors, including history. However, the region has a clear opportunity to make tourism a mechanism for improving the economic well-being of the population.

Competition in global markets forces destinations to implement policies to promote innovation and entrepreneurship in tourism at the local level. This implies the generation of better processes and better products to take advantage of the existing opportunities. The tourism sector in the Canary Islands is concentrated on accommodation facilities, with an important presence of Spanish multinational hotel chains, but it has had difficulties to have a greater participation in the intermediary sector or air transport. In addition, the leisure sector, apart from a few exceptions consists of very small firms.

The development of tourism in the Canary Islands has not taken advantage of a second tier of activities (design, architecture, audio-visual, renewable energies, consulting, tourism education, etc.) that could improve living standards in the region. In addition, the internalization of locally owned tourism firms has been very scarce.

All these characteristics of the Islands' tourism model and historical aspects like the educational backwardness can help explain the low impact of tourism in enhancing the economic conditions of the local population.

In the context of monitoring, the Canary Islands have very good statistics on tourism expenditure, there is an annual report on the impact of tourism on the economy, and there are also good figures on employment in the tourism industry. Nevertheless, the question as to why the impact of tourism in improving living standards is so limited remains unanswered as does the question on what could be the best policies to improve the economic impacts of tourism and to spread them among the population. This is why in the context of monitoring, there are many tasks to be carried out related to the economic impacts and benefits of tourism. There is a need to know what happens to each euro spent by a tourist and what would be the impact of such an amount spent on alternative goods and services.

\section{Tourism seasonality}

The main feature of tourism in the Canary Islands and the basis of its leadership position among sun and beach tourism destinations in Europe is the possibility of tourism throughout the whole year. In fact, the peak season in the Canary Islands corresponds to the winter. The Canary Islands enjoy a mild winter with temperatures that are normally between $18^{\circ} \mathrm{C}$ and $25^{\circ} \mathrm{C}$. This contrasts favorably with the climatic conditions in the European continent and competing sun and beach 
destinations in the Mediterranean. The periods with the lowest incoming tourists are some months between the winter and the summer season (May, beginning of October), but, in general monthly differences are not very significant in the number of tourists and, even in the price they pay for the tourism services such as transport or accommodation. The summer season shows good results but in this period the islands suffer from the competition of Mediterranean destinations located closer to the main outbound European markets.

Nevertheless, tourism seasonality is a crucial factor in tourism policy and a topic demanding monitoring. The possibilities of increasing tourism income in the Canary Islands are strongly related to the generation of relevant information on tourism preferences and behavior in periods of low tourist affluence to support policies aimed at reducing even more the seasonality pattern. In fact, it is true that the aggregated seasonality pattern is not very marked but a closer look at tourism in certain islands, leisure activities or local destinations shows that the seasonality pattern is sometimes clearer. The same happens with the seasonal behavior of demand, with Nordic tourists flying to the islands during the winter, while the Spanish or the British have a higher presence during the summer.

A tourism region dependent on its climate must monitor its influence, particularly in a global warming context. The changes in habits and climate in origin countries and competing destinations must be considered. In addition, the risk and monitoring of extreme climate events is new information needed in this international context.

The basic data required to monitor seasonality of tourism demand in the Canary Islands is adequate in the sense that the Institute of Statistics of the Canary Islands provides monthly statistics for each island for tourism arrivals, international air passengers or tourists staying in hotels and self-catering accommodation. $\mathrm{Ne}$ vertheless, the statistics on expenditure are only available on a quarterly basis. Other complementary statistics that could help to monitor seasonality are those related to energy and water consumption in tourism, as well as waste production. Available quarterly figures for tou- rism employment in tourism characteristic activities do not show a significant seasonality pattern.

Improved seasonality monitoring for better policy design can be a way of enhancing the economic benefits of tourism in general, and certain local destinations, activities and firms in particular.

\section{Tourism products, culture, leisure and tourist satisfaction}

The archipelago has a high volume of resources capable of generating new and varied tourist experiences supported by micro-segmentation. Aspects such as culture, identity or authenticity, the enhancement of landscapes, urban environments, opportunities for sports, etc. represent a strategic scope of work for the future. While accommodation facilities have reached high quality standards and transport is provided by foreign operators, the future of tourism development in the Canary Islands must be related to developing new products in niche markets, enhancing the expansion of the leisure sector to increase the satisfaction and expenditure of tourists. The accessibility of tourism infrastructures and services for all kind of users is another key factor for the competitiveness of the tourism sector in the long run.

The unique climatic conditions of the Canary Islands for the practice of outdoor activities throughout the whole year offers possibilities for the renovation of the tourism model with the focus on tourists and their tastes and preferences. Cost competition with other destinations is difficult because of the price of air transport and because the cost of living in the Canary Islands is relatively high. Therefore, the development of the leisure sector is a key factor for the sustainability of tourism in the mid and long term in the Canary Islands with the help of entrepreneurship and innovation.

\section{Digitalization, knowledge and smart tourism}

The digitization process is a worldwide trend that affects multiple sectors of society, administrations and 
companies. Tourism, as a sector of special interest for the Canary Islands, has quickly been incorporated into the digital society due to its high strategic importance. Introducing digitalization favors such important aspects as the generation and exploitation of tourism intelligence, favoring decision-making based on information and knowledge, developing an R\&D sector directly linked to tourism and taking advantage of other opportunities. Digitalization and technology contribute to cooperation, tourism development and collective well-being, the development of intelligent destinations, applied big data, etc.

Monitoring digitization is not a simple process. The Canary Islands, at the regional government level, have a Canary Island Agency for Research, Innovation and Information Society, among its tasks is the dynamization and measurement of different sectors in these areas. In addition, every year the Canary Island Observatory of Telecommunications and the Information Society tries to provide an overview of the progress with functions such as "the definition and adaptation of indicators for the development of telecommunications and the information society. In general, there is an analysis of the metrics of the telecommunications sector and the Information Society in the Canary Islands" or the valuation of said development and evolution" in the social, administrative and business fields, especially in small and medium enterprises, and an annual report on them, for which the necessary statistical information will be available". In addition, the Institute of Statistics of the Canary Islands offers data sets that help evaluate and add to the effects of this progress.

In the Canary Islands, the capacity and autonomy of each island government in regional development must be taken into account. This means that each Island Council (Cabildo) has instruments - own or external - to enhance areas related to digitalization and tourism. A good example of this process of digital transformation (not exclusive) is found in the "Smart Island" projects planned or underway in all the islands of the archipelago. Each strategy includes elements related to tourism and digitalization, but in order to be more successful and consistent, they need to be evaluated.
In summary: It is necessary to conduct an integration task that helps to share better the digitization processes. From the point of view of tourism, and although the Smart Specialization Strategy of the Canary Islands RIS3 considers it as one of its vital axes, everything must be implemented in a coordinated way.

\section{Energy management}

The Canary Islands has historically had a high dependence on overseas suppliers of fossil fuels - mainly oil - for its energy needs, with a relatively low presence of renewable energies coming from internal sources. Currently, $98.6 \%$ of energy needs are supplied by oil. A total of 7,130,415 tons of hydrocarbons were imported in 2017, including crude and finished products such as gasoline, diesel, fuel oil and kerosene.

Primary energy is calculated as the sum of net imports of energy resources and internal energy production, deducting the exports produced from these products, supplies to international maritime navigation and changes in stocks. In the Canary Islands, the production of internal primary energy represents a very small fraction, which corresponds to the joint contribution of all renewable energies (wind, photovoltaic, solar thermal, hydroelectric, mini-hydraulic and landfill biogas). Despite depending on the weather conditions, the total share of renewable energies has been practically stable for years, and its contribution to total primary energy stands at $1.4 \%$ in 2017 . The energy sources with the highest contributions to renewables in the Canary Islands are wind power(50.4\%), followed by photovoltaic solar (33\%).

The final energy demand is obtained by deducting from primary energy the losses of the energy sector (in power plants, energy waste, self-consumption, transport and distribution of electrical energy). Therefore, it includes all the energy consumption of processes that are used for the production of goods and services. Two segments are distinguished: i) the demand for oil products and ii) the demand for electricity. The supply of oil to end users within the structure of Canary Island energy demand is of great importance, representing 
$80.02 \%$ of the total. The rest is divided between electricity $19.75 \%$ and solar thermal $0.23 \%$.

According to power generation capacities, renewable energies represented $13.6 \%$ in 2017 , while thermal power plants stood at $83.5 \%$. However, not all of this installed power is converted into final consumption on demand. That is, meeting the demand for electricity with renewable sources is lower than the installed power, representing only $7.5 \%$, although renewables can reach temporary peaks of $20 \%$ depending on weather conditions.

The island of El Hierro is where the greatest use of renewables in electricity demand is achieved with $45.5 \%$ in 2017 . This is due to the implementation of a system that combines a hydraulic source facility with wind power. Considering the share of the various sources within the renewables sector, the one originating in the photovoltaic solar represented $38.5 \%$, while wind power was $56.3 \%$.

Regarding final energy consumption by sector in 2017, the most important is the transport sector (land, air and sea), which represents $75.1 \%$ of final energy demand. In particular, land and air transport $(67.11 \%$ of final energy consumption) shows a consumption of $33.6 \%$ for the former and $33.4 \%$ for the latter. Agriculture and fishing have a more reduced consumption share of the total energy demanded, with a joint $1.13 \%$, while industry represents $2.5 \%$. The services sector, which includes hospitality and tourism services, uses $12.21 \%$, and the residential sector of the population of the Canary Islands accounts for $8.6 \%$ of total demand.

The relationships between energy consumption and some economic production indicators provide information about the degree of energy intensity and performance. Energy intensity measures the degree of energy efficiency by relating energy consumption to economic activity, while the energy consumption per capita provides an indicator of the energy needed to meet human and social needs. Thus, in 2017 the final energy intensity was $0.0845 \mathrm{Tep} /$ thousand $€$, which represents an increase of $0.79 \%$ compared to the previous year, while the energy consumption per inhabitant was $1.7241 \mathrm{Tep} / \mathrm{hab}$, which was $3.41 \%$ higher than the previous year.

\section{Water and wastewater management}

Due to tourism and industrial development, the increase of the population of the archipelago and the expansion of the irrigation area, water demand in the Canary Islands has significantly increased in the last decades, augmenting water scarcity in the region. As a result, many springs were dried and the water from galleries and wells increasingly lost its quality, which brings together a very serious danger of desertification. In the archipielgo, industrial production water (desalination, proper treatment, biological depuration and reuse) is an essential element in guaranteeing tourism consumption because of groundwater and surface resource scarcity. Indeed, about a $100 \%$ of urban water supplies in the oriental islands of Lanzarote, Fuerteventura and Gran Canaria is produced by desalination plants, while the use of groundwater supplies in the rest of the islands vary from $50 \%$ (Tenerife) to a $100 \%$ (Gomera, Hierro and La Palma). Climate change and the expected decrease of rainfalls in the region call for a proactive water management all sectors of the economy. Due to the increase in water supply prices during the last decades and water technology innovations, the tourism sector (mainly accomodation firms) are prone on water efficiency and conservation measures in most of the touristic municipalities.

In the Canary Islands, the legislation in this field has its main milestone in the Water Law 12/1990, of 26th of July (Ley de Aguas). According to this Law, administrative functions of the Canary Islands in the water area shall be exercised by:

- Government of the Canary Islands: responsible for the management of water resources in the archipelago and main data provider.

- Competent Area of the Government: La Dirección General de Aguas de la Consejería de Transición Ecológica, Lucha contra el Cambio Climático y Planificación Territorial.

- Island Councils (Cabildos).

- Island Water Departments: autonomous organizations assigned for administrative purposes to the 
Island Councils that are responsible for the management and planning of the water resources on each island. Also, they prepare Insular Hydrological Plans intended to achieve the highest degree of rationalization in the use of water resources at the island level.

As presented in the table, the tourism sector accounts for $12.1 \%$ of the total water demand of the archipelago.
The tourism sector, in terms of water consumption, includes hotel and non-hotel establishments, due to the difficulty to define precisely the concept of tourism activity. The average consumption in tourism reaches 600 liters per bed and day (Gobierno de Canarias, 2014), meanwhile, the average consumption per inhabitant is only 150 liters per day (ISTAC, 2016). This shows that tourism water consumption may be four times greater than the residential consumption.

\begin{tabular}{|l|l|l|l|l|l|l|}
\hline SECTOR & URBAN & TOURISM & RECREATIONAL & INDUSTRIAL & AGRICULTURAL & TOTAL \\
CUBIC HECTOMETERS $\left(\mathrm{hm}^{3}\right)$ & $\mathbf{1 9 1 . 3 8}$ & $\mathbf{6 3 . 8 2}$ & $\mathbf{2 7 . 0 5}$ & $\mathbf{1 8 . 8 3}$ & $\mathbf{2 2 6 . 0 7}$ & 527.15 \\
SECTOR & $\mathbf{3 6 . 3 \%}$ & $\mathbf{1 2 . 1 \%}$ & $\mathbf{5 . 1 \%}$ & $\mathbf{3 . 6 \%}$ & $\mathbf{4 2 . 9 \%}$ & $100.0 \%$ \\
& & & & & \\
\end{tabular}

Table 1. Estimated water demands by sectors in the Canary Islands in 2015

Source: General Water Management of the Canary Islands Government (Dirección General de Aguas del Gobierno de Canarias)

We can see in Table 1 that agriculture accounts for $42.9 \%$ of water consumption in the Canary Islands despite contributing to just $1.2 \%$ of GDP (ISTAC, 2018). By contrast, tourism direct and indirect impacts account for $35.0 \%$ of GDP (IMPACTUR, 2018), while accommodation activities are responsible for $12.1 \%$ of water consumption. To make this comparison from another point of view: agriculture accounts for $2.6 \%$ of total employment in the Canary Islands and accounts for $42.9 \%$ of water consumption, while the accommodation sector accounted for $8.2 \%$ of employment and it represented $12.1 \%$ of water consumption. It is worth noting that around $20 \%$ of the wastewater in the Canary Islands is treated and reused. Most of the reused water is for agricultural purposes.

Water consumption in the archipelago, especially in the tourism sector, is highly dependent on desalination of seawater, which increases energy demand and additional contributes to greenhouse emissions. Nevertheless, there is no information on the distribution of desalinated and treatment of water by sectors. A number of accommodation establishments have their own desalination plants, especially in the more oriental and dry islands.

There is a range of organizations that collect data on water statistics within the region. The Government provides estimated data on total water consumption by tourism. The Island Water Councils, through their Hydrological Plans, publish information on water consumption in tourism, overall consumption and by municipalities, predictions and tourist consumption per guest-night. Additionally, the Island Councils prepare data about desalination plants in hotel establishments.

Although there appears to be a wide range of data collected on this topic, there are no regularly published and publicly accessible reports outlining water management. There is no public data at the level of the Canary Islands on water in tourism except the total consumption and more detailed information is available only at island level. In addition, these data are obsolete with a minimum of two-year delay.

Likely, one of the most urgent needs in the Canary Islands nowadays is to improve water the sewage network 
and increase the number of wastewater treatment plants. Despite the vulnerability of the coastal and ocean resources of the islands, the rithm of investments in this matter has not meet tourism development or the increase in population. As a result, there is an evident lack of water treatment and still a large number of black wells in the islands. In addition, water reuse is only testimonial instead of a source of water resources for a number of uses.

Tourism puts a lot of pressure on the natural resources of the archipelago, especially water, and raises questions about the necessity of changing the current model to ensure its sustainability. Given this circumstance, there is no doubt that carrying out a rational management of water in this insular space, with adverse geoclimatic factors and substantial tourism activity is essential to ensure its sustainability.

\section{Solid waste management}

Overall waste generation in the Canary Islands is well above the 1.2 million tons reached in 2015, and most ends up in the islands' landfills. Unlike the other Spanish archipelago, Balearic Islands, in the Canary Islands the main treatment facilities are landfills, since there is a strong social opposition to incineration and estimated recycling rates are below $10 \%$ of total municipal waste. Thus, minimization of MSW generation and maximization of sorting waste have become priorities to comply with the European Directive 2018/851/EC and Spanish National Waste Plan (2014-2020). The per capita waste generation in the Canary Islands in 2015 was $594.1 \mathrm{~kg}$ per inhabitant, above Spain's national average (466 kg per inhabitant). In fact, the Canary Islands have the second highest waste per capita indicator within Spain, just below the Balearic Islands (INE, 2017). In some tourist municipalities, waste per capita reached $964 \mathrm{~kg}$ per inhabitant (Adeje, Tenerife), 1,008 kg (Tias, Lanzarote) or even 1,172 kg (Yaiza, Lanzarote) for 2015.

Tourism has a large and increasing impact on $\mathrm{Mu}$ nicipal Solid Waste (MSW) generation, which, in some regions, may be larger than that of residents. Waste pressure is especially relevant in island destinations, due to their isolation from mainland recycling networks and facilities, resulting in a greater prevalence of landfills rather than other waste management techniques. In addition, as shown elsewhere, tourism islands have several common waste management problems, such as reduced number of treatment and disposal facilities, high population densities, limited land mass to manage MSW, difficulties to achieve economies of scale in waste management services and significant seasonality in waste generation due to tourism, among others.

Tourism waste flows in the Canary Islands remain hidden within the residential contribution to municipal waste. One reason is that tourism waste production is mainly domestic or similar to domestic waste. About $50 \%$ of municipal solid waste is food waste coming from the residential sector and the main characteristic tourism activities such as accommodation and the F\&B sector. One important reason for the invisible contribution of the tourism sector to municipal waste generation is that regional and municipal regulation of waste management systems has not been updated to the EU and national directives. As a result, main tourism firms are charged by municipalities by flat year fees based on capacity (usually the number of beds), regardless of their waste generation and recycling efforts.

Therefore, tourism contributes intensively to municipal solid waste, yet the waste from tourism systematically remains hidden behind residential waste flows. As a result, municipal fees are set without precise information about the waste producers' contribution, causing financial imbalances and cross-subsidies between residential and economic activities. Given the observed difficulties to improve waste management and promote the circular economy in island destinations, it is urgent to monitor tourism's contribution to waste flows and to explicitly design municipal, island and regional regulatory frameworks that help tackle the problem and boost the recycling rates of the tourism sector.

When the attention is paid to tourism's contribution to MSW generation, most studies estimate this impact by means of a demand-side approach using tourist flows. However, the main problem of this approach is it can overestimate the direct effect of tourism to waste generation, as both tourism and non-tourism economic 
activities are being considered. From the supply side, on the other hand, residents and non-residents consume services from the main tourism characteristic activities. Therefore, efforts are being made to establish a methodology that helps obtain accurate estimates of the contribution of tourism to waste flows. However, in order to have accurate estimates of tourism firms' contribution to waste flow, a new incentive scheme for waste management in tourism firms must be designed.

Bearing in mind previous information, it is necessary to carry out a mixed demand-supply approach, which provides accurate estimates of tourism's contribution to MSW generation and, consequently, improve the waste management, especially in regions with high tourism population. Moreover, in order to reduce solid waste and increase recycling rates, establishing economic incentives through the more precise estimation of waste producers' contributions is essential.

\section{Climate change impacts and mitigation}

Climate change is caused by the emissions into the atmosphere of gases that increase the difficulty in release of heat trapped on the planet. These greenhouse gases $(\mathrm{GHG})$ are carbon dioxide $(\mathrm{CO} 2)$, methane $(\mathrm{CH} 4)$, nitrous oxide (N2O), fluorocarbons (HFC and PFC) and sulfur hexafluoride (SF6), which are released primarily by human activities through industry and the use of fossil fuels. The Canary Islands, due to their extreme dependence on fossil fuels, have a high GHG emission rate, both in terms of their productive composition and in socioeconomic terms.

The Canary Islands have increased their total GHG emissions from 8,938.4 Gigagrams of $\mathrm{CO} 2$ equivalent in 1990 to $12,976.9$ in 2016, which represents an increase of $45.2 \%$ in that period. This growth is somewhat higher than that for mainland Spanish territory, and higher than the increase allocated to Spain in the Kyoto Protocol. In 2016, the increase in GHG was 3.4\% compared to the previous year.

The evolution of GHG emissions in the Canary Islands has been closely linked to its economic and pro- ductive cycle, up till 2008, there was an almost continuous increase until the level of $17,327.5 \mathrm{Gg} \mathrm{CO} 2$-eq in that year. The highest level of emissions was obtained in 2005 (17,732.3 Gg CO2-eq), a year of significant economic and tourist growth. After 2008, the economic crisis led to a substantial reduction in GHG emissions, which in 2016 are still 23.6\% below those of 2006.

According to the types of GHG, $\mathrm{CO} 2$ is the most abundant, representing $85 \%$ of the total, followed by methane that represents $9.7 \%$. The latter has increased its proportion in recent years, which needs to be monitored, since methane has a greater global warming potential. The remaining gases represent about $4.9 \%$ of GHG emissions. In the context of Spain, the Canary Islands were responsible for about $4 \%$ of total GHG emissions throughout the national territory in 2016, which is 0.9 points above the share it represented in 1990.

In per capita terms, emissions have decreased by $27.4 \%$ in the last ten years until 6.17 tons of $\mathrm{CO} 2-\mathrm{eq} / \mathrm{in}$ habitant in 2016, which is $12.1 \%$ lower than the Spanish average of 7.02 tons of CO2-eq/inhabitant. However, per capita emission levels would be considerably higher if the impacts of air and sea transportation emissions of tourists visiting the Canary Islands from overseas and the Spanish mainland were considered.

According to GHG emission sources, the most important is the "energy processing" sector, which contributed $85.52 \%$ of total emissions in 2016 . This sector includes electricity production, oil refining and the transportation system. Although it has been losing some relevance in recent years in favor of the sectors of "industrial processes and product use" and "waste treatment and disposal" -it represented 92.2\% in 1990-, it is clear that it shows a behavior closely linked to the economic and productive cycle, with very significant increases of emissions during periods of strong growth of the Gross Domestic Product.

The second sector with the highest GHG emissions is "waste treatment and disposal" with $9.15 \%$ of total emissions in 2016. The rest of the sectors have very small representations. In 2016, the sectors of "industrial processes and product use" and "agriculture" had relative shares of $3.86 \%$ and $1.47 \%$ respectively. The 
growing importance of GHG emissions from the waste treatment sector is due to the greater management of waste in economic activity, including tourism. This is also exacerbated by higher localized methane emissions produced by the decomposition of buried organic waste. Thus, the emissions in the Canary Islands can significantly be reduced with the implementation of circular economy policies.

The energy processing sector involves large amounts of fossil fuel combustion, and therefore, it is the sector with the highest amount of emissions, since it includes all those that come from the energy, transportation, and manufacturing industries. In 2016, the energy sector emitted $53.4 \%(5,923.25 \mathrm{Gg}$ of CO2-eq) of the total, while transportation was responsible for $42.6 \%$ $(4,724.31 \mathrm{Gg}$ of CO2-eq). Among the types of transportation, the largest emitter of GHGs is land transport (3,458 Gg of CO2-eq), followed by sea transport (604.5 $\mathrm{Gg}$ of CO2-eq), and air transport (669.6 Gg of CO2-eq). Considering 1990 as the 100 base year, land transport has increased its emissions $217 \%$, while sea transport has reduced its to $47 \%$. Therefore, the growing demand for land mobility in the Canary Islands due to the increase in the number of private vehicles has been a relevant factor leading to the increase in GHG emissions, which should to be avoided through the implementation of more sustainable mobility policies.

\section{Governance and the territorial scale of analysis and policies}

The governance of any tourist destination is mediated by multiple actors (collective subjects with group recognition or their own identity) with a gradient of interest that ranges from indifference to commitment in decision making. From those located at the most distant degree, the indifferent, to the decision makers, passing through all the intermediate actors, there must be suficient means for the flow of knowledge and positive socio-economic relations. Without this premise, which focuses on the quality of life of residents, non-resident workers and visitors, tourism activity cannot be linked to just the development of a territory. The users of the system need and sometimes demand both administrative simplification and active listening and means to express their views. Indeed, it is the management departments themselves that suffer the most from a situation that delays, obliges and makes performance of the tasks entrusted to them less efficient. At a lower level, there is the user-company or entrepreneurs, who depend on the administrative departments, as well as any citizen who needs paperwork, complaints or making proposals. In general, it is a tremendously regulated system, but with a low level of control and lacking an effective design of information and coordination mechanisms, as well as lacking simplification and consolidation of regulations.

Solving the above and supported by digital innovation and previous diagnoses, a destination can position each group of actors in degrees of responsibility for their transformation and gradual adaptation to the changes demanded by the market, competition and internationally marked lines around sustainability and inclusion. Tourist activity thus transcends its economic aspect, to include the expectations and desires of its users, which will improve the management of the system with their collaboration and contribution. The strategic planning of destination governance and tourist activity, of the set of norms, relations and actions focused on the people and the territory will allow a frame of reference and evaluation to be implemented from a local level, reinforcing the identity of the destination, without giving up the optimization of resources and the novel generation of a diversified, singularized and adaptable offer with contained costs.

Thus, there is a need to establish criteria for action and transversal planning that promote an approach of active reflection and citizen participation (common spaces) based on assessable indicators of public-private responsibility and commitment. To do this, the leadership of administrations and sectoral agents-citizens must be accompanied by institutions with sufficient power to organize and enforce the agreements made, mediating non-convergent interests and bringing positions closer together and creating synergies to respond to the needs of the destination. 
Such a strategic conception based on governance does not presuppose the absence of risks derived from the relational inequality between the actors (interactions between agents with diverse and unbalanced capacity). This conflict is part of the relations at the destination and its reasonable management depends on consensus between the operators active in the territory. The cohesion of the destination will be reflected as a strength both in its capacity to respond to the continuous change of the tourism system, and to its competitive capacity.

\section{Air transport connectivity and intermediation}

The island nature of the destination and even more, the archipelagic nature make external connections a key factor for the development of tourism. Reaching the Canary Islands by boat is not easy given that it is 1,300 kilometers from the nearest port in Spain. Therefore, the guarantee of air connections with hundreds of outbound airports, particularly in Europe is crucial for the development of tourism in the islands. The dependence on air transport of the tourism sector of the Canary Islands helps explain why the islands continue depending on tour operators, which provide charter flights to the islands.

The dependence on international air transport firms has put the issue of connectivity at the core of the concerns of the Canary Island government given that a lack of capacity directly affects the prices paid by visitors, the flow of tourists to the destination and the profitability of the local tourism sector. The air transport market is very dynamic and changing, and the Canary Islands must adapt to the changes that take place.

The emergence of the low-cost model in the air transport market was a shock for all the incumbent stakeholders, given that this model tends to reduce the intermediation of the tourism market. Nevertheless, in recent years, clear movements towards the creation of tourism packages by low-cost carriers has been observed, particularly in the case of Easyjet. In addition, new actors have joined the market of air-transport and intermediation while other big players, like Thomas Cook, have disappeared. In fact, the dependence on air transport firms is added to the dependence on main European tour operators. More than $50 \%$ of the tourists that arrive to the islands have bought a tourism package and an increasing number of them are also using the online travel agents like Booking or Expedia.

Air transport is a precondition for the development of tourism in the Canary Islands and that is why forecasts of plane seats are important to plan and negotiate in the tourism market. Promotur is the public-owned firm for tourism promotion in the Canary Islands. It devotes many resources to monitoring and promoting connectivity in terms of quantity and in terms of the variety of origin airports and destinations airports in the Canary Islands. In fact, the Canary Island residents are entitled, as an Outermost Region of the European Union, to subsidies in air transport to the Spanish Mainland and among the islands to improve mobility. Monitoring connectivity and intermediation in a region so dependent on tourism is a crucial issue to design better policies and incentives to make the tourism sector of the Canary Islands more sustainable from an economic point of view.

\section{Overtourism, vacation homes and mass tourism}

Qualifying a tourism area as "saturated" verifies the existence of a negative impact, understood as an undesirable change by tourists. Thus, it increases the difference between the perceived value and the expected value. Accommodation saturation is particularly concerning in island destinations, especially when we include it in the sustainability paradigm. The impact of insularity on territorial planning for tourism is manifested in the consideration of the islands as closed, fragile, discontinuous and limited systems. Not only does this complicate the management of key environmental factors, but also has an impact on the destination's carrying capacity and, therefore, on the multiple dimensions of sustainability (environmental, economic, social and institutional). The territorial characteristics of islands make the considera- 
tion of accommodation saturation different than in continental areas.

This concern about tourism overcrowding is especially relevant in the insular spaces of the Canary Islands. It is one of the main European destinations of mass tourism, according to the Institute of Statistics of the Canary Islands (ISTAC), the islands received 15,975,510 tourists in 2017 and are ranked first in Europe for overnight stays of non-residents in tourist accommodation. However, because the demand is not seasonal, there are no concentrations of tourists at certain times of year.

Given that the Canary Islands specializes in coastal vacation accommodation, a large number of the tourism establishments are located on only $1.76 \%$ of the total surface area of the region (Simancas, 2015). The territorial concentration of urban-tourism explains why the coastal tourist areas in the archipelago have densities similar to central European cities. Despite this, $60 \%$ of these areas have densities lower than the regional average $\left(121,461\right.$ visitors housed per $\left.\mathrm{km}^{2}\right)$. The accommodation density at the regional scale is 35.66 accommodation spaces per hectare and 14.08 establishments per km² (Simancas \& Peñarrubia, 2019).

The data on accommodation saturation in coastal tourism areas in the Islands are largely the result of applying a specific regulation on accommodation density. Decree 7/1995, which modified Gran Canaria's Territorial Planning Law, was the first to incorporate accommodation density into urban planning instruments for the Canary Islands. It considers the density of each plot of land according to the concept of "net density", proposing specific thresholds. Thus, article 35 of Law 7/1995 establishes the maximum density permitted in the plots used for tourist accommodation through a standard minimum of square meters of land per accommodation space, which can be no less than $60 \mathrm{~m}^{2}$. This decreased what had been set in Gran Canaria's Territorial Planning Law of $70 \mathrm{~m}^{2} /$ hotel accommodation space on the North Coast, which implied that a maximum of 285 accommodations spaces could be authorized for a plot of 20,000 $\mathrm{m}^{2}$. In this way, the relation between gross density (of the area) and net density (of the plot of land) became a basic control variable. This was an attempt to eliminate the excessive occupancy densities of the coastal tourism areas (30/50 $\mathrm{m}^{2}$ of plot per accommodation space) which had predominated to that point. It also attempted to establish low densities in still-undeveloped land by limiting the number of new accommodation spaces per buildable plot by fixing a net density (understood as a tourism ratio) directly applicable to new tourism authorizations, and introducing various proportions of accommodation/ services and equipment. This was converted into a variable to control the authorized gross density and its consequent relation with net density.

Subsequently, Decree 10/2001, 22 January, which regulated tourism standards and proposed higher densities, was added to the tourism moratorium mentioned above. These standards set the minimum sizes of the plots that could be occupied by new constructions of tourist accommodation establishments. It maintained the $60 \mathrm{~m}^{2}$ plot/accommodation space standard and added a $50 \mathrm{~m}^{2}$ standard for building renovation areas or zones, as well as a series of parameters related to infrastructures, equipment, buildability and heights; these parameters were slightly modified by article 13 of Decree 142/2010, 4 October, which approved the Tourist Accommodation Regulation. The territorial implementation of the minimum standard has generated a relation between accommodation capacity and the physical dimensions of new tourist accommodation establishments, giving rise to a construction model that Simancas \& Garcia (2010) have denominated "horizontal hotels", in an attempt to imitate "Caribbean resorts" (Simancas, 2015).

Finally, the Canary Island Tourism Planning Guidelines, approved by Law 19/2003, consider a tourism area to be "saturated" when its gross density exceeds 200 accommodation spaces per hectare. This parameter is lower than the minimum required by Decree 42/2010. According to this parameter, $42 \%$ of the tourism areas have "saturated" plots of land and, therefore, a significant number of tourist accommodation establishments whose plots surpass $50 \mathrm{~m}^{2}$ per accommodations space.

In this sense, the competitive success of any tourism destination depends, among other factors, on its 
differentiation, segmentation and diversification, security, connectivity, the provision of quality services, as well as the availability of innovative infrastructure, equipment and prestige. Therefore, it is necessary to measure the degree of tourist satisfaction. Their satisfaction has repercussions not only on their repetition at the destination, but also on their positive assessments conveyed on social networks, which have become a decisive factor in choice and recommendation. It also affects the main indicators of tourism business and business profitability (number of overnight stays, average stay, occupancy rates, Average Daily Rate, Revenue Per Available Room, Gross Operating Profit Per Available Room, etc.).

\section{Maturity of the destination and renovation}

The qualification of a coastal tourist destination as mature, consolidated, stagnant, "in the final stage of growth" or similarly according to the terminology of the different descriptive-predictive evolutionary models is usually the previous step to its decline. The obsolescence of spaces, equipment and services, public and private, of the coastal tourist areas causes this decline, and if there is no intervention can lead to situations of permanent decline. This is due to the fact that the destination suffers a loss of attraction capacity and market share with respect to other destinations, as well as a deterioration in the tourist experience it provides, with the consequent impact on the main indicators of the tourism business (tourist arrivals, number of overnight stays, average stay, expense and occupancy rates, etc.). Furthermore, there is deterioration in their territorial competitiveness, with the risk of relocation of private investments, which move towards new territory in annexed or nearby areas, other municipalities or even other countries and emerging or less congested destinations. However, this deterministic and linear situation is not so easily reached and, in no case, is it an irreversible, unidirectional, consummate and automatic fact. Indeed, to reverse this decline the sequential process of generation-degeneration-regeneration of tourist desti- nations must be followed. The " $r$ " strategies are revealed as basic elements of any policy, program or project of a destination's competitive repositioning.

The so-called "third tourist boom", developed in the Canary Islands during the second half of the nineties, generated extraordinary expectations of growth in the supply of tourist accommodation that could be incorporated into the market in a short, medium and long term. The need to correct this risk of tourist accommodation oversupply has given rise to an intense debate since 1999 on the "liberalizing deregulation of the market versus public interventionism". Finally, the latter was chosen, giving rise to what is commonly referred to as a "tourism moratorium". It is a type of public regulation aimed at limiting or modulating the quantitative growth in the offer of tourist accommodation and is complemented by a set of factors aimed at a sustainable transformation of the tourism model and the renovation of public and private areas coastal tourism. The proposed model is based on the combination of three interdependent strategic axes while the first two axes (sustainable transformation of tourism and the limitation of housing growth seek the repositioning of this destination, the third is related to the renovation of public and private space of tourist areas as proposed in the Tourism Management Guidelines (2003). Thus, it is necessary to know the impact and degree of effectiveness of the renovation actions in the private and public spaces of the tourist areas.

\section{Natural capital supporting tourism.}

Protected areas and fragile ecosystems

European islands host a large part of the biodiversity of the whole EU, while their representative ecosystems exhibit high vulnerability, and their landscapes form part of the core image of islands as tourist destinations. In the case of the Canary Islands, endemic wet forest (laurel forest or laurisilva) in medium-altitude northern-oriented lands, relic of the European tertiary-age wet forest; the high-mountain moors on the very top of Tenerife, La Palma and Gran Canaria, also hosting endemic species; endemic pine tree forests at the near-top of the highest islands; endemic palm forests, mainly spread out over 
the bottom of the basins of all the islands; endemic xerophilous scrubs covering lands till 500-700 m height (tabaibal-cardonal); precious dune systems hosting local endemism; near-shoreline marshes, and marine habitats structured around phanerogam and macro-algae meadows; constitute not just a rich biodiversity-based patrimony that concerns just nature-oriented visitors, but unique landscapes that model the image of the islands for the vast majority of tourists.

Over decades, most of them have suffered from pressures threatening their conservation status. Coastal tourist and residential urbanism, the extension of agricultural borders, dispersed rural dwelling, tourists and leisure activities in nature, forest fires and marine pollution by sewage are the main hazards in a context of understanding the tourism attractiveness of the Canary Islands and their potential to strengthen economic, social and environmental sustainability of the entire tourism system. Also climate change is adding pressures to these habitats, by itself or in combination with other hazards, e.g., exacerbating fires, making the survival of endangered species and ecosystems (laurisilva) harder, modifying coastal sedimentary processes determining beach surfaces, and attracting exotic species to the coastal ecosystems, some of them highly toxic, amongst others.

Although natural areas on several of the islands, mainly National Parks, are highly visited, to a certain extent the Canary Islands have failed to take advantage of their exclusive nature to differentiate themselves from other destinations and add more value to visitors' experiences. Thus, nature governance must be enhanced either in conservation or in tourists' valuation, and more interestingly, adding intelligence to jointly achieve better conservation and higher tourist valorisation. Conservation and tourism governmental departments should work together, also integrating tourist and societal stakeholders. This complex system of interactions between tourism, nature and society is what needs to be observed through defining, implementing and monitoring a widely agreed and viable indicator system.

Summarizing, the Canary Islands' Network of Protected Natural Spaces is made up of 146 protec- ted areas, which together constitute $310,918.50$ ha, approximately $40 \%$ of the total land (see https://www3. gobiernodecanarias.org/medusa/wiki/index.php?title=Red_Canaria_de_Espacios_Naturales_Protegidos).

The representation of the Canary Islands in the Natura 2000 European Network is even higher. It consists of 174 Special Areas of Conservation with a total of 454,932 ha, of which 283,322 are terrestrial and 171,610 marine; in addition to 43 Special Protection Areas for Birds, with 271,251 ha of land and 6,056 of marine areas. If we focus on habitats and species, the Canary Islands hosts 24 of the list of European natural habitats, 4 marine and 20 terrestrial ones, as well as 73 species included in Annex 2 of the Habitats Directive (see https://www.eea.europa.eu/data-and-maps/figures/natura-2000-sites-biogeographical-regions/macaronesian_canary_0812.eps)

The Canary Islands also have a number of Biosphere Reserves: La Palma (1983), Lanzarote (1993), El Hierro (2000), Gran Canaria (46\% of the Island) (2005) and Fuerteventura (2009), La Gomera (2012) and the Anaga Massif in Tenerife (2015). This program awards sustainable management of the natural and cultural heritage, usually creating attractive areas for natureand culture-oriented tourism. It also attempts to engage local people in conservation and development policies through participation. Governance, however, is, with exceptions, poor. See at https://www.grafcan. es/2016/03/la-red-canaria-de-las-reservas-de-la-biosfera-en-mapa

Finally, regional authorities have established a set of Marine Reserves of Fishing Interest in northern Lanzarote and western El Hierro and on La Palma covering more than 75,000 ha. Notwithstanding, these marine areas are mostly already integrated in the Nature 2000 Network. These marine areas are amongst the most attractive ones for diving, receiving every year thousands of divers from all over Europe. See https://www.gobiernodecanarias.org/pesca/temas/reservas_marinas/

Available information on natural capital uses, pressures and conservation status is globally large but heterogeneous and disperse. Most of the information has been generated for protected areas, so information on 
non-protected but relevant natural capital, mostly marine, is poorer and mostly available in scientific publications. Administrative sources of information are several (Europe, State, Region, Island level) but lack homogeneity. The main sources on the characteristics and management status of the protected areas are:

- The Canary Islands in Natura 2000 Network, European Environment Agency, at https://www.eea. europa.eu/data-and-maps/figures/natura-2000-sites-biogeographical-regions/macaronesian_canary_0812.eps

- Marine reserves of Spain, Government of Spain, at https://www.mapa.gob.es/es/pesca/temas/proteccion-recursos-pesqueros/reservas-marinas-de-espana/

- Canary Network of Protected Natural Spaces, The Canary Island Government, at https://www3.gobiernodecanarias.org/medusa/wiki/index.php?title=Red_Canaria_de_Espacios_Naturales_Protegidos.

- The Regional System of Environmental Indicators (SIMAC) are available at https://www.gobiernodecanarias.org/medioambiente/temas/ informacion-ambiental/derecho_de_los_ciudadanos_a_la_informacion_ambiental/simac/ sistema-indicadores-ambientales/. It provides information on the protected area having or not a management plan. Nothing else to evaluate the conservation status.

- Annual Reports on Protected Areas Management are provided by Island Governments but not for all areas and not homogeneously. There is not a conservation status indicators system shared by all islands. Used indicators are usually poorly defined. See for example: https://www. lagomera.es/wp-content/uploads/2017/04/PROGRAMA-ANUAL-DE-TRABAJO-ANO-2017.pdf and http://www.gobiernodecanarias.org/politicaterritorial/descargas/EENN/GRAN_CANARIA/C_01_ RNI_Inagua/ISA.pdf

- Changes in landscape attractiveness obtained through surveys and can be measured with
GIS-based tools such as Corine Land Cover. These provide a homogeneous system of information layers all over Europe and could give rise to an interesting indicator on the perception and valuation of landscape changes.

About tourist use of protected areas, conservation boards mostly report on number of visitors and some items of visitors' profiles. They are still lacking an information system providing more relevant information on motivations, activities and satisfaction when visiting the areas. To cover this gap, a more supportive tourism planning-oriented information is needed.

Finally, there is valuable information published in scientific journals and $\mathrm{PhD}$ dissertations on different aspects of the experiences of tourists with the natural heritage of the Canary Islands (whale watching, National Parks and so on). It would be worth devoting efforts to collect and classify this information in order to provide authorities in charge of statistics systems feedback on tourists' preferences, assessments and valuations during their experiencing with nature.

\section{Universal accessibility and inclusiveness}

The competitiveness and quality of tourist destinations are becoming increasingly complex as the variety of consumers grows. In this time of pandemic, when health is of major importance in the world, together with the fact that we are heading towards an increasingly ageing society; efforts to create accessible and inclusive spaces in our cities and destinations are essential.

The Canary Islands, both as an Autonomous Region as well as a tourist destination, has been very committed to this issue. The law 8/1995 on accessibility and removal of physical and communication barriers in the Autonomous Region of the Canary Islands is an example of this commitment. Some public bodies have also appeared in these years with the aim of social, physical, economic and technological inclusion of people with access difficulties; such as the Insular Society for the Promotion of Disabled People of Tenerife (SINPROMI, 
Sociedad Insular para la Promoción de Personas con Discapacidad) founded in 1993. And in the other capital island, we can find "Accessible Gran Canaria" created in 2010 by the Island Council with the aim of giving representation to all the associations representing the disabled.

The commitment of municipalities to accessible tourism has also been quite significant. For example Arona, in the South of Tenerife, is a case study of tourism accessibility with the recognition of the European Commission as seen in this link. Arona Municipal Council has developed in the last decades accessibility plans that have been recognised as a leading institution in this field. We also find other several efforts in Tenerife to turn public buildings, sites of interest and culture, as well as beaches, into accessible places under the support of SIMPROMI, as we can see in this link.

The efforts and observation of progress in terms of accessibility and inclusion are not disseminated in the Canary Islands, as they often appear as local initiatives. Therefore, the Observatory must provide comprehensive data management in order to create more global knowledge regarding tourism accessibility and inclusiveness in the whole Canary Islands.

Another relevant experience concerning inclusive and accessible tourism is related to the Spanish program of IMSERSO, which promotes travel among the elderly with public financial support, thus offsetting seasonality in destinations. Some tourism destinations in the Canary Islands, like Puerto de la Cruz, have been committed for a long term to it. In general, the Canary Islands and several of their destinations, particularly during the winter, are specialised in attracting elderly people and providing opportunities to travel, benefit from the mild weather and improve health and wellness. The social, economic and environmental implications of these initiatives are part of the monitoring and reporting tasks of the Observatory.

The European Network for Accessible Tourism considers that access to tourism is a universal right that is guaranteed by the Convention on the Rights of Persons with Disabilities (United Nations, 2006) and that travel and tourism are social rights. In fact, there are several destinations in the Canary Islands that have been recognised or are in process of becoming smart destinations, where accessibility is considered part of this new paradigm. Accessibility and inclusiveness should be included in the resources or services that benefit citizens during their tourist experience, improving their personal autonomy and their inclusion in society. It would be convenient to carry out from the Observatory an identification in relation to the good practices carried out by tourist destinations in terms of accessibility and inclusiveness. In addition, the Observatory could also go beyond, analyzing accessibility from a gender perspective, managing to position women with disabilities on an equal basis with the rest of the citizenship.

Likewise, inclusive tourism is another aspect that must be analyzed and observed. According to Biddulph and Scheyvens (2018), there is a need to implement inclusive tourism as a fundamental element that allows tourist destinations to be more sustainable. They define inclusive tourism as 'transformative tourism in which marginalized groups are engaged in ethical production or consumption of tourism and the sharing of its benefits'. The transformation of tourism is constant and tourist destinations and their societies must adapt themselves. It is necessary to carry out an initial proposal and subsequent analysis of the indicators of inclusive tourism to monitor progress.

\subsection{Key sustainability issue areas and UN Sustainable Development Goals}

To foster global commitment to the environmental, economic and social sustainability in tourism, the World Tourism Organization and the United Nations Development Program (UNDP) are committed to inspiring leadership and facilitating collaboration between all stakeholders to advance tourism's contribution to the Sustainable Development Goals (SDGs) listed in UNWTO \& UNEP (2017). An initiative that is aligned with the aims of the Tourism Observatory of the Canary Islands.

This set of objectives and indicators will guide UN member states in defining their agendas and policies up to 2030 . The SDGs were approved at the 68th session of the UN General Assembly in autumn 2014 (Hák, 
Janoušková \& Moldan, 2016). The objectives of tourism and sustainable development are to build knowledge and inspire tourism stakeholders to take the necessary actions to make the tourism sector more sustainable by aligning policies, business operations and investments (UNWTO \& UNEP, 2017).

The support of the tourism sector to advance SDGs is possible through integrated policies. However, there are still few tourism policies that seem to be fully integrated with the national planning of SDGs. Nevertheless, some tourism companies already recognize that aligning business objectives with SDGs can lead to greater efficiency, cost savings and competitiveness, improving their social image, but there is still a lack of awareness of the benefits that sustainability can bring.

Another determining factor for the success of SDGs is the financial assistance to tourism, which is still modest but can be improved thanks to innovative finan- cing mechanisms (green bonds, loan facilities for energy efficiency, mixed financing, intelligent incentives for eco-certification, voluntary contributions) (UNWTO \& UNEP, 2017).

It is essential to unleash the full potential of tourism to achieve sustainable development goals and to share knowledge and good practices between all stakeholders - governments, businesses, the United Nations system, the donor community, academia and civil society (UNWTO \& UNEP, 2017). Finally, it is necessary to strengthen statistical capacities in order to measure and monitor through data and results. In this line, the Tourism Observatory of the Canary Islands tries to integrate its strategy into the new policy agenda. In the next table, the key sustainability issue areas in the Canary Islands' tourism sector are allocated to the UN sustainable development goals and targets with which they are mainly related.

\begin{tabular}{|c|c|c|}
\hline $\begin{array}{l}\text { Key issue areas in } \\
\text { the Canary Islands }\end{array}$ & UN Sustainable Development Goals & Targets \\
\hline \multirow{4}{*}{$\begin{array}{l}\text { 1. Local satisfaction } \\
\text { with tourism and } \\
\text { local well-being }\end{array}$} & $\begin{array}{l}\text { Goal 8. Promote sustained, inclusive and sustainable economic growth, full and } \\
\text { productive employment and decent work for all }\end{array}$ & 8.9 \\
\hline & $\begin{array}{l}\text { Goal 9. Build resilient infrastructure, promote inclusive and sustainable } \\
\text { industrialization and foster innovation }\end{array}$ & 9.1 \\
\hline & $\begin{array}{l}\text { Goal 11. Make cities and human settlements inclusive, safe, resilient and } \\
\text { sustainable }\end{array}$ & 11.3 \\
\hline & Goal 12. Ensure sustainable consumption and production patterns & $12 . b$ \\
\hline \multirow{4}{*}{$\begin{array}{l}\text { 2. Labor skills, } \\
\text { entrepreneurship } \\
\text { and employment }\end{array}$} & $\begin{array}{l}\text { Goal 4. Ensure inclusive and equitable quality education and promote lifelong } \\
\text { learning opportunities for all }\end{array}$ & $\begin{array}{l}4.3,4.4 \\
4.5\end{array}$ \\
\hline & Goal 5. Achieve gender equality and empower all women and girls & 5.5 \\
\hline & $\begin{array}{l}\text { Goal } 8 \text {. Promote sustained, inclusive and sustainable economic growth, full and } \\
\text { productive employment and decent work for all }\end{array}$ & $\begin{array}{l}8.3,8.5 \\
8.6,8.8, \\
8.9\end{array}$ \\
\hline & $\begin{array}{l}\text { Goal 9. Build resilient infrastructure, promote inclusive and sustainable } \\
\text { industrialization and foster innovation }\end{array}$ & 9.5 \\
\hline \multirow{4}{*}{$\begin{array}{l}\text { 3. Destination } \\
\text { innovation, } \\
\text { economic impacts } \\
\text { and benefits }\end{array}$} & $\begin{array}{l}\text { Goal 8. Promote sustained, inclusive and sustainable economic growth, full and } \\
\text { productive employment and decent work for all }\end{array}$ & $8.2,8.3$ \\
\hline & $\begin{array}{l}\text { Goal 9. Build resilient infrastructure, promote inclusive and sustainable } \\
\text { industrialization and foster innovation }\end{array}$ & $9.1,9.5$ \\
\hline & Goal 12. Ensure sustainable consumption and production patterns & $12 . b$ \\
\hline & $\begin{array}{l}\text { Goal 17. Strengthen the means of implementation and revitalize the Global } \\
\text { Partnership for Sustainable Development }\end{array}$ & $\begin{array}{ll}17.8 \\
17.19\end{array}$ \\
\hline
\end{tabular}




\begin{tabular}{|c|c|c|}
\hline \multirow{2}{*}{$\begin{array}{l}\text { 4. Tourism } \\
\text { seasonality }\end{array}$} & Goal 12. Ensure sustainable consumption and production patterns & 12.b \\
\hline & Goal 13. Take urgent action to combat climate change and its impacts & 13.1 \\
\hline \multirow{5}{*}{$\begin{array}{l}\text { 5. Tourism } \\
\text { products, culture, } \\
\text { leisure and tourist } \\
\text { satisfaction }\end{array}$} & $\begin{array}{l}\text { Goal 9. Build resilient infrastructure, promote inclusive and sustainable } \\
\text { industrialization and foster innovation }\end{array}$ & 9.1 \\
\hline & $\begin{array}{l}\text { Goal 11. Make cities and human settlements inclusive, safe, resilient and } \\
\text { sustainable }\end{array}$ & 11.4 \\
\hline & Goal 12. Ensure sustainable consumption and production patterns & 12.2 \\
\hline & $\begin{array}{l}\text { Goal 14. Conserve and sustainably use the oceans, seas and marine resources } \\
\text { for sustainable development }\end{array}$ & $\begin{array}{l}\text { All } \\
\text { targets }\end{array}$ \\
\hline & $\begin{array}{l}\text { Goal 15. Protect, restore and promote sustainable use of terrestrial ecosystems, } \\
\text { sustainably manage forests, combat desertification, and halt and reverse land } \\
\text { degradation and halt biodiversity loss }\end{array}$ & $\begin{array}{l}\text { All } \\
\text { targets }\end{array}$ \\
\hline \multirow{6}{*}{$\begin{array}{l}\text { 6. Digitalization, } \\
\text { knowledge and } \\
\text { smart tourism }\end{array}$} & $\begin{array}{l}\text { Goal 7. Ensure access to affordable, reliable, sustainable and modern energy for } \\
\text { all }\end{array}$ & 7.2 \\
\hline & $\begin{array}{l}\text { Goal 8. Promote sustained, inclusive and sustainable economic growth, full and } \\
\text { productive employment and decent work for all }\end{array}$ & 8.2 \\
\hline & $\begin{array}{l}\text { Goal 9. Build resilient infrastructure, promote inclusive and sustainable } \\
\text { industrialization and foster innovation }\end{array}$ & $9.4,9.5$ \\
\hline & $\begin{array}{l}\text { Goal 11. Make cities and human settlements inclusive, safe, resilient and } \\
\text { sustainable }\end{array}$ & $\begin{array}{ll}11.2 \\
11.3\end{array}$ \\
\hline & Goal 12. Ensure sustainable consumption and production patterns & 12.2 \\
\hline & $\begin{array}{l}\text { Goal 17. Strengthen the means of implementation and revitalize the Global } \\
\text { Partnership for Sustainable Development }\end{array}$ & $\begin{array}{ll}17.7 \\
17.8\end{array}$ \\
\hline $\begin{array}{l}\text { 7. Energy } \\
\text { management }\end{array}$ & $\begin{array}{l}\text { Goal 7. Ensure access to affordable, reliable, sustainable and modern energy for } \\
\text { all }\end{array}$ & $\begin{array}{l}\text { All } \\
\text { targets }\end{array}$ \\
\hline \multirow{2}{*}{$\begin{array}{l}\text { 8. Water and } \\
\text { wastewater } \\
\text { management }\end{array}$} & $\begin{array}{l}\text { Goal } 6 \text {. Ensure availability and sustainable management of water and sanitation } \\
\text { for all }\end{array}$ & $\begin{array}{l}\text { All } \\
\text { targets }\end{array}$ \\
\hline & Goal 12. Ensure sustainable consumption and production patterns & 12.2 \\
\hline \multirow[t]{2}{*}{$\begin{array}{l}\text { 9. Solid waste } \\
\text { management }\end{array}$} & $\begin{array}{l}\text { Goal 11. Make cities and human settlements inclusive, safe, resilient and } \\
\text { sustainable }\end{array}$ & 11.6 \\
\hline & Goal 12. Ensure sustainable consumption and production patterns & $\begin{array}{l}12.4 \\
12.5\end{array}$ \\
\hline \multirow{3}{*}{$\begin{array}{l}\text { 10. Climate change } \\
\text { impacts and } \\
\text { mitigation }\end{array}$} & $\begin{array}{l}\text { Goal 11. Make cities and human settlements inclusive, safe, resilient and } \\
\text { sustainable }\end{array}$ & $\begin{array}{l}11 . b \\
11.6\end{array}$ \\
\hline & Goal 12. Ensure sustainable consumption and production patterns & 12.4 \\
\hline & Goal 13. Take urgent action to combat climate change and its impacts & $\begin{array}{l}\text { All } \\
\text { targets }\end{array}$ \\
\hline \multirow{2}{*}{$\begin{array}{l}\text { 11. Governance } \\
\text { and the territorial } \\
\text { scale of analysis } \\
\text { and policies }\end{array}$} & $\begin{array}{l}\text { Goal 11. Make cities and human settlements inclusive, safe, resilient and } \\
\text { sustainable }\end{array}$ & $11 . b$ \\
\hline & $\begin{array}{l}\text { Goal 17. Strengthen the means of implementation and revitalize the Global } \\
\text { Partnership for Sustainable Development }\end{array}$ & $\begin{array}{l}17.14 \\
17.17\end{array}$ \\
\hline
\end{tabular}




\begin{tabular}{|c|c|c|}
\hline \multirow{2}{*}{$\begin{array}{l}\text { 12. Air transport } \\
\text { connectivity and } \\
\text { intermediation }\end{array}$} & $\begin{array}{l}\text { Goal 9. Build resilient infrastructure, promote inclusive and sustainable } \\
\text { industrialization and foster innovation }\end{array}$ & 9.1 \\
\hline & $\begin{array}{l}\text { Goal 11. Make cities and human settlements inclusive, safe, resilient and } \\
\text { sustainable }\end{array}$ & 11.2 \\
\hline $\begin{array}{l}\text { 13. Overtourism, } \\
\text { vacation homes } \\
\text { and mass tourism }\end{array}$ & $\begin{array}{l}\text { Goal 11. Make cities and human settlements inclusive, safe, resilient and } \\
\text { sustainable }\end{array}$ & 11.3 \\
\hline \multirow{2}{*}{$\begin{array}{l}\text { 14. Maturity of the } \\
\text { destination and } \\
\text { renovation }\end{array}$} & $\begin{array}{l}\text { Goal 8. Promote sustained, inclusive and sustainable economic growth, full and } \\
\text { productive employment and decent work for all }\end{array}$ & 8.9 \\
\hline & $\begin{array}{l}\text { Goal 11. Make cities and human settlements inclusive, safe, resilient and } \\
\text { sustainable }\end{array}$ & 11.3 \\
\hline \multirow{4}{*}{$\begin{array}{l}\text { 15. Natural capital } \\
\text { supporting } \\
\text { tourism. Protected } \\
\text { areas and fragile } \\
\text { ecosystems }\end{array}$} & $\begin{array}{l}\text { Goal 6. Ensure availability and sustainable management of water and sanitation } \\
\text { for all }\end{array}$ & 6.6 \\
\hline & Goal 12. Ensure sustainable consumption and production patterns & 12.2 \\
\hline & $\begin{array}{l}\text { Goal 14. Conserve and sustainably use the oceans, seas and marine resources } \\
\text { for sustainable development }\end{array}$ & 14.2 \\
\hline & $\begin{array}{l}\text { Goal 15. Protect, restore and promote sustainable use of terrestrial ecosystems, } \\
\text { sustainably manage forests, combat desertification, and halt and reverse land } \\
\text { degradation and halt biodiversity loss. }\end{array}$ & $\begin{array}{l}\text { All } \\
\text { targets }\end{array}$ \\
\hline \multirow{4}{*}{$\begin{array}{l}\text { 16. Universal } \\
\text { accessibility and } \\
\text { inclusiveness }\end{array}$} & Goal 1. End poverty in all its forms everywhere & 1.3 \\
\hline & $\begin{array}{l}\text { Goal 9. Build resilient infrastructure, promote inclusive and sustainable } \\
\text { industrialization and foster innovation }\end{array}$ & $9.1,9.2$ \\
\hline & Goal 10. Reduce inequality within and among countries & 10.2 \\
\hline & $\begin{array}{l}\text { Goal 11. Make cities and human settlements inclusive, safe, resilient and } \\
\text { sustainable }\end{array}$ & $\begin{array}{l}11.2,1.3 \\
11.7\end{array}$ \\
\hline
\end{tabular}

\subsection{A proposal of key performance indicators for} the issue areas

This document includes the essential sustainability issue areas for the region, relevant indicators to the destination and shows the correspondence between identified key issue areas and the 17 Sustainable Development Goals set by the United Nations.

For each issue area, three-five relevant indicators are established based on international guidelines with particular focus on the following data sources:

- Indicators of Sustainable Development for Tourism Destinations: A Guidebook (UNWTO, 2004): an essential document of UNWTO that establishes sustainability issue areas in tourism and a set of indicators for each of them.

- The European Tourism Indicator System (ETIS) is a toolkit for sustainable destination management (European Commission, 2016). This system is suitable for all tourist destinations helping them create a more intelligent approach to tourism planning.

- The Strategic Plan of the Canary Islands towards Tourism 2018-2025. This document embraces observations of the most relevant stakeholders in tourism of the Canary Islands that also facilitates the creation of the most relevant sustainability indicators. 
The Tourism Observatory of the Canary Islands will systematically monitor the established indicators and develop new ones according to the tourism situation in order to support and enhance tourism policies in the destination.
The following list of proposed indicators are partially available, but there is still not a formal agreement between the partners of the observatory and stakeholders to establish a timeline of data availability. Therefore, the list is provided here as a roadmap for the Observatory that can be useful as a checklist for the future.

\section{Local satisfaction with tourism and local well-being}

\begin{tabular}{l|l}
\hline Indicator & Description \\
\hline $\begin{array}{l}\text { Support for tourism } \\
\text { development }\end{array}$ & $\begin{array}{l}\text { Rate of local population favorable to additional growth in tourist arrivals or } \\
\text { beds }\end{array}$
\end{tabular}

Perception of tourism impacts

Environmental awareness
Average evaluation of economic, social, cultural and environmental impacts of tourism

Rate of local population who prefer to protect environment, even if it means lower economic growth

\section{Labor skills, entrepreneurship and employment}

\begin{tabular}{|l|l|l}
\hline Indicator & Description \\
\hline Tourism employment & $\begin{array}{l}\text { Employment in tourism, distribution by gender, age, inclusion of people with } \\
\text { disabilities. Employment should be measured from a supply approach and } \\
\text { through a demand side approach. }\end{array}$ \\
& $\begin{array}{l}\text { Analyzes the over and under qualification of tourism professionals and jobs } \\
\text { Over and under qualification } \\
\text { in tourism }\end{array}$ & \\
& allowing initiative to improve policies and take improvement actions. \\
\hline Index of creation and survival & Identifies the creation of new companies in the Canary Islands that provide \\
rate of startups in tourism & their services in tourism and their age as an indicator of survival.
\end{tabular}

\section{Destination innovation, economic impacts and benefits}

\begin{tabular}{l|l}
\hline Indicator & Description \\
\hline Employment conditions & $\begin{array}{l}\text { These indicators monitor salaries, labor conditions and the contribution of } \\
\text { tourism employment to the well-being of the local population }\end{array}$ \\
\hline $\begin{array}{l}\text { Distribution of local value } \\
\text { added related to tourist } \\
\text { expenditure }\end{array}$ & $\begin{array}{l}\text { This indicator assesses the success of the region in translating tourism } \\
\text { expenditure into local value-added for the different economic activities } \\
\text { (primary, secondary and tertiary) and economic agents (salaries, gross } \\
\text { operating surplus and taxes) }\end{array}$ \\
\hline $\begin{array}{l}\text { Research, development and } \\
\text { innovation investments and } \\
\text { results in tourism-related } \\
\text { firms }\end{array}$ & $\begin{array}{l}\text { Indicators on the number of initiatives, the value and the current or expected } \\
\text { results }\end{array}$
\end{tabular}




\section{Tourism seasonality}

Indicator

Tourism demand in high season and low season

Seasonality of inbound countries of residence

Seasonality of islands and municipalities

\section{Description}

This analysis must be conducted for tourist arrivals, overnight stays, expenditure, average daily rates (ADR), Revenue per available room (RevPAR) and occupancy rates.

Analysis of detailed seasonal patterns for demand segments, particularly countries of origin

Analysis of seasonality patterns for main tourism islands, municipalities and local tourism destinations.

\section{Tourism products, culture, leisure and satisfaction}

Indicator

Overall tourist satisfaction

Satisfaction of tourists with nature, culture, sport and leisure activities

Supply and demand of nature, culture, sport and leisure activities and events

\section{Description}

The global satisfaction of tourists for the whole experience

This indicator comprises the satisfaction of tourists with some of the main components of the tourist experience

The identification of the activities of tourist within the destination that result in unique tourist experiences

\section{Digitalization, knowledge and smart tourism}

Indicator

Infrastructure and connec-

tivity

Presence and use of the Internet

Key technologies and digital talent

\section{Description}

Companies / Organizations that have an Internet connection, with broadband and mobile $3 G, 4 G$ or higher.

Companies / Organizations that have a website, use social networks, advertise on the Internet and / or interact with the public administration through the networks.

Companies / Organizations that use cloud services, big data analysis, security and / or robotics. It also identifies the employment of ICT specialists, and specific training for its employees.

\section{Energy management}

Indicator

Renewable energy share in primary energy utilization

Share of energy consumption by economic sectors.

\section{Description}

Tons of petroleum equivalent of renewable energy sector/ Total tons of petroleum equivalent of total primary energy.

Tons of petroleum equivalent demand of economic sector/ Total tons of petroleum equivalent of energy demand. 
Energy intensity by economic sector
Total tons of petroleum equivalent demand of economic sector/ value added of economic sector.

Water and wastewater management

Indicator

Total volume consumed and liters per tourist per day

Water awareness among enterprises

Recycled water efforts

\section{Description}

Total water consumed in the tourism sector (cubic meters) and per guest-night (liters). It could also be compared to the consumption per inhabitant per day in the area

Percentage of tourism enterprises taking action to reduce water consumption

Percentage of water use derived from recycled water in the destination

\section{Solid waste management}

\begin{tabular}{l|l} 
Indicator & Description
\end{tabular}

Mixed waste volume pro-

Tons per resident per year

duced by destination (pres-

sure)

Waste management awareness in tourism

Percentage of tourism enterprises sorting different types of waste

Volume of sorted waste (recycling effort)

Percentage or per resident sorted waste volume per year

\section{Climate change impacts and mitigation}

\begin{tabular}{l|l} 
Indicator & Description \\
\hline $\begin{array}{l}\text { Total greenhouse gases } \\
\text { emissions }\end{array}$ & Tons of $\mathrm{CO}_{2}$ equivalent of total gases \\
\hline
\end{tabular}

Per capita greenhouse gases Tons of $\mathrm{CO}_{2}$ equivalent of total gases/ Population

emissions

Share of greenhouse gases

emissions by economic

sectors

Tons of $\mathrm{CO}_{2}$ equivalent of emissions by economic sector/ Total greenhouse gases emissions

\section{Governance and the territorial scale of analysis and policies}

\begin{tabular}{l|l} 
Indicator & Description \\
\hline Government effectiveness & $\begin{array}{l}\text { It reflects perceptions of the quality of public services that involve the areas } \\
\text { included in the tourism system, the quality and readiness of policy formulation } \\
\text { and its execution, as well as the credibility of the public administration. }\end{array}$
\end{tabular}




\begin{tabular}{|l|l|}
\hline Participation & $\begin{array}{l}\text { It reflects the inclusion level of the different groups of stakeholders in the de- } \\
\text { cision-making of the tourist system of the territory, measured through mecha- } \\
\text { nisms of representative and informal organization, perception of effectiveness, } \\
\text { etc. }\end{array}$ \\
\hline $\begin{array}{l}\text { Communication and respon- } \\
\text { sibility }\end{array}$ & $\begin{array}{l}\text { It reflects media and quality of communications between stakeholder groups, } \\
\text { including different levels of public administration; fulfilment of commitments } \\
\text { acquired according to levels of responsibility, existence of efficient mechanisms } \\
\text { for the promotion of training, employment, gender equity and innovation. }\end{array}$ \\
\hline
\end{tabular}

\section{Air transport connectivity and intermediation}

\begin{tabular}{l|l} 
Indicator & Description \\
\hline $\begin{array}{l}\text { Number and frequency of } \\
\text { direct routes from airports in } \\
\text { the Canary Islands }\end{array}$ & $\begin{array}{l}\text { Connectivity with a large number of airports is a crucial factor on the competi- } \\
\text { tiveness of the tourist industry }\end{array}$ \\
\hline $\begin{array}{l}\text { The share of distribution } \\
\text { channels and the number of } \\
\text { operators }\end{array}$ & $\begin{array}{l}\text { Share of tourists using tourist packages, OTAs and direct purchase of tourist } \\
\text { products and number of intermediaries and airlines }\end{array}$ \\
\hline $\begin{array}{l}\text { Monthly airline scheduled } \\
\text { capacity }\end{array}$ & $\begin{array}{l}\text { Airline capacity is measured through landing slots, as a way of forecasting the } \\
\text { tourism trends for a region dependent on airlines }\end{array}$ \\
\hline
\end{tabular}

\section{Overtourism, vacation homes and mass tourism}

\begin{tabular}{|l|l|}
\hline Indicator & Description \\
\hline Level of tourist satisfaction & $\begin{array}{l}\text { Average assessment of the overall satisfaction of the trip and the intention to } \\
\text { recommend the Canary Islands }\end{array}$ \\
\hline Level of fidelity & Average share of tourists interested in traveling again to the Canary Islands \\
\hline $\begin{array}{l}\text { Percentage of holiday rent- } \\
\begin{array}{l}\text { als in relation to the hotel } \\
\text { and non-hotel supply }\end{array}\end{array}$ & $\begin{array}{l}\text { It measures the relative importance of the holiday rental with respect to the } \\
\text { total accommodation supply }\end{array}$ \\
\hline
\end{tabular}

\section{Maturity of the destination and renovation}

Indicator

Investment in new tourism assets

Tourism renovation investment

Renovated tourist bed places

\section{Description}

Construction of new tourist accommodation and equipment

Investment in renovation of private spaces (housing and equipment offer) and public areas

Number of bed places renewed and year of renewal 
Natural capital supporting tourism. Protected areas and fragile ecosystems

\begin{tabular}{l|l} 
Indicator & Description
\end{tabular}

Percentage of protected land exhibiting high conservation status (according to Natura 2000 criteria)

Number and percentage of flagship species for tourism (birds, marine mammals, reptiles) that are threatened.

Natura 2000 conservation network has a uniform scale for assessing the conservation status of all European protected areas belonging to it. It allows comparability between territories.

Flagships species are those that attract visitors. Once experts in nature-based tourism provide the list of the relevant ones, experts in conservation would provide their conservation status

Percentage of protected areas having effective management (conservation head and staff, annual plan being assessed).

Number and surface of land and marine spaces managed under social safekeeping schemes.

Management quality is critical for the conservation and valorization of protected natural areas. For this purpose, having management staff and ex post assessed plans are required.

Tourists' satisfaction with landscapes and protected areas

Natural habitats and landscapes relevant for tourism are much more than those protected by law. Non-protected valuable land can also be conserved through social safekeeping schemes, currently coming up all over Europe and in the Canary Islands.

It provides feedback about the results of efforts to preserve nature using a Likert scale

Accessibility and inclusiveness

\begin{tabular}{l|l} 
Indicator & Description \\
\hline $\begin{array}{l}\text { Local awareness of the ac- } \\
\text { cessibility and inclusiveness } \\
\text { importance }\end{array}$ & Level of implementation of accessibility and inclusiveness policies \\
\hline Infrastructure accessibility & $\begin{array}{l}\text { Share of hotels, public buildings, leisure services and cultural and natural sites } \\
\text { with accessible facilities }\end{array}$ \\
\hline Transport accessibility & $\begin{array}{l}\text { Public transport suitable for mobility challenges and accessible private trans- } \\
\text { port supply }\end{array}$ \\
\hline Assistance assured & Local level of health coverage and distance to hospitals or medical facilities \\
\hline
\end{tabular}

This list of indicators is proposed as a working tool for the Observatory to be shared with stakeholders and with all the bodies involved in the network of tourism knowledge in the Canary Islands (Promotur, ISTAC, Universities, other stakeholders, etc.), in order to refine the list. From this process, available information will be identified for some indicators, proxies for others will be found, and there will be an agreement on the timeframe for the availability of other indicators.
At this stage, regarding the reporting of tourism indicators, the most organised available websites are: the section on tourism in the Institute of Statistics of the Canary Islands; the section on research (in English) within the website of Promotur; and the website of the Observatory itself, within the page of the Ministry of Tourism, Industry and Commerce of the Canary Islands. These websites provide very detailed information on tourism statistics but lack a more detailed approach to 
social and environmental aspects. The information on tourism-related social and environmental issues is, anyway, partially available but often disseminated in other official websites and bodies. The Observatory has the task of managing information to provide a systematic overview of existing indicators and a timeline for the availability of new data.

For further information, the expected initiatives of ISTAC in tourism and beyond can be found in the Statistical Plan 2018-2022 of the Canary Islands, approved by decree 78/2018 of the Canary Islands. The content of the plan is available at the following link, where we can find new statistical operations such as: a census of vacation homes; census of tourist points of interest; environmental indicators (for tourism and beyond); indicators of the quality of swimming water; census of sport infrastructures; tourism satellite account updates; survey on tracking of the brand "Canary Islands" in outbound markets; survey on domestic tourism within the Canary Islands; survey on accommodation establishments including water and energy consumption and waste production; survey on tourism accommodation prospects; survey on tourist excursions by visitors; survey on visitors to tourist point of interest; and the tourism synthetic indicator.

\section{The Regional Tourism Information System}

T his section includes the key role of the Institute of Statistics of the Canary Islands in the tourism monitoring system along with current information needs, gaps and availability.

\subsection{The Institute of Statistics of the Canary Islands}

The Institute of Statistics of the Canary Islands has developed over the last decades a Regional Tourism Information System (R-TIS) that supports decision-making in tourism at a regional, island and municipality scale.

In fact, the Canary Islands is a good example that demonstrates the implications of accurate and proper measurement for analytical purposes in tourism destinations where tourism activity is highly concentrated geographically:
- Around 15 million tourists every year (before the pandemic). First, European region (NUTS 2) regarding overnights in hotels.

- $1.7 \%$ of the territory includes $92 \%$ of bed places and account for $94 \%$ of tourist overnights in hotels.

- Such concentration of tourism activity refers to 16 municipalities out of 88 ( $18 \%$ of the total).

- Resident population is around 2.1 million.

This lack of homogeneity in terms of administrative territorial entities also has implications in monetary terms, as there is clear evidence based on data provided by the Canary Islands Regional Tourism Information System (R-TIS) main indicators such as:

- Average expenditure at destination: differences between nationalities.

1 This section is based on a previous document elaborated by ISTAC for the UNWTO \& INRouTe workshop Subnational Tourism Measurement workshop held in Venice 2016. 
- Tourists from the main countries of origin have their own geographical concentration in such municipalities.

- RevPAR differences in 16 municipalities are relevant, etc.

These and other type of relevant differences of those 15 million tourists can be analyzed in terms of main variables measuring tourism activity, such as: accommodation establishments, bed places, overnight stays, visitors, occupancy rates, Average daily rate, RevPAR, employment associated with accommodation establishments, profiles of tourists, characteristics of tourism trips, average daily expenditure, tourism expenditure profile, etc. For all these indicators the institute publishes data on a regular and up-to-date basis.

These basic data and indicators are provided by the Canary Island R-TIS, which has been developed using links between national / regional official statistics and following UNWTO guidelines and with the support of the International Network on Regional Economics, Mobility and Tourism (INRouTe \& UNWTO, 2013). The Tourism Information System includes different types of statistical sources with the directory of accommodation establishments being its basic support. Such Directory (named ALOJATUR) is geo-referenced and this explains why that all those variables already mentioned are also geo-referenced.

The Institute of Statistics of the Canary Islands, adopting 2008 international tourism statistics standards (UNWTO, 2010a), has developed a research strategy with the aim of providing more and better tourism information at the sub-national level. However, public administrations and economic agents request information at a higher level of specialization and territorial disaggregation in order to address both tourism promotion activities and tourism excellence plans at the micro level.

In this sense, the Canary Islands R-TIS focuses not only on providing subnational macroeconomic tourism data, but also on providing data for tourism management in all its dimensions, as a necessary input for the Canary Islands or some of its local tourism destinations to become Smart Tourism Destinations. Moreover, the Canary Islands R-TIS is aligned with the Smart Specialization Strategy of the Canary Islands 2014-2020 fostered by the Regional Government, which stresses the smart leadership of tourism, identifying two general objectives: (1) Improving the competitiveness and productivity of the Canary Island "tourism product"; (2) Productive diversification of the tourism based economy.

\section{Components of Canary Islands R-TIS}

Canary Islands R-TIS consist of different statistical operations. These operations combine different data gathering methods as well as conventional methods such as surveys, census, and administrative records, new methods such as sensors or other renowned sources embodied in big data. The following table gathers a classification of the statistical operations according to analysis dimensions and data gathering methods.

\begin{tabular}{|l|l|}
\hline Statistical operations & Data gathering methods \\
\hline Tourism demand operations & Surveys / Administrative records \\
\hline Tourism supply operations & Census / Administrative records / Sensors \\
\hline Tourism employment & Administrative records \\
\hline Synthesis operations & Secondary information \\
\hline
\end{tabular}

Table 3. Main statistical operations performed by ISTAC | Source: ISTAC 
R-TIS aims at not only providing regional tourism macroeconomic figures for the eight islands, but mainly at answering different questions that arise when managing tourism destinations in all its dimensions, such as: Where do tourists obtain information and what motivates them to visit the Canary Islands. Which distribution channels they use. Where they overnight and what influences their choice. What activities they do in the destination and how they move within the destination. How much tourists and excursionists spend and how expenditure is distributed. What image of the destination tourists have and what image they project to others. What the tourists' opinions of the destination are and how many of them would recommend it. What the level of social and environmental pressure of tourism is.
In order to answer these questions, the launching of an extensive set of data gathering tools is needed, including:

- statistical information obtained as a disaggregation of the operations officially conducted at the national level.

- official statistical operations conducted by regional public entities.

The statistical activities, both main and secondary, which today are part of the action plan of the Canary Islands R-TIS are those gathered in the following table.

\begin{tabular}{|c|c|c|c|c|}
\hline \multicolumn{5}{|c|}{ SET OF MAIN AND SECONDARY OPERATIONS BY THE CANARY ISLANDS R-TIS } \\
\hline Statistical & \multicolumn{2}{|c|}{ Data gathering methodology } & \multirow{2}{*}{$\begin{array}{l}\text { Analysis Dimensions } \\
\text { Tourism market } \\
\text { Position of the Canary tourism } \\
\text { brand }\end{array}$} & \multirow{2}{*}{$\begin{array}{l}\text { Time and } \\
\text { Space Disag- } \\
\text { gregation }\end{array}$} \\
\hline DEMAND & $\begin{array}{l}\text { Monitoring Survey } \\
\text { Canary Islands Tour- } \\
\text { ism Brand (TRACK- } \\
\text { ING-Canarias) }\end{array}$ & Survey & & \\
\hline & $\begin{array}{l}\text { Collection of Air } \\
\text { Transport Statistics } \\
\text { Collection of mari- } \\
\text { time transport statis- } \\
\text { tics }\end{array}$ & $\begin{array}{l}\text { Administra- } \\
\text { tive records }\end{array}$ & $\begin{array}{l}\text { Passengers } \\
\text { Cruise ship passengers }\end{array}$ & $\begin{array}{l}\text { Months } \\
\text { Islands, airports, } \\
\text { ports }\end{array}$ \\
\hline & $\begin{array}{l}\text { Survey of Tourist } \\
\text { Movements in Ca- } \\
\text { nary Borders (FRON- } \\
\text { TUR-Canarias) }\end{array}$ & $\begin{array}{l}\text { Monthly } \\
\text { survey }\end{array}$ & $\begin{array}{l}\text { Tourists } \\
\text { Tourists (forecasts) } \\
\text { Excursionists } \\
\text { Cruise ship passengers }\end{array}$ & $\begin{array}{l}\text { Months, years } \\
\text { Islands }\end{array}$ \\
\hline & $\begin{array}{l}\text { Tourism Expenditure } \\
\text { Survey }\end{array}$ & $\begin{array}{l}\text { Monthly } \\
\text { survey }\end{array}$ & $\begin{array}{l}\text { Tourism expenditure, Profile, Sat- } \\
\text { isfaction } \\
\text { Trip characteristics } \\
\text { Specific annual modules (shop- } \\
\text { ping, active tourism, sports tour- } \\
\text { ism, health tourism, etc.) }\end{array}$ & $\begin{array}{l}\text { Months, quar- } \\
\text { ters, years } \\
\text { Micro-destina- } \\
\text { tion, tourism } \\
\text { municipalities, } \\
\text { islands }\end{array}$ \\
\hline
\end{tabular}




\begin{tabular}{|c|c|c|c|c|}
\hline \multirow[t]{4}{*}{ SUPPLY } & $\begin{array}{l}\text { Tourism Accommo- } \\
\text { dation Survey on } \\
\text { Non-Hotel Establish- } \\
\text { ments }\end{array}$ & $\begin{array}{l}\text { Census, } \\
\text { every estab- } \\
\text { lishment, } \\
\text { every day }\end{array}$ & $\begin{array}{l}\text { Occupation (passengers entered, } \\
\text { travelers staying, average stay, } \\
\text { occupancy rates) } \\
\text { Rates (ADR, RevPar, revenue) } \\
\text { Employment } \\
\text { Tourist population equivalent } \\
\text { Land use } \\
\text { Power } \\
\text { Water } \\
\text { Waste } \\
\text { Renewal range of accommoda- } \\
\text { tion } \\
\text { Infrastructure Equipment } \\
\text { Services }\end{array}$ & $\begin{array}{l}\text { Days, spe- } \\
\text { cial periods, } \\
\text { months, years } \\
\text { Micro-destina- } \\
\text { tion, tourism } \\
\text { municipalities, } \\
\text { islands }\end{array}$ \\
\hline & $\begin{array}{l}\text { Hotel Establishments } \\
\text { Survey }\end{array}$ & $\begin{array}{l}\text { Census, } \\
\text { every estab- } \\
\text { lishment }\end{array}$ & $\begin{array}{l}\text { Confidence } \\
\text { Outlook } \\
\text { Situation }\end{array}$ & $\begin{array}{l}\text { Quarters } \\
\text { Islands }\end{array}$ \\
\hline & $\begin{array}{l}\text { Companies Regis- } \\
\text { tered to Social Secu- } \\
\text { rity (tourism compa- } \\
\text { nies) }\end{array}$ & $\begin{array}{l}\text { Administra- } \\
\text { tive record, } \\
\text { the last day } \\
\text { of the quar- } \\
\text { ter }\end{array}$ & $\begin{array}{l}\text { Companies with employees in } \\
\text { tourism characteristic activities }\end{array}$ & $\begin{array}{l}\text { Quarters } \\
\text { Towns, Islands }\end{array}$ \\
\hline & $\begin{array}{l}\text { Directory of Econom- } \\
\text { ic Units of the Canary } \\
\text { Islands (DUE) } \\
\text { Collective Tourist Ac- } \\
\text { commodation Direc- } \\
\text { tory (ALOJATUR) }\end{array}$ & $\begin{array}{l}\text { Census } \\
\text { prepared by } \\
\text { combined } \\
\text { methods }\end{array}$ & $\begin{array}{l}\text { Companies and establishments in } \\
\text { tourism characteristic activities }\end{array}$ & $\begin{array}{l}\text { Month, year } \\
\text { Georeferenced }\end{array}$ \\
\hline \multirow[t]{2}{*}{$\begin{array}{l}\text { EMPLOY- } \\
\text { MENT }\end{array}$} & $\begin{array}{l}\text { Statistics of Social } \\
\text { Security Affiliation }\end{array}$ & $\begin{array}{l}\text { Administra- } \\
\text { tive record, } \\
\text { the last day } \\
\text { of the quar- } \\
\text { ter }\end{array}$ & Registered employment & $\begin{array}{l}\text { Quarter } \\
\text { Towns, Islands }\end{array}$ \\
\hline & $\begin{array}{l}\text { Movement Labor } \\
\text { Statistics Joined }\end{array}$ & $\begin{array}{l}\text { Administra- } \\
\text { tive record, } \\
\text { the last day } \\
\text { of the month }\end{array}$ & $\begin{array}{l}\text { Registered unemployment } \\
\text { Registered contracts }\end{array}$ & $\begin{array}{l}\text { Month } \\
\text { municipalities, } \\
\text { Islands }\end{array}$ \\
\hline
\end{tabular}




\begin{tabular}{|l|l|l|l|l|}
\hline $\begin{array}{l}\text { SYNTHESIS } \\
\text { (in progress) }\end{array}$ & $\begin{array}{l}\text { Synthetic Index of } \\
\text { Tourism Activity }\end{array}$ & $\begin{array}{l}\text { Secondary } \\
\text { source }\end{array}$ & Indicators & $\begin{array}{l}\text { Quarter } \\
\text { Islands }\end{array}$ \\
\cline { 2 - 5 } & $\begin{array}{l}\text { Indicator System } \\
\text { Tourism Situation }\end{array}$ & $\begin{array}{l}\text { Secondary } \\
\text { source }\end{array}$ & Indicators & $\begin{array}{l}\text { Quarter } \\
\text { Towns, Islands }\end{array}$ \\
\cline { 2 - 5 } & $\begin{array}{l}\text { Simplified Tourism } \\
\text { Account }\end{array}$ & $\begin{array}{l}\text { Secondary } \\
\text { source }\end{array}$ & VAB & Aperiodic \\
\hline
\end{tabular}

Table 4. Set of Main and Secondary Operations by the Canary Islands R-TIS | Source: ISTAC

One of the main contributions of ISTAC to tourism statistics worldwide is defining territorial boundaries for setting up a small tourism destination area or micro-destination (see Hernández-Martín et al. 2016). This refers to the use of tourism-related establishments to define territorial boundaries between "small tourism destination areas" and "non-tourism areas". It is proposed to use as the main criterion for the identification of local tourism destinations the "Accommodation for visitors" ISIC Rev.4 class, which includes the following categories.

- 5510 Short-term accommodation activities.

- 5520 Camping grounds, recreational vehicle parks and trailers parks.

- 6810 Real estate activities with own or leased property.

- 6820 Real estate activities on a fee or contract basis.

In practically all EU member countries as well as in non-European countries pertaining to the G20 (all of them statistically developed countries), the corresponding establishments provide regular data on accommodation, other provision of services to guests, equipment, any other type of information to National and/ or Regional Statistical Offices (either monthly or annually); also data provision of any physical improvement of such establishment (or the construction of new ones) are administratively recorded and mighty be included in the frame of accommodation units held by such Offi- ces. Also bed capacity associated with such establishments are a stable parameter over a medium-term for tourism destinations and consequently, micro-destinations also benefit from such spatial stability.

As might seem obvious, economic territorial impact derived from expenditure associated with visitors lodged in a given small tourism destination area will be linked to a specific territorial entity unless itinerary type surveys or IT records allow this expenditure to be distributed over the different territorial entities visited during the stay.

In addition to the main criterion (type of accommodation establishment for tourists), other complementary ones could be used for zone design if required, depending on the type and location of the tourism destination.

- The existence of different main tourism products in a specific spatial area.

- Proposals received after consultation with tourism key stakeholders at a specific tourism destination.

- Inspection of the proposed zone design.

In the case of the Canary Islands, this main criterion was used complemented with the existence or absence of some other types of tourism industry establishments (Hernández-Martín et al., 2016).

It is worth highlighting that the Directory of Accommodation Establishments (ALOJATUR) is geo-referen- 
ced and regularly updated including legal and not fully legalized establishments. More specifically, in order to improve the directory, the Institute of Statistics of the Canary Islands (ISTAC) uses a very useful source - the Tourism Expenditure Survey. In this monthly survey around 37,000 tourists are asked every year at their departure at the airport for the name of the collective accommodation establishment (if applicable) in which they have stayed. If the name provided is not already in the directory, then research begins in order to clarify the situation and, eventually, to ensure its inclusion.

Two different issues regarding the central role played by the Directory of Accommodation Establishments in the setting up of the Canary Islands R-TIS must be highlighted:

- Linking the main demand side surveys to ALOJATUR requires the inclusion of a question in surveys about the identification of the name of the establishment where the tourist overnighted; by doing so, it is not only possible to update the Directory but also to geo-reference the answers of tourists. Consequently, because of being geo-referenced, the database including both demand and supply side basic data and indicators would expand the original regional set of data (by linking national/regional main national statistical sources) with proper regional surveys so as to include in the database sub-regional extensions of official statistical data.

- As visualized in the following figure, ALOJATUR is the basic core of such a system; the way this Directory is being updated and the fact that it is geo-referenced explains the difference with the conventional way such directories are designed and updated.

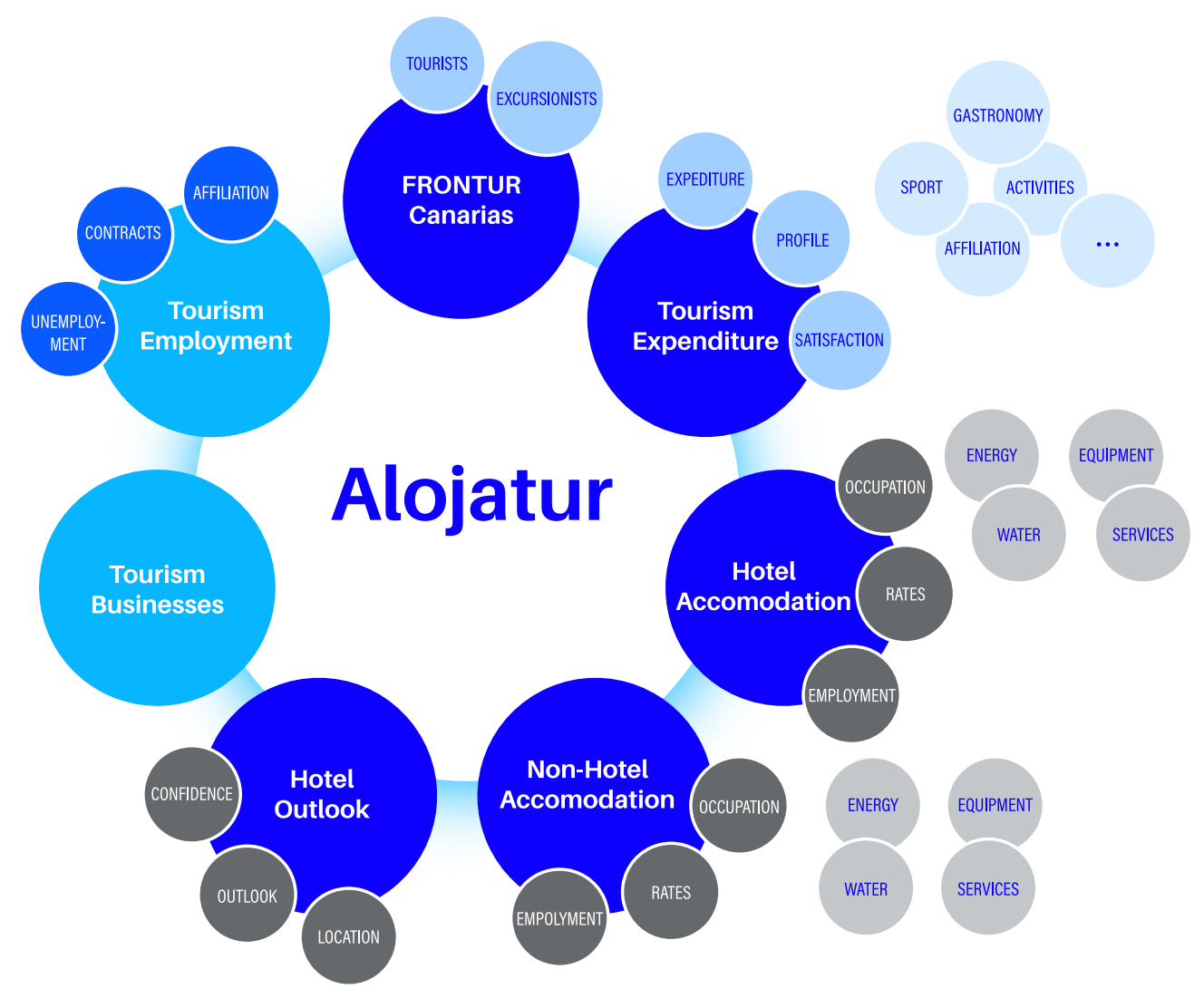

Figure 11. Outline of the Regional Tourism Information System of the Canary Islands.

Source: Institute of Statistics of the Canary Islands. ISTAC 
What is also relevant in this case study is that the main operations described in the Canary Islands R-TIS include a spatial set of basic data and indicators duly checked (looking for coherence) and properly linked (seeking for a proper integration of the same or related data provided by different sources). For instance, data obtained from tourists using boats and airplanes are coherent with the number of total arrivals, which are also consistent with data of guests in accommodation establishments. Furthermore, data on employment provided by these establishments can be checked for coherence with administrative registers.

Once identified and delimited the 47 small tourism destination areas or micro-destinations, non-official and/or non-statistical data should be geo-referenced and added to the R-TIS data base.

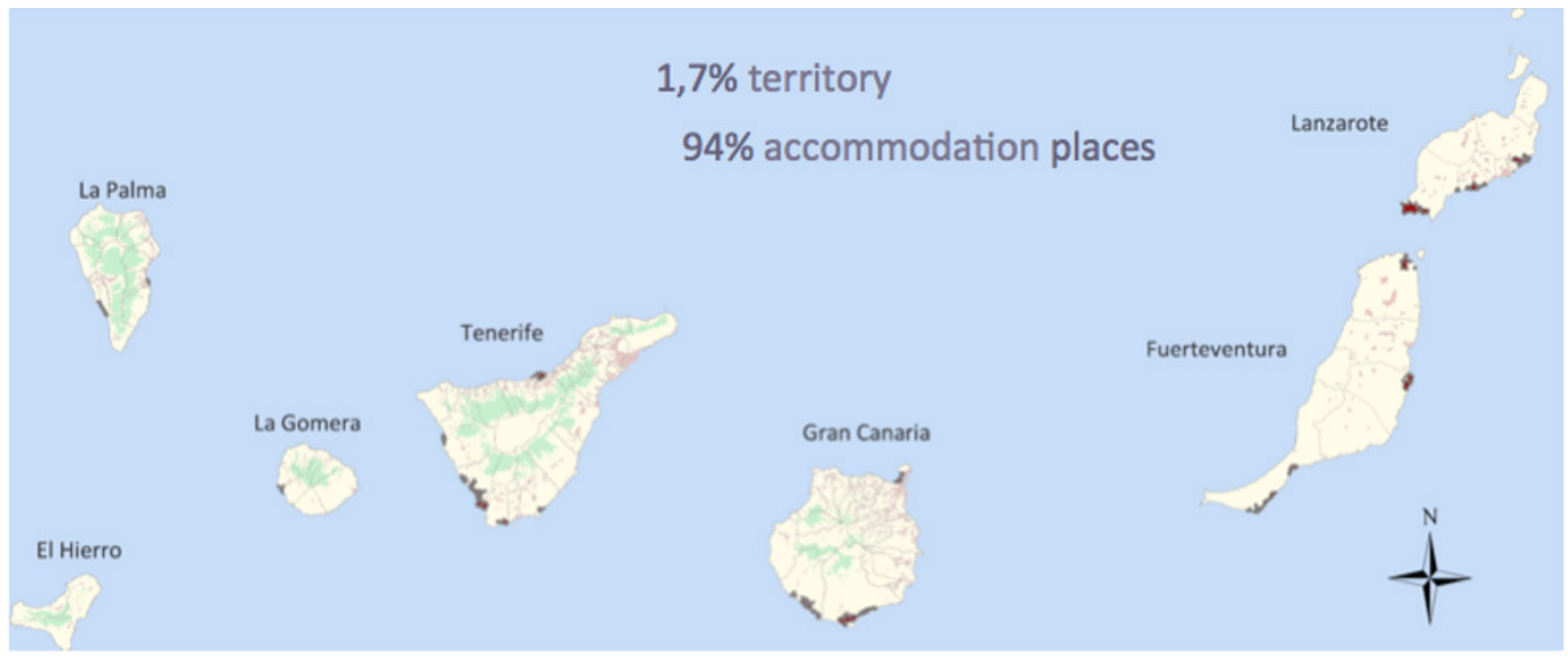

Figure 12. Concentration of the tourism activity in the Canary Islands.

Source: University of La Laguna \& ISTAC

The existence of small tourism destination areas has contributed to a more holistic approach regarding tourism and environmental sustainability. In the case of the Canary Islands, the project for the coming years in ISTAC is that the actual database should be supplemented with geo-referenced information on water and electricity consumption as well as with other data useful for connecting tourism and environmental sustainability analysis. There are also many other topics at destination levels that could greatly benefit from more data and analysis. Just as an example, a relevant issue to be analyzed is the place where tourists stay and the places they visit, because they explain the mobility of tourists and consequently, allows for environmental impact analyses. However, the available information on places visited by tourists is still not related to geo-loca- ted information on accommodation establishments in the case study used. When this could be achieved, the information on the mobility of tourists in destination will be significantly improved.

The Framework for the Development of Environmental Statistics (FDES 2013) (United Nations, 2017) approved by the UN Statistics Commission, recognizes that the environmental statistics gather a wide range of information and are interdisciplinary in nature. Their sources are different data producers, collected with numerous methods.

FDES (2013) enumerates the most important environmental statistics for the description of statistical topics, thus being useful to guide countries developing national programs of environmental statistics. The minimum set of environmental statistics is conceived with 
enough flexibility so that it can be adapted to the concerns, priorities and resources of each country within the environmental field, and therein several indicators are defined for which breakdowns linked to tourism are recommended. These indicators are as follows:

- Final consumption of energy

- Water use

- Total emissions of direct greenhouse gases (GHGs), by gas

- Consumption of ozone depleting substances (ODS), by substance

- Emissions of other substances

- Volume of wastewater generated

- Amount of waste generated

On the other hand, from the point of view of human pressure, tourism population is a tourism statistics concept proposed by INRouTe \& UNWTO (2013) for tou- rists, as a subset of visitors, and for measurement and analytical purposes linked to concentration/diffusion of tourism activity indexes as well as for setting up tourism environmental indicators.

Finally, for island territories, with a relevant surface area under environmental protection, coinciding with a land shortage, it is important to measure the amount of land used by the tourism supply.

The measurement of many of the cited indicators is complex. The Institute of Statistics of the Canary Islands (ISTAC) strategy involves providing data from the accommodation supply and for tourism micro-destinations, which is valuable for the sustainable management of tourism destinations. The data gathering strategy within the Tourism Accommodation Survey embodies different types of methods: survey, crosscheck of administrative records and sensorization. The indicators that will be dealt with as part of the first phase are presented in the next table:

\begin{tabular}{|l|l|}
\hline Indicator & Data gathering methods \\
\hline Final consumption of energy & Survey Intake sensorization \\
\hline Water use & Survey Intake sensorization \\
\hline Amount of waste generated & Sensorization by waste type \\
\hline Tourism population (already published) & Survey \\
\hline Land use & Administrative record (Cadastre) \\
\hline
\end{tabular}

Table 3. Main statistical operations performed by ISTAC | Source: ISTAC

The Canary Islands Tourism micro-destination project as well as other similar initiatives in other countries will pave the way towards operational initiatives to support tourism stakeholders at the local scale. Such experiences will certainly improve regional insights into those four topics already discussed, which seem particularly relevant for all types of stakeholder tourism practitioners -including tourism officials who commission surveys and research, and those who undertake such surveys - as well as public institutes and agencies, regional and local governments, universities, research centers, industry associations, trade bodies and specialized firms - and obviously, it will help by improving definitions and guidelines recommended in this document.

In the last few years, the Institute of Statistics of the Canary Islands has developed an ambitious plan of production of georeferenced information and open data for all areas of official statistics, including tourism. In fact, ISTAC is a leading statistical institution in the field of open access. This initiative has been aimed both at 
the internal treatment of the information and at releasing better and more detailed information to the public. Regarding the internal statistical processes, most tourist data that are collected and produced by ISTAC are already georeferenced. The tourist expenditure survey is geolocated by the place of accommodation of the visitor, while the accommodation statistics are also linked to establishments. This way of proceeding allows ISTAC, for example, to rearrange information for specific purposes and to publish data at the scale of the so-called micro-destinations: previously identified areas with a high concentration of tourism activity. In fact, the georeferenced directory of tourism accommodation establishments (includes official hotels and apartments, but not vacation homes) is already available to the public on the webpage. A KML file with the location of the accommodation establishments in the Canary islands can be downloaded from this link.

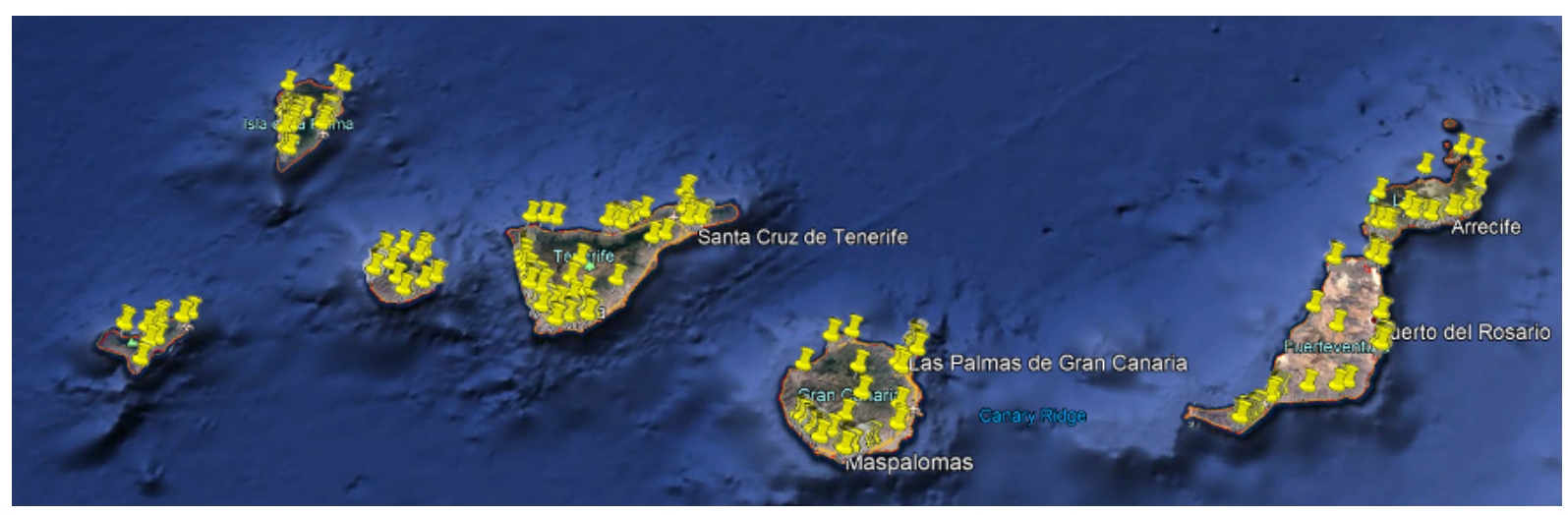

Figure 13. Snapshot of the KML file containing the location of accommodation establishments Source: ISTAC

The geolocation of tourism accommodation facilities can be accessed at the very local scale as can be seen in the next chart.

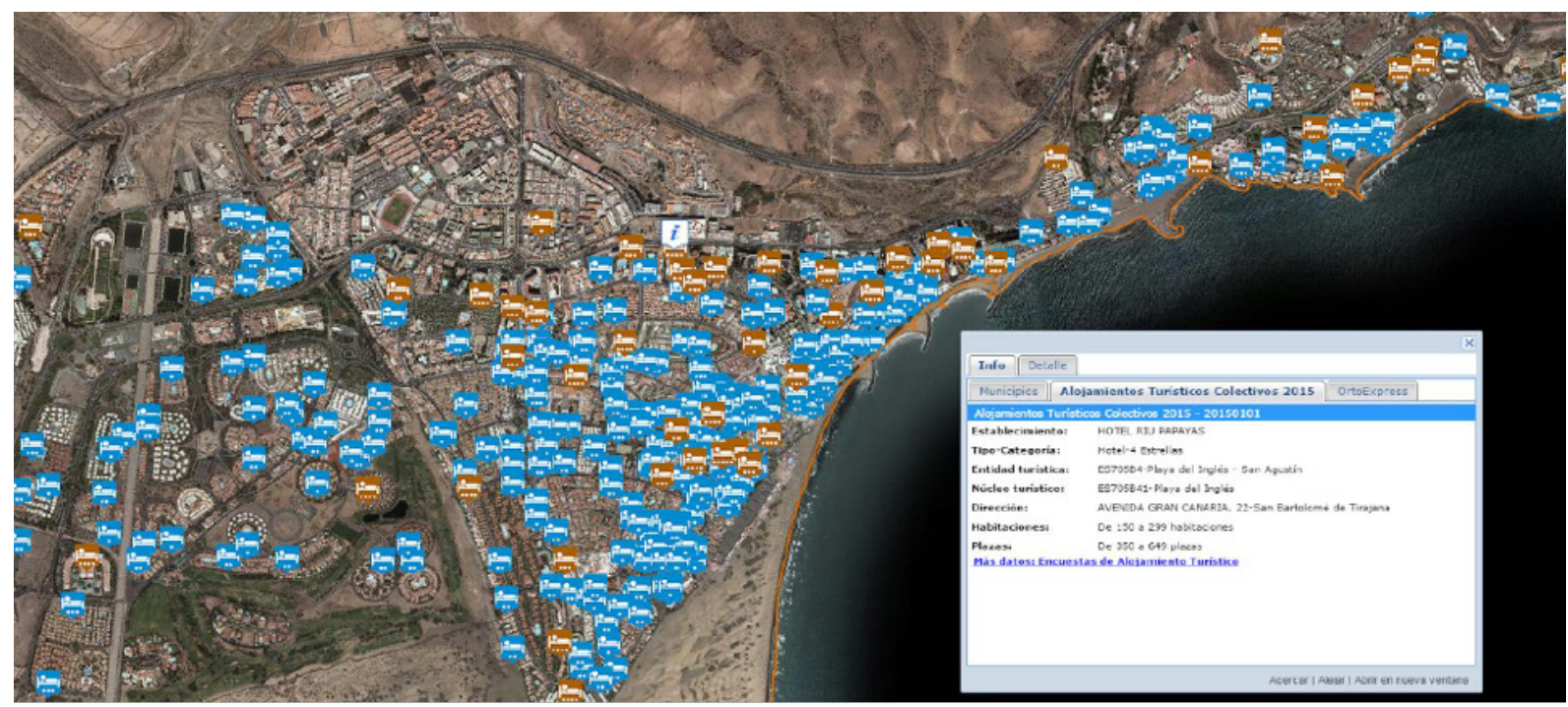

Figure 14. Example of the geolocation of tourism accommodation facilities in the South of Gran Canaria 
In addition to accommodation establishments, ISTAC has also published open data information on the delimitation of micro-destinations. The KML file with the delimitation of these tourism micro-destinations can be found at the following link. However, the publication of georeferenced statistics is limited by statistical secrecy laws and, therefore, most information is for internal use of the institute and cannot be published individually. The aggregation of this kind of information is used to provide data on municipalities and infra-municipal areas, such as micro-destinations.

All the historical data produced by ISTAC are now available in open data format from this link. In addition, ISTAC publishes statistical maps with detail for the 88 municipalities of the Archipelago and for each island on several economic, social and environmental indicators related to tourism that can be accessed through this link. An example of the maps are shown in the following figure.
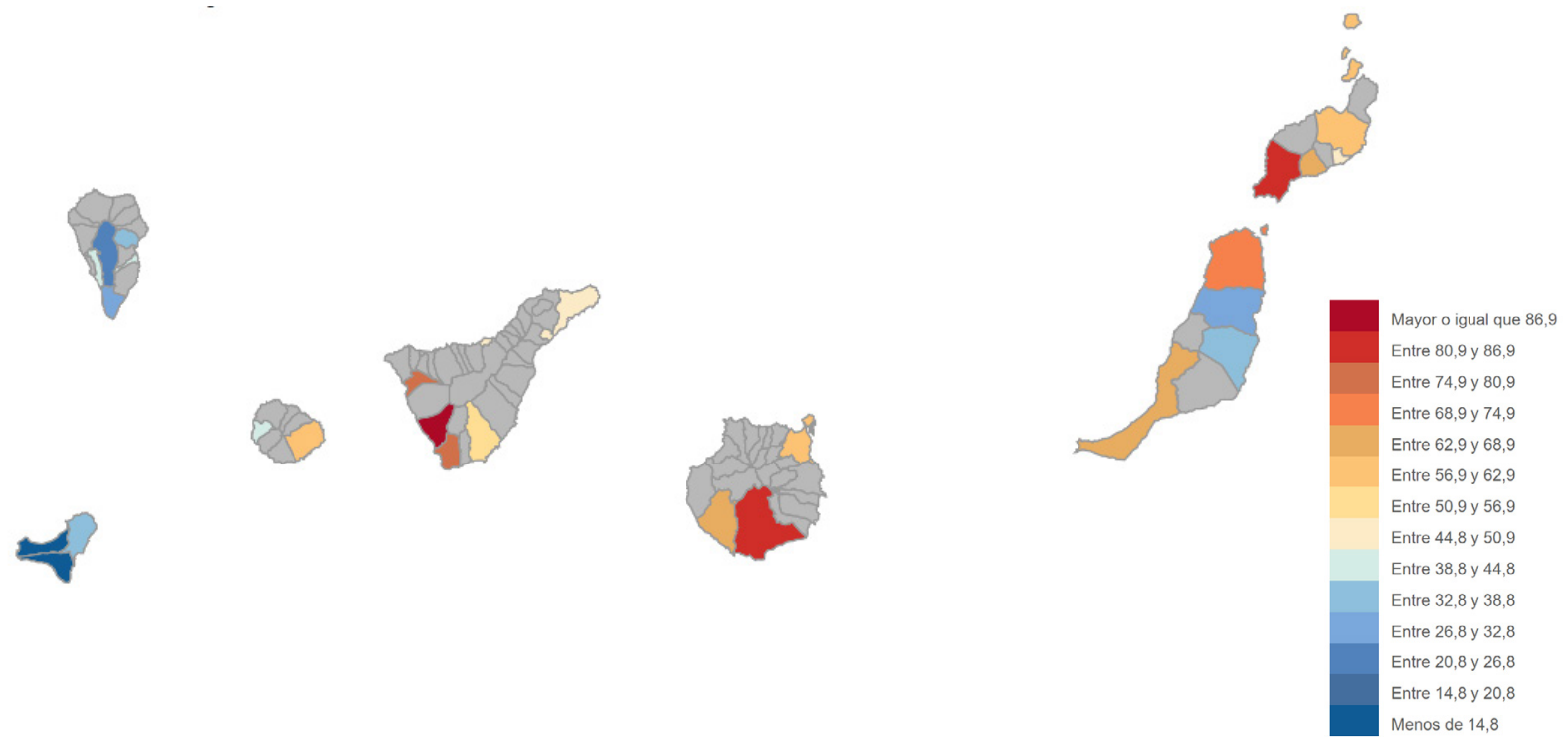

Figure 15. Revenue per Available Room December 2019 | Source: ISTAC data visualization

The list of statistical maps related to tourism that are already available is:

- Employment in the hospitality sector by municipality

- Inbound tourists by island

- Number of hotel and apartment establishments by municipality

- Monthly open places in hotel and apartment establishments by municipality

- Monthly average length of stay in hotels and apartments by municipality

- Monthly overnights in hotel and apartment establi- shments by municipality

- Monthly room occupancy rates of hotel and apartment establishments by municipality

- Monthly place occupancy rates of hotel and apartment establishments by municipality

- Monthly total revenue by hotel and apartment establishments by municipality

- Monthly revenue per available room (RevPAR) by hotel and apartment establishments by municipality

- Monthly average daily rates (ADR) revenue by hotel and apartment establishments by municipality

- Yearly equivalent tourist population by municipality 
- Monthly total revenue by hotel and apartment establishments by municipalityies

- Monthly guests in hotels by municipality

- Monthly foreign guests in hotels by municipality

- Monthly rest of Spain guests in hotels by municipality

- Monthly Canary Islands' guests in hotels by municipality

- Quarterly total tourist expenditure by island

- Quarterly average tourist expenditure by island

- Quarterly daily average tourist expenditure by island

- Monthly air passenger arrivals by islands

- Monthly air passengers arrivals from foreign countries by islands

- Monthly air passenger arrivals from the rest of Spain by islands

- Monthly air passenger arrivals interisland flows

All this information produced by ISTAC is open access and it is available through APIs (Application Programming Interface) for professional users and prepared to create graphs and widgets by non-professional end users as can be seen in this link.

\subsection{Data and information availability, gaps and needs}

In the previous section a compilation of the main statistical operations related to tourism developed by ISTAC was presented. In summary, we can conclude that ISTAC is an outstanding institute of statistics, but there are still gaps in tourism information that should be filled to improve the tourism information system. Some of these gaps are related to the environmental impacts of tourism (energy, water, waste, climate change, etc.); some of them are related to having more precise statistics at the local scale; some are related to the social impacts of tourism and the relationship with education and employment; others are connected with improving the existing knowledge on the behavior of tourists both at the destination and along the purchasing process at home; and, finally, some are related to the challenges of new trends in tourism (digitalization, circular economy, vacation homes, all-inclusive packages, cruises, etc.).
The main information gaps in tourism in the Canary Islands can be summarized in the following list:

- Water consumption and management.

- Energy consumption and management.

- Waste production and management.

- Wastewater management.

- Data at the local destination scale.

- Tourism information dashboards for decision-making of different stakeholders.

- Tourism statistical information more accessible and useful for stakeholders.

- Impact of the sharing-economy on tourism.

- Impacts of the digitalization on tourism.

- Impacts of the circular economy on the tourism.

- Airline emissions and their impact on travelling to the Canary Islands.

- Airline connectivity.

- Performance of competing tourism destinations.

- Channels of commercialization of the supply and the role of online market.

- Economic impacts of all-inclusive and time-sharing.

- Impacts of vacation homes.

- Tracking tourists, knowledge on tourism behavior while visiting the destination.

- Big data and tourism: payments; tracking; consumption of energy; event management; congestion management.

- Tourism expenditure patterns and determinants during the visit.

- Required skills and employment mismatch (the local tourism labor market).

- The real impact of tourism expenditure on the economic well-being of local population.

- Perceptions of tourism impacts, satisfaction and preferences for tourism development of local population.

- The environmental impacts of tourism on the fragile ecosystems.

- Structure of the leisure sector firms.

- Niche tourism.

- Best practices regarding sustainability in the tourism sector. 


\section{Current monitoring entities and relevant stakeholders in tourism}

$\mathrm{n}$ this section, we provide a summary of the main initiatives and stakeholders related to the process of monitoring tourism in the Canary Islands. There is a complex network of actors which is related to the fragmentation of the territory, differences in tourism models and tourism relevance among the islands.

The Ministry of Industry, Trade and Tourism of the Canary Islands includes a Vice ministry of Tourism, which leads and coordinates the responsibilities in tourism infrastructures, regulation and tourism promotion. By contrast, the responsibilities more related to product creation are concentrated at the island and municipality levels.

There are several entities dependent on the Ministry of Industry, Trade and Tourism of which, the most directly related to monitoring tourism are the Tourism Observatory and Promotur:

- The Tourism Observatory of the Canary Islands is the technical body in charge of the study and monitoring of tourism with the support of a Tourism Information System.

- $\quad$ Promotur is the public owned firm in charge of tourism promotion at the region level.

- Tourism Council of the Canary Islands: an advisory body for the tourism policy with representatives of the public sector and economic and social agents.

- The Agency for Tourism Quality is a body supporting the quality of the tourism sector.

- The Commission for Tourism Professional Training is an advisory and study body for tourism education.

- Hecansa is a public owned firm in charge of providing tourism education and in charge of hotel schools.

There are four key tourism stakeholders at the regional scale that are going to have a central role in the Tourism
Observatory of the Canary Islands. The Vice Ministry of Tourism, the Canary Islands Institute of Statistics; Promotur; and the two public universities of La Laguna and Las Palmas de Gran Canaria.

The Vice Ministry of Tourism has been in charge of several monitoring initiatives. In previous years, it has supported a report on vacation homes that has provided a lot of information on the distribution of this growing part of the accommodation supply, providing useful information for the design of regulations for the activity. Moreover, the Vice Ministry has been in charge, with the support of Exceltur, of the publication of an annual report on the economic impact of tourism in the Canary Islands, following as far as possible, the methodologies proposed by the UNWTO (2010b) for the elaboration of the Tourism Satellite Accounts. Another relevant initiative of the Vice ministry has been the preparation of the Strategic Plan of the Canary Islands towards Tourism, with the support of several consultancy firms and the universities. Finally, the Vice Ministry of Tourism maintains a database called Turidata, where the data of accommodation in the Canary Islands is gathered from tourism registries.

Promotur is a public owned firm primarily focused on the external tourism promotion of the Canary Islands and is also a key stakeholder on producing information for decision-making through its own research department that produces reports on several topics. In addition, Promotur publishes, on a regularly basis, statistical reports on several relevant topics for tourism marketing. It has also developed projects on tracking the image of the Canary Islands in the main outbound countries, with a survey conducted in twenty origin countries that has provided much information on the way Europeans 
perceive the destination. There is also information generated and contained in the Tourism Marketing Plan of the Canary Islands released in 2019. In addition, Promotur produces on a regular basis a detailed statistical analysis of the profile of tourists visiting each island of the archipelago and the profile of tourists from the main European countries. Another crucial monitoring activity of Promotur is producing information on the air connectivity of the Canary Islands based on the airport slots (air capacity) for the following months in all the airports of the Canary Islands. Finally, Promotur produces a summary dashboard of tourism in the Canary Islands. The information on air connectivity is an input for the Flight Development Fund, an incentive program intended to support the start-up of new regular direct air routes between the Canary Islands and certain international airports.

Institute of Statistics of the Canary Islands: As mentioned before, the Canary Islands count with an Institute of Statistics that is a leading regional institute in Europe regarding the quality of tourism statistics. The Institute of Statistics of the Canary Islands is in charge of producing statistics on all the topics of relevance for the region, and particularly on tourism. This institute is independent but coordinates with the National Institute of Statistics. The accommodation survey published by ISTAC is obtained on a census basis and provides accurate data for all the islands, main municipalities and 47 local tourism destinations. In addition, there is a quarterly survey on tourist expenditure, with 37,000 responses every year, which provides information on tourists' profiles, trip characteristics and tourist expenditure. This information is displayed for the islands and municipalities and not only for the main countries of origin but also for outbound regions, in the case of Germany and the United Kingdom. Furthermore, the Institute of Statistics of the Canary Islands produces Frontur, the statistics of tourist arrivals to the Canary Islands, with details by islands as main and secondary destinations, with information of the tourist arriving from the rest of Spain, etc. This is the only region of Spain that has this kind of information. The institute also publishes forecasts on tourism flows for the following months and detailed employment figures in the tourism industry.

Two public universities: The universities of La Laguna (Tenerife) and Las Palmas de Gran Canaria (Gran Canaria) also play a relevant role in providing the government with information for policy making. In fact, universities play a very important role in research and knowledge generation in tourism, in addition to leading tourism training and education. The research results of these universities have been widely acknowledged in recent years. The University of Las Palmas de Gran Canaria (ULPGC) is considered the first Spanish university in tourism-related academic research publication, as well as the first European university outside the United Kingdom, and the first in all of Latin America, continuing its improvement and path to excellence. This has been recognized by the most renowned international ranking of universities - ARWU 2019 (Ranking of Shanghai). The ULPGC is ranked 35th worldwide and 1st in Spain in the area of Tourism Management (Hospitality and Tourism Management). The importance of occupying such a prominent position in this world ranking, in the current complex global environment is crucial. The University of La Laguna (ULL) also supports research in a variety of tourism topics and publishes an international tourism research journal. Thus, the tourism departments in the University of Las Palmas de Gran Canaria and the University of La Laguna are the leading institutions in tourism research carried out in and about the Canary Islands, generating both international projection and immediate social impact on their hinterland.

Beyond the stakeholders mentioned above, there is another layer of relevant stakeholders with whom the observatory must coordinate efforts:

Island Councils and municipalities: The allocation of political power to different levels in the Canary Islands gives the main responsibility of tourism management to Island Councils and municipalities. This explains the island nature of the practical implementation of policies regarding tourism products. Each island has its own tourism board and the most important tourism islands 
have their own research units for monitoring tourism and producing reports. The island of Tenerife has Tenerife Tourism Board (Turismo de Tenerife); Gran Canaria has a Tourism Board (Patronato de Turismo de Gran Canaria); Lanzarote Promotion Board (Sociedad de Promoción Exterior de Lanzarote) is a public owned firm established in November 2006 with its own research department; and The Fuerteventura Tourism Board (Patronato de Turismo de Fuerteventura) is in charge of tourism promotion in the island.

Biosphere reserves and national parks management bodies: All the islands or at least some of its territory have been declared Biosphere Reserves by UNESCO (United Nations Educational, Scientific and Cultural Organization). The island of La Palma was declared in 1983, Lanzarote (1993), El Hierro (2000), Gran Canaria (46\% of the surface area of the island) (2005), Fuerteventura (2009); La Gomera (2012) and Macizo de Anaga, in the northwest of Tenerife (2015). Each of the Biosphere Reserves counts with monitoring and reporting schemes, mainly devoted to environmental topics. The Canary Islands have four National Parks located in the islands of Tenerife, La Palma, La Gomera and Lanzarote. Their management bodies are also relevant stakeholders in the monitoring of tourism.

National Institute of Statistics: The National Institute of Statistics provides relevant information on accommodation surveys (hotels, self-catering, rural and campsites); information on tourism expenditure; on tourism flows; and country related Tourism Satellite Accounts. This information is mainly displayed at the regional sca- le with a lack of detail on the scales and the topics that are relevant for each island and that is why the Institute of Statistics of the Canary Islands has developed its own statistics. In any case, there has been a strong collaboration between both institutes, for example in the case of the (Frontier Statistics) Frontur.

\section{Other relevant stakeholders:}

- Municipalities and the Federation of Municipalities.

- Spanish Airports and Air Navigation (AENA): company that manages airports in Spain.

- Port Authorities of the Canary Islands: Manages the ports and maritime navigation of the Canary Islands

- Hospitality Association of Tenerife, La Palma, La Gomera and El Hierro. (ASHOTEL)

- Association of Hotel and Apartment Entrepreneurs of Lanzarote (ASOLAN)

- Federation of Hospitality and Tourism Entrepreneurs of Las Palmas (FETH)

- Association of Tourism Entrepreneurs of Fuerteventura (ASOFUER)

- Canary Islands Professional Association of Tourism Graduates (COPTURISMO)

- Think tank and Association of Spanish Tourism Companies (EXCELTUR)

- Canary Islands Tourism Innovation Factory (FIT)

- Chambers of Commerce of the Canary Islands

- Turisfera (Cluster of firms for innovation in Tenerife)

- Turismo Innova (Cluster for firm innovation in Gran Canaria)

- Firms related to the tourism knowledge system (consultancy, marketing, etc.). 


\section{Design of the Tourism Observatory}

T he Tourism Observatory of the Canary Islands is currently undergoing a process of renovation and redesign. The original observatory was an internal body of the Vice Ministry of Tourism, but in recent years it has almost disappeared. In fact, monitoring activities and responsibilities were divided among several stakeholders. The new demands of tourism stakeholders, the complex tourism environment, the need to improve tourism intelligence and the lack of coordination among various initiatives and stakeholders involved in tourism monitoring have led to the renovation and redesign of the existing structures with a network of collaboration approach.

The Tourism Observatory of the Canary Islands was created in 2004 (Official Bulletin of the Canary Islands, number 138/2004). This founding document establishes that the Observatory as a technical body of the Tourism department of the Canary Islands Government in charge of the study and monitoring the tourism sector in the Canary Islands.

The recently released Strategic Plan of the Canary
Islands towards Tourism (Gobierno de Canarias, 2019) considered tourism intelligence as a key aspect in the development of the sector in the Canary Islands and stakeholders. Hence a permanent board is supported which will include the main actors in the region (The Vice Ministry of Tourism as the leading institution; the Institute of Statistics of the Canary Islands; PROMOTUR; the public Universities; and with the support of the island public bodies on data and tourism intelligence and private firms). In addition, the action plan of the same document proposes the reformulation of the Tourism Observatory of the Canary Islands to improve it as an instrument to support the monitoring and analysis of tourism for better decision-making. Thus, the Tourism Observatory of the Canary Islands is expected to be guided by the Tourism Council of the Canary Islands, an existing body where the regional and island tourism administrations, the main municipalities along with representatives of private firms and organizations, design the main tourism guidelines for tourism policy.

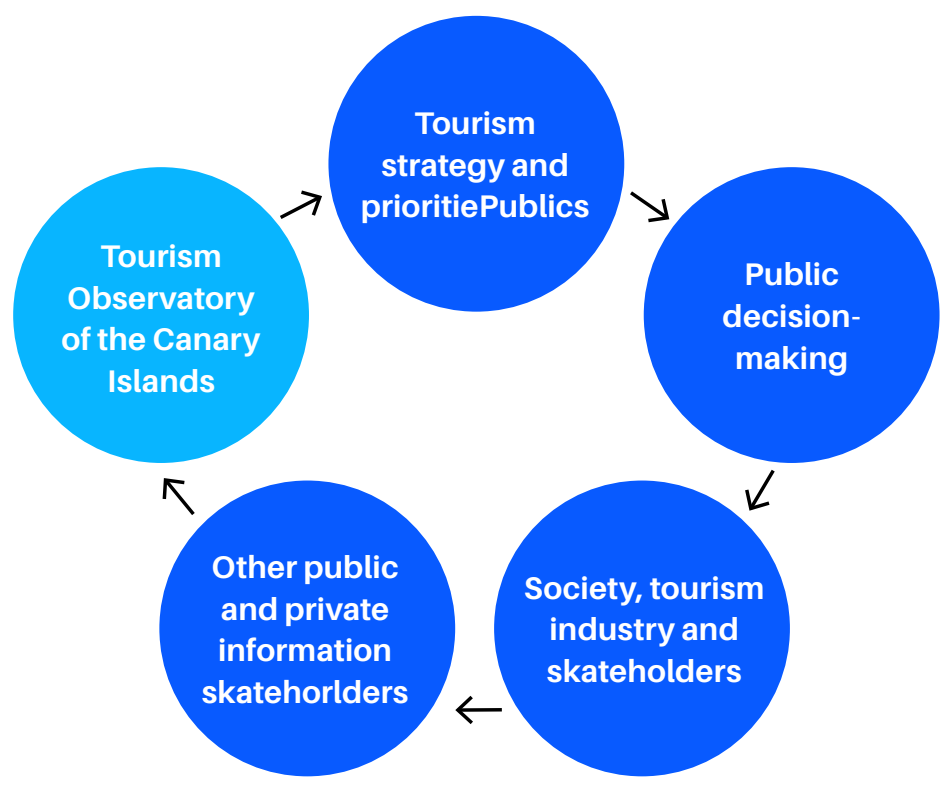

Figure 16. The role of the observatory in the tourism knowledge system of the Canary Islands 
The analysis carried out of numerous international experiences, including the observatories integrated in the UNWTO network of sustainable tourism observatories, clearly shows that there is no single observatory model. As for its organizational structure, some observatories include the unique presence of the public tourism administration. In other observatories, different departments and public administrations of different levels participate (statistical institutes, universities, private entities, business representatives, or chambers of commerce, among others).

The Tourism Observatory of the Canary Islands must be considered within the context of the other components of the Canary Islands tourism system. It is essential that each piece collaborates in the development of the archipelago's strategy. Its structure must not only feed relevant information for decision-making processes to the public and private sector, but also can receive the necessary data for the development of relevant indicators and information. The observatory is conceived as a facilitator and a communication framework that allows not only to formulate but also monitor and evaluate the regional touris
Figure 17. Design of the Tourism Observatory of the Canary Islands

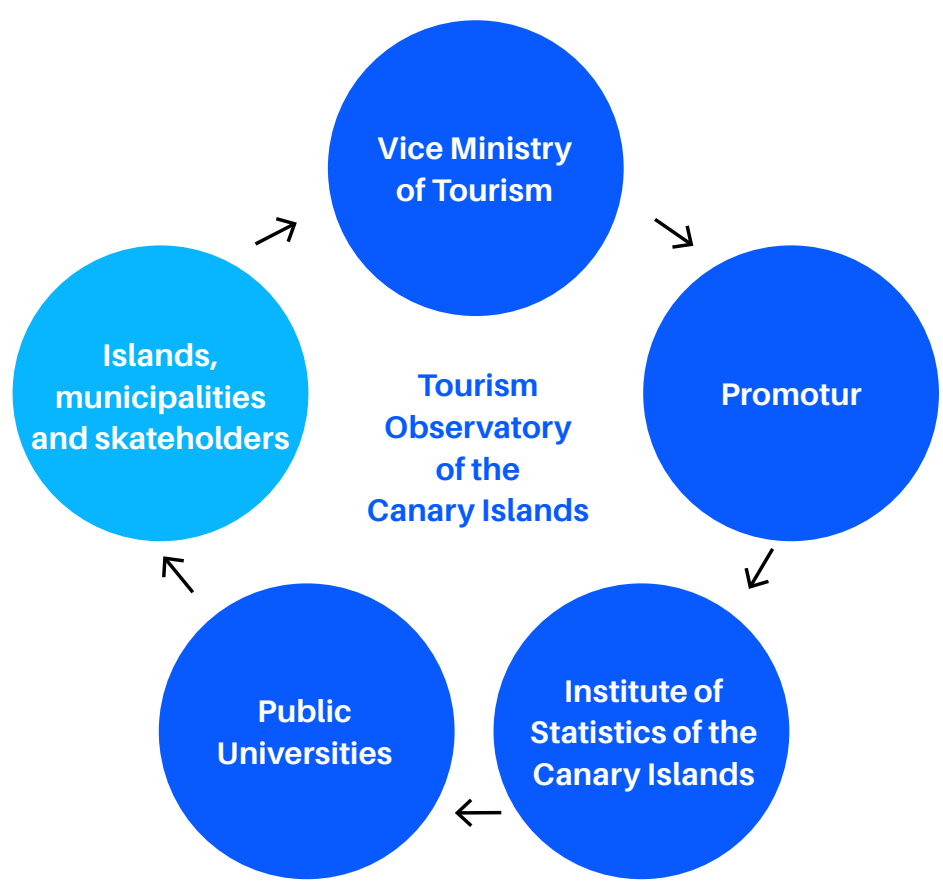

beaches, tourism products, risks, connectivity, economic impacts, residents' perceptions, environmental impact, labor conditions, etc.

- Communicating/disseminating tourism relevant information to stakeholders and the society.

- Partnership in the building and maintenance of tourism databases on economic, environmental and social issues relevant for decision-making.

- Detection of information needs in tourism official statistics, databases, bigdata and tourism knowledge. - Analysis of market trends, competitors and prospects. 
- Development of excellence of tourism knowledge of international value to be transferred to Africa, Latin America and Europe.

Regarding tourism planning the observatory's main objectives are to:

- Contribute to the design, monitoring and evaluation of the Strategic Plan of the Canary Islands towards Tourism.

- Contribute in the detection of tourism resources and opportunities of development aligned with the strategic objectives of the destination.

- Provide advice to the Government of the Canary Islands, the Council of Tourism and other public and private bodies.

- Collaborate with other bodies in improving tourism governance, and the intensity of tourism knowledge creation and use. Fostering the application of technology, the digitalization, modernization, quality, sustainability and social well-being related to tourism.

- Collaborate with other bodies in the development of tourism strategic projects.

\subsection{Organization of the observatory} and the role of stakeholders

The management of the Tourism Observatory of the Canary Islands resides in the Vice Ministry of Tourism of the Canary Islands. There is an advisory board on which its four pillars are represented: Vice Ministry of Tourism of the Canary Islands, Promotur (Canary Islands Tourism Marketing), Institute of Statistics, and the two public universities. Among these organizations, the Vice Ministry of Tourism exercises a leader position, as the official body with the responsibilities in tourism but trying to establish a common strategy. Beyond this core, the observatory coordinates its activities with the whole tourism system of knowledge and, therefore, this structure has strong links with tourism stakeholders in the public, private and territorial levels. In particular, the observatory is linked to the Island Councils and island tourism boards throughout the region.
The Vice Ministry of Tourism provides funding to support the activities of the Observatory to fulfil the objectives of each part of the observatory, which will be included in an annual operative plan. This structure is flexible, dynamic and scalable over time. The initial proposal is to establish an observatory with the support of ISTAC, Promotur, the two public universities of the Canary Islands, and dependent on the Regional Vice Ministry of Tourism.

\subsection{Monitoring methodology and objectives} for the first reporting year

The Tourism Observatory of the Canary Islands will coordinate the existing initiatives and institutions related to tourism monitoring and intelligence in the Canary Islands and will promote synergies among them. This monitoring activity relies particularly on the Observatory Board, which includes representatives of its four pillars, the Vice Ministry, ISTAC, Promotur and the Universities. The Observatory Board must approve the annual plan and allocate tasks. The Canary Islands Tourism Council, where the main stakeholders from the public and private sector as well as from each island are represented, proposes the priorities and annual objectives that will be considered by the Observatory Board and finally approved by the Vice Ministry of Tourism.

The observatory is structured in several work areas to promote its efficacy: strategy, economy and business, social affairs and environmental issues. This structure is flexible and dynamic to adapt to changes in the needs of the sector.

The objectives for the first reporting year should be proposed by the Observatory Board and approved by the Ministry of Tourism. Some main guideline tasks for the first reporting year can be found in the list below:

1. Continue to develop a strong organizational base.

2. Develop the Observatory's website.

3. Establish contacts with other members of UNWTO INSTO (to learn from them and share experiences).

4. Organize a stakeholders' workshop.

5. Provide strength and coherence to the network of tourism monitoring.

6. Establish a list and frequency of the reports the Ob- 
servatory will prepare for stakeholders.

7. Prepare initial reports on monitoring the mandatory issue areas.

8. Advance the work on indicators of sustainable tourism development.

9. Establish the indicators for tracking the of Strategic Plan of the Canary Islands towards Tourism.

10. Explore the use of Big Data in tourism information systems through pilot studies.

11. In conclusion, renovation and redesign of the existing Tourism Observatory of the Canary Islands along with taking into account the mentioned sustainability key issue areas and the existing statistics system will improve the quality of decision-making processes in the tourism sector of the Canary Island Archipelago on its way to sustainable development. 


\section{References}

Acemoglu, D., Robinson, J. A., \& Woren, D. (2012). Why nations fail: the origins of power, prosperity, and poverty. New York: Random House Audio.

Agarwal, S. (2002). Restructuring seaside tourism: The Resort Lifecyle. Annals of Tourism Research, 29, 25-55.

Aguiló, E., Alegre, J., \& Sard, M. (2005). The persistence of the Sun and Sand Tourism Model, Tourism Management 26(2), 219-231.

Beritelli, P., Bieger, T., \& Laesser, C. (2014). The New Frontiers of Destination Management. Journal of Travel Research, 53, 403-417.

Biddulph, R., \& Scheyvens, R. (2018). Introducing inclusive tourism. Tourism Geographies, 20(4), 583-588.

Candela, G., \& Figini, P. (2012). The Economics of Tourism Destinations (pp. 73-130).

Claver-Cortés, E., Molina-Azorin, J., \& Pereira-Moliner, J. (2007). Impacto del tamaño, el tipo de gestión y la categoría sobre el desempeño de los hoteles españoles. Cuadernos de turismo, ISSN 1139-7861, No. 19, 2007, pags. 27-45, 19.

United Nations (2006). Convention on the Rights of Persons with Disabilities (CRPD).

Exceltur \& Gobierno de Canarias (2019). Estudio del Impacto Económico del Turismo: IMPACTUR Canarias 2018.

Gobierno de Canarias (1990). Ley 12/1990, de 26 de julio, de Aguas.

Gobierno de Canarias (1995). Ley 7/1995, de 6 de abril, de Ordenación del Turismo en Canarias.

Gobierno de Canarias (2001): DECRETO 10/2001, de 22 de enero, por el que se regulan los estándares turísticos.

Gobierno de Canarias (2003). Ley 19/2003, de 14 de abril, por la que se aprueban las Directrices de Ordenación General y las Directrices de Ordenación del Turismo de Canarias.

Gobierno de Canarias, (2014): Decreto 142/2010, de 4 de octubre, por el que se aprueba el Reglamento de la Actividad Turística de Alojamiento.

Gobierno de Canarias (2019): Plan Estratégico de Canarias para el Turismo.

Gobierno de Canarias (2019). Estragegia Canaria de Activación para el empleo 2018-2020.

Hák, T., Janousková, S. \& Moldan, B. (2016). Sustainable Development Goals: A need for Relevant Indicators. Ecological Indicators, 60, 565-573.

Hernández Martín, R. (2015). Canarias, una potencia turística ante crecientes desafíos. Economía de Canarias: dinámica, estructura y retos. 679-718.

Hernández-Martín, R., Álvarez-Albelo, C.D. \& Padrón-Fumero, N. (2015). The economics and implications of moratoria on tourism accommodation development as a rejuvenation tool in mature tourism destinations, Journal of Sustainable Tourism, 23(6), 881-899.

Hernández Martín, R., Simancas-Cruz, M. R., González-Yanes, J. A., Rodríguez-Rodríguez, Y., García-Cruz, J. I., \& González-Mora, Y. M. (2016). Identifying micro-destinations and providing statistical information: A pilot study in the Canary Islands. Current Issues in Tourism, 19(8), 771-790.

Hernández Martín, R. (2016). Impactos Económicos Del Turismo. In M. Simancas Cruz, \& E. Parra López (Eds.), ¿Existe Un Modelo Turístico Canario? (pp. 8-31). Santa Cruz de Tenerife: PROMOTUR TURISMO CANARIAS, S.A..

Hernández Martín, Raúl, Jaén, M., Bolaños González, J., Santana Talavera, A., Cruz, M., Rodríguez Rodríguez, Y., \& García Cruz, J. (2012). El clima en Canarias como recurso turístico frente a sus principales mercados emisores y competidores.

INE. (2017). Statistics on the Collection and Treatment of Waste. 
INRouTe \& UNWTO. (2013), A Closer Look at Tourism: Sub-national Measurement and Analysis - Towards a Set of UNWTO Guidelines, UNWTO, Madrid.

Ioannides, D., \& Debbage, K. (1997). Post-Fordism and flexibility: The travel industry polyglot. Tourism Management, 18(4), 229-241.

Knowles, T., \& Curtis, S. (1999). The Market Viability of European Mass Tourist Destinations. A Post-Stagnation Life-cycle Analysis. International Journal of Tourism Research - INT J TOUR RES, 1, 87-96.

Ledesma, O., \& Simancas, M. (2016). An opportunity to implement territorial governance in the management of tourist destinations in the Canary Islands (Vols. 2016-January).

Promotur (2018). Estudio de la Reputación Online del Patrimonio Cultural de Canarias.

Promotur (2018). Posicionamiento Estratégico de la Marca Islas Canarias.

Promotur (2018). La imagen de marca de Islas Canarias en los mercados europeos.

Promotur (2019). Plan de Marketing Islas Canarias.

Ritchie, B. W., \& Jiang, Y. (2019). A review of research on tourism risk, crisis and disaster management: Launching the annals of tourism research curated collection on tourism risk, crisis and disaster management. Annals of Tourism Research, 79:1-15.

Scott, N. and Marzano, G. (2015). Governance of tourism in OECD countries. Tourism Recreation Research 40 (3),1-13

Simancas Cruz, M. (2015). La moratoria turística de Canarias. La reconversión de un destino maduro desde la Ordenación del Territorio. San Cristóbal de La Laguna, Servicio de Publicaciones de la Universidad de La Laguna.

Simancas Cruz, M., \& Peñarrubia Zaragoza, P. M. (2019). Analysis of the Accommodation Density in Coastal Tourism Areas of Insular Destinations from the Perspective of Overtourism. Sustainability, 11(11).

Simancas, M. and García, J. (2010): El impacto territorial de la estrategia de mejora de la calidad de los destinos maduros: la aplicación de estándares edificatorios a los alojamientos turísticos. Destinos turísticos maduros ante el cambio: reflexiones desde Canarias. 161-182

United Nations (2017). Framework for the Development of Environment Statistics (FDES, 2013). Statistics Division, New York.

UNWTO \& UNEP. (2017). Tourism and the sustainable development goals-journey to 2030. UNWTO: Madrid.

UNWTO. (2004). Indicators of Sustainable Development for Tourism Destinations: A Guidebook. Madrid.

UNWTO. (2010a). International Recommendations for Tourism Statistics 2008. United Nations, Madrid.

UNWTO. (2010b). Tourism Satellite Account: Recommended Methodological Framework. 2008. Madrid.

UNWTO, Centre of Expertise Leisure, Tourism \& Hospitality, NHTV Breda University of Applied Science \& NHL Stenden University of Applied Sciences. (2019). 'Overtourism'? Understanding and Managing Urban Tourism Growth beyond Perceptions Volume 2: Case Studies. World Tourism Organization (UNWTO). 


\section{Tourism Observatory of the Canary Islands}

PRELIMINARY REPORT 